NBER WORKING PAPER SERIES

THE INTERTEMPORAL APPROACH

TO THE CURRENT ACCOUNT

Maurice Obstfeld

Kenneth Rogoff

Working Paper No. 4893

\author{
NATIONAL BUREAU OF ECONOMIC RESEARCH \\ 1050 Massachusetts Avenue' \\ Cambridge, MA 02138 \\ October 1994
}

This paper is a chapter in the forthcoming Handbook of International Economics, volume 3, edited by Gene M. Grossman and Kenneth Rogoff (North-Holland Publishing Company, 1995). We thank Geun Mee Ahn, Harald Hau, Matthew Jones, Giovanni Olivei, and Clara Wang for excellent research assistance and the National Science Foundation, the German Marshall Fund of the United States, and the Ford Foundation for financial support. Helpful suggestions were made by David Backus, Richard Clarida, Jon Faust, Cedric Tille, and participants in the March 1994 conference for the Handbook at Princeton University. This paper is part of NBER's research programs in Intemational Finance and Macroeconomics and International Trade and Investment. Any opinions expressed are those of the authors and not those of the National Bureau of Economic Research.

(c) 1994 by Maurice Obstfeld and Kenneth Rogoff. All rights reserved. Short sections of text, not to exceed two paragraphs, may be quoted without explicit permission provided that full credit, including $\odot$ notice, is given to the source. 


\title{
THE INTERTEMPORAL APPROACH TO THE CURRENT ACCOUNT
}

\begin{abstract}
The intertemporal approach views the current-account balance as the outcome of forwardlooking dynamic saving and investment decisions. This paper, a chapter in the forthcoming third volume of the Handbook of International Economics, surveys the theory and empirical work on the intertemporal approach as it has developed since the early 1980s. After reviewing the basic one-good, representative-consumer model, the paper considers a series of extended models incorporating relative prices, complex demographic structures, consumer durables, asset-market incompleteness, and asymmetric information. We also present a variety of empirical evidence illustrating the usefulness of the intertemporal approach, and argue that intertemporal models provide a consistent and coherent foundation for open-economy policy analysis. As such, the intertemporal approach should supplant the expanded versions of the Mundell-Fleming IS-LM model that currently furnish the dominant paradigm used by central banks, finance ministries, and international economic agencies.
\end{abstract}

Maurice Obstfeld Department of Economics University of California at Berkeley Berkeley, CA 94720 and NBER
Kenneth Rogoff

Department of Economics

Princeton University

Princeton, NJ 08544

and NBER 


\section{Contents}

1 Introduction 2

2 The current account: Basic concepts and historical overview 3

3 Intertemporal approaches to the current account $\quad 7$

3.1 Deterministic models of the current account . . . . . . . 8

3.1.1 A one-good model with representative national residents 8

3.1.2 The role of comparative advantage . . . . . . 14

3.1.3 Modeling output fluctuations and investment . . . . . 15

3.1.4 Nontradables, consumption, and investment ..... 18

3.1.5 Consumer durables and the current account . . . . . 21

3.1.6 The terms of trade and the transfer problem . . . . . 23

3.1.7 Demographic structure, fiscal policy, and the current account ................... 26

3.2 Stochastic models of the current account . . . . . . . . 32

3.2 .1 Complete markets . . . . . . . . . . . . . . 32

3.2.2 Bonds as the only asset . . . . . . . . . . . 35

3.2.3 Partially complete markets . . . . . . . . . . . . 39

3.2.4 Endogenous market incompleteness . . . . . . . . . 41

4 Empirical evidence on the intertemporal approach 46

4.1 The relationship between national saving and domestic invest-

ment rates . . . . . . . . . . . . . 47

4.2 Tests of intertemporal current-account models . . . . . . . . 51

4.2.1 Measuring permanent values: A digression . . . . . . 51

4.2 .2 Early tests . . . . . . . . . . . . . 53

4.2.3 Present-value models of the current account ..... 55

4.2.4 Global versus country-specific shocks and the current account .................. 59

4.2 .5 Extensions . . . . . . . . . . . . 61

5 How useful is the theory? 63 


\section{Introduction}

The intertemporal approach views the current-account balance as the outcome of forward-looking dynamic saving and investment decisions. Intertemporal analyses of the current account became common in the early $1980 \mathrm{~s}$ as a result of papers by Buiter (1981), Obstfeld (1982), Sachs (1981), Svensson and Razin (1983), and many others, although the approach had explicit precursors in work on trade and growth by Bardhan (1967), Bruno (1970), and Hamada (1969). ${ }^{1}$ As usual, this new focus in open-economy macroeconomics resulted both from theoretical advances in other parts of economics and from economic events that existing open-economy models seemed ill equipped to examine.

Lucas's (1976) influential critique of econometric policy evaluation was one important theoretical motivation for an intertemporal approach. Lucas's insistence on grounding policy analysis in the actual forward-looking decision rules of economic agents suggested that open-economy models might yield more reliable policy conclusions if demand and supply functions were derived from the optimization problems of households and firms rather than specified to match reduced-form estimates based on ad hoc econometric specifications.

Further impetus to develop an intertemporal approach came from events in the world capital market, especially the substantial current-account imbalances that followed the sharp world oil-price increases of 1973-74 and 1979-80. The divergent patterns of current-account adjustment by industrialized and developing countries raised the inherently intertemporal problem of characterizing the optimal dynamic response to external shocks. Neither the classical monetary models nor the Keynesian models in vogue at the time offered reliable guidance on this question. Similarly, the explosion in recycled bank lending to developing countries after the first oil shock sparked fears that borrowers' external debt levels might become unsustainable. The need to evaluate developing-country debt levels again led naturally to the notion of an intertemporally optimal current-account deficit.

This chapter surveys the theory and empirical work on the intertemporal approach to the current account as it has developed since the early

${ }^{1} \mathrm{~A}$ number of studies published in the early 1980 s based exchange-rate or balanceof-payments models on intertemporal foundations. These contributions are surveyed in the chapter by Maurice Obstfeld and Alan C. Stockman in volume 2 of this Handbook (Obstfeld and Stockman 1985). 
1980s. ${ }^{2}$ Recently, some researchers have studied dynamic stochastic international models with complete Arrow-Debreu forward markets for uncertain consumption. This particular offshoot of the intertemporal approach is the 'complete-markets' model. Because complete-markets models fit more naturally into Marianne Baxter's chapter in this Handbook, they are summarized only briefly here. We reserve the term 'intertemporal approach'-as well as the bulk of our discussion-for models with international borrowing and lending but not necessarily with complete international markets in statecontingent claims.

The chapter begins with an introductory section, Section 2, that explores the concept of the current account, its behavior in recent history, and the conceptual adequacy of measures of the current account as reported by government agencies.

Section 3 lays out basic intertemporal models of the current account, starting with the deterministic case and then exploring stochastic models. Section 4 shows how stochastic models can be used to devise tests of the intertemporal approach, and goes on to evaluate the resulting evidence.

Much of the discussion through section 4 of this chapter focuses on positive predictions of the intertemporal approach. A major advantage of the approach, however, is its relevance to normative questions. Section 5 therefore takes up the reasons why an intertermporal approach to the current account is essential for sound policy formulation.

Finally, we note that, given the extensive recent literature this chapter aspires to encompass, there are several instances where space permits us only to sketch algebraic derivations. We try to alert the reader whenever intermediate algebra has been pruned especially severely, so that he or she will not become bogged down during a first reading.

\section{The current account: Basic concepts and historical overview}

A country's current-account balance over any time period is the increase in residents' claims on foreign incomes or outputs, less the increase in similar foreign-owned claims on home income or output. Thus, in theory, the current

\footnotetext{
${ }^{2}$ For a complementary survey, see Razin (1995).
} 
account includes not only exports less imports (broadly defined to include all the income on and payouts on cross-border assets: dividends, interest payments, insurance premia and payments, etc.), but also net capital gains on existing foreign assets. From the close of World War I until relatively recently, most countries' holdings of foreign assets had been limited both in quantity and scope, so the latter consideration was secondary. A focus on the current account as the net export balance led some economic thinkers to view relative international prices as its central determinant. Thus was born the elasticities approach to the current account, under which the determinants of international expenditure levels and incomes are held fixed in the background while static price elasticities of demand and supply determine the net international flow of capital.

As intermediate macroeconomics texts demonstrate, however, the current account also is national saving less domestic investment. If saving falls short of desired investment, for example, foreigners must take up the balance, acquiring as a result claims on domestic income or output. This alternative viewpoint, which led to the absorption approach, stresses how macroeconomic factors must ultimately determine international borrowing or lending patterns (Alexander 1952).

The intertemporal approach to current-account analysis extends the absorption approach through its recognition that private saving and investment decisions, and sometimes even government decisions, result from forwardlooking calculations based on expectations of future productivity growth, government spending demands, real interest rates, and so on. The intertemporal approach achieves a synthesis of the absorption and elasticities view, however, by accounting for the macroeconomic determinants of relative prices and by analyzing the impact of current and future prices on saving and investment.

International capital flows, in the form of trade credits and commercial traffic in such assets as jewels and precious metals, were already common by biblical times. By the early fourteenth century, Italian banks spanning Western Europe and the Levant had become large-scale lenders to sovereigns such as King Edward III of England, whose invasion of France in 1340, aided by foreign finance, initiated the Hundred Years War. The two most powerful Florentine banking houses, those of the Bardi and the Peruzzi, were bankrupted along with many lesser banks in 1343 when Edward proved unable to meet his obligations. But as Europe recovered from this early 
banking crisis and from the subsequent Black Death (1348), international financial linkages grew strong once again. The Catholic church, through its usury doctrine, unwittingly promoted the internationalization of banking in this period. While domestic loans for interest were prohibited, there was no definitive ban on exchanges of bills payable in different countries and currencies, even when the terms negotiated included implicit interest charges (de Roover 1966). Theological constraints thus led the largest banks to maintain extensive systems of foreign branches.

The expulsion of the Jews from the Iberian peninsula at the end of the fifteenth century, followed by widespread and continuing persecutions of Protestants after the Reformation, created networks of refugee communities with both the motivation and connections to move capital between countries. During European wars of the seventeenth and eighteenth centuries, international capital markets developed further as some governments turned to large-scale debt sales to foreigners. (See Neal 1990.) By the early nineteenth century at the latest, the outlines of modern international capital markets are visible in investors' search for profit opportunities on distant shores. British savers, for example, helped finance the ill-fated American canal boom in the first half of the nineteenth century.

The era of the classical international gold standard, spanning the late nineteenth and early twentieth centuries, often is held up as a benchmark case of unfettered capital mobility between nations. Figure 1 shows data on saving, investment, and their difference, the current account, for a dozen countries over 1885-1913. (All data are nominal flows divided by a nominal income or output measure.) ${ }^{3}$ The graphs indeed show several examples of large and protracted current-account imbalances, indicators of extensive trade across time. Canada ran persistent deficits which, by the early twentieth century, approached 20 percent of gross national product (GNP). These large flows were undoubtedly promoted by Canada's close political and cultural links with the United Kingdom, the largest lender. But even countries without such close ties to potential lenders were able to draw extensively on international capital markets. Japan ran an external deficit of 10 percent of national expenditure in financing its 1905 war with Russia. Standing on the

\footnotetext{
${ }^{3}$ These data, as well as those shown in figure 2 below, are from Jones and Obstfeld (1995). Finland was actually a possession of Russia during the 1885-1913 period, but it was afforded a fair amount of administrative autonomy.
} 
Figure 1

\section{Saving, Investment, and the Current Account: Classical Gold Standard, 1885-1913}

\section{United States}

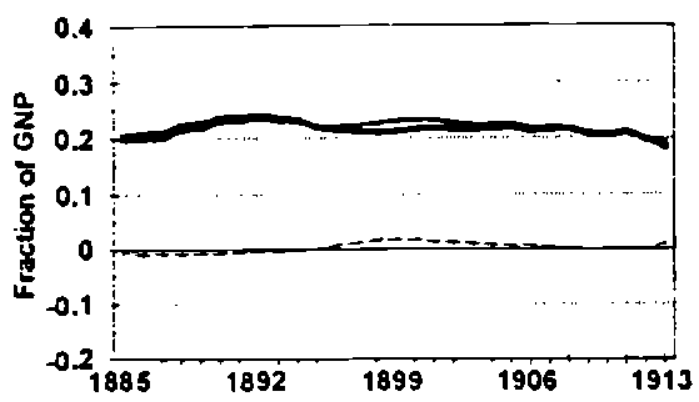

Canada

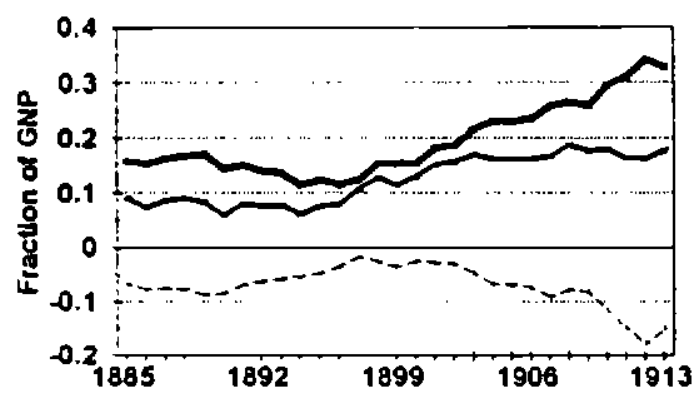

Germany

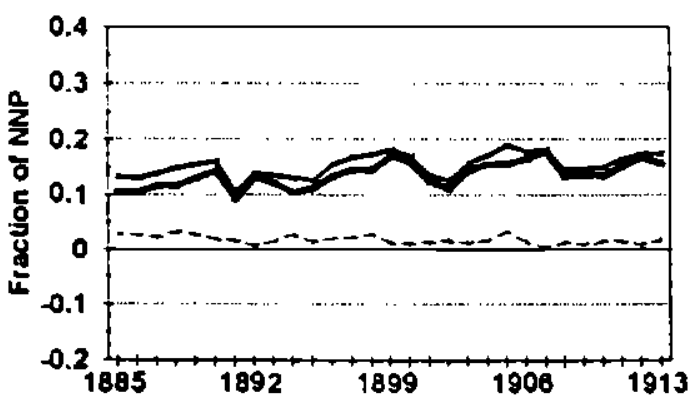

-Investment
United Kingdom

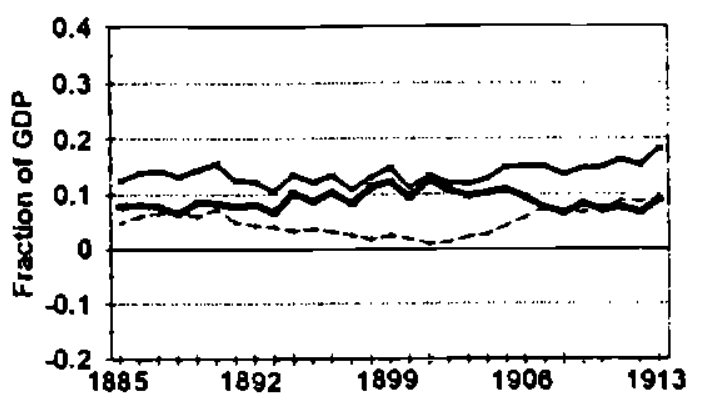

France

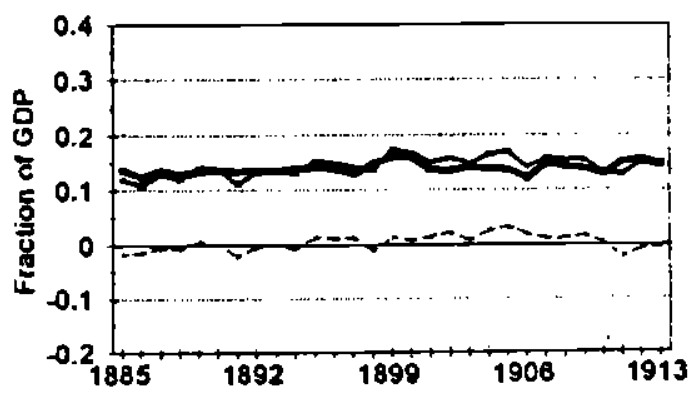

Japan

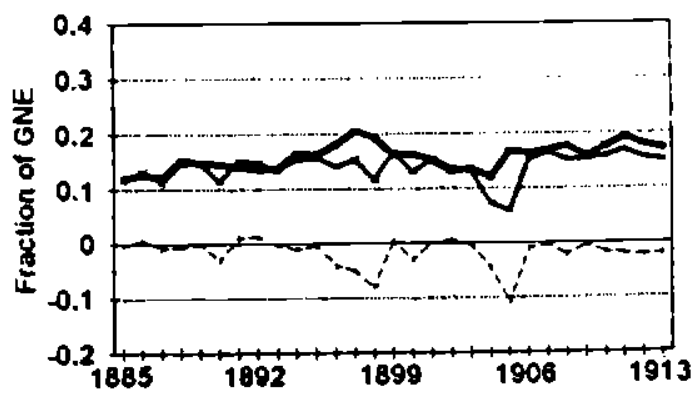

-Current Account 
Figure 1

Saving, Investment, and the Current Account: Classical Gold Standard, 1885-1913

Australia

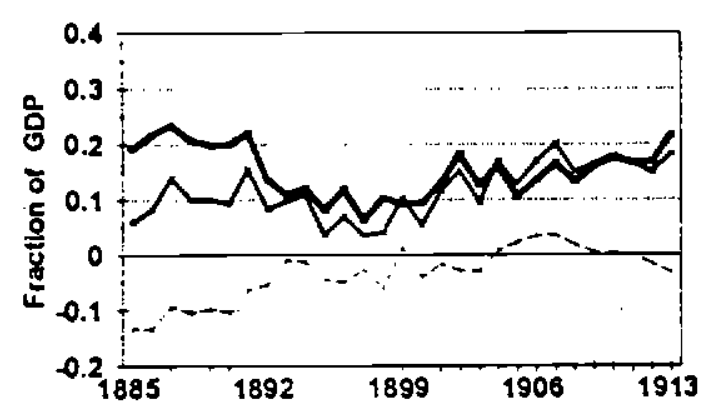

Sweden

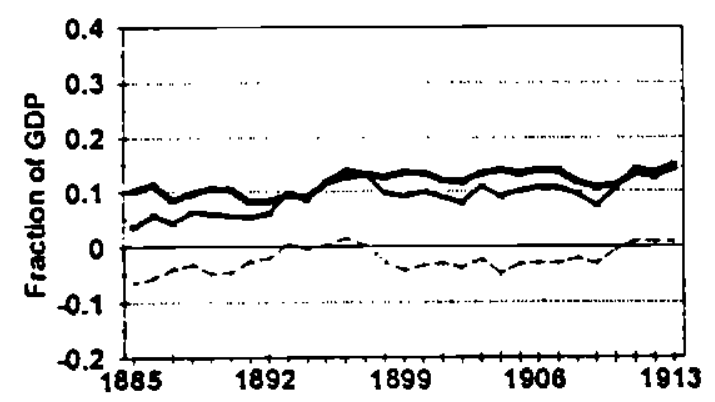

Denmark

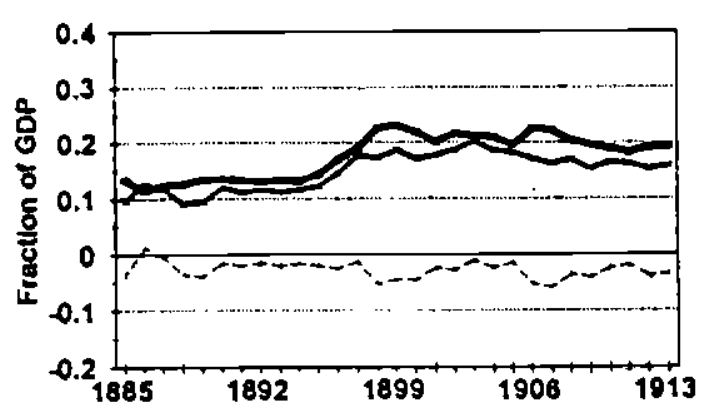

-Investment

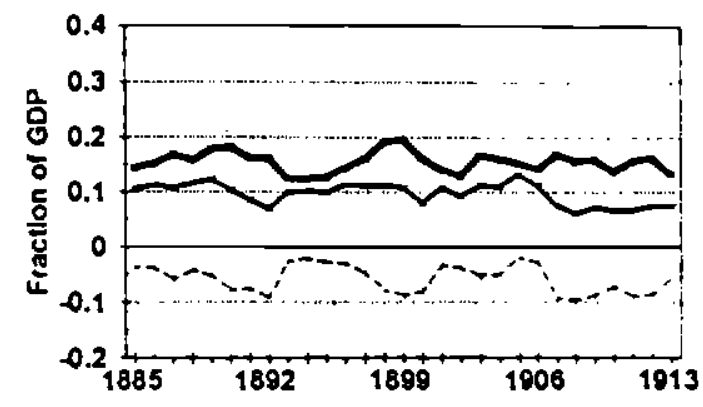

Norway

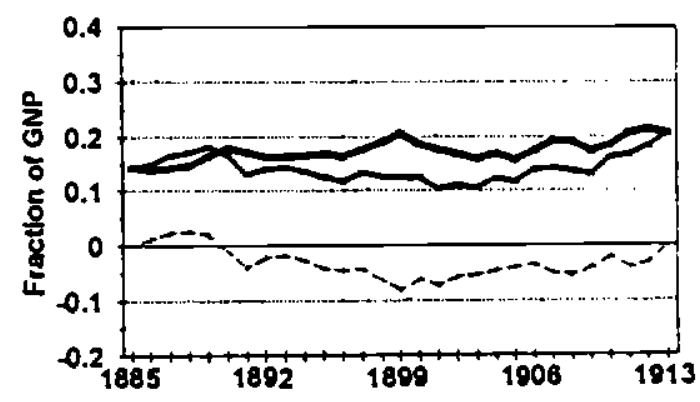

Italy

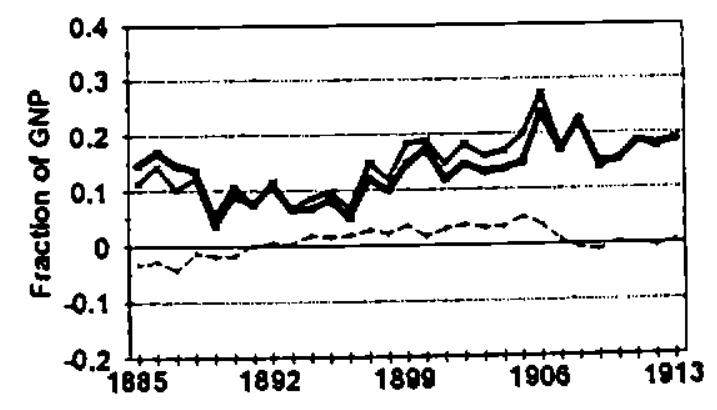

-Current Account 
sidelines during World War I, the country ran a comparable surplus to help finance the belligerents. ${ }^{4}$

Data from the interwar period, shown in figure 2, reveal a partial resurgence of net international borrowing and lending as postwar reconstruction progresses, but this process comes to a sudden halt as restrictions on international payments proliferate after the onset of the Great Depression. ${ }^{5}$ Post1945 data disclose a reverse evolution. Initially, current-account imbalances were slight due to official restrictions on international capital movements, with most industrial-country currencies being inconvertible through 1959. After the early 1970s (see figure 3), net international capital flows expanded as a result of petrodollar recycling, the removal of many industrial-country restrictions on international payments following the adoption of floating exchange rates, and technological evolution in the financial industry. By the 1980s, the largest industrial countries, Germany, Japan, and the United States, were running substantial external imbalances. At the same time many developing countries, caught in a debt crisis brought on in part by vigorous borrowing in the 1970 s, found themselves denied access to resource inflows. Only in the early 1990s did this stark borrowing constraint begin to ease.

Unfortunately, the saving and investment flows reported in national income and product accounts (NIPA) and shown in figures 1 through 3 don't always conform closely to theoretically correct concepts of saving and investment, particularly when international capital mobility is extensive. One especially serious defect is the failure of NIPA national income measures fully to reflect capital gains and losses on net foreign assets. During 1991, for example, the NIPA measure of saving less investment for the United States, the current account, was reported by the U.S. Department of Commerce as - $\$ 3.7$ billion. The Department of Commerce also calculated, however, that on a market-value basis, U.S. assets held abroad rose in dollar value by $\$ 67.8$ billion (more than the entire 1991 increase in holdings of foreign assets by U.S. residents, $\$ 62.2$ billion). At the same time, the dollar value of foreign claims on the U.S. rose by $\$ 172.8$ billion (more than two-and-a-half times as large as the 1991 increase in foreign holdings of U.S. assets, $\$ 67.0$ billion).$^{6}$

\footnotetext{
${ }^{4}$ For a discussion of wars and the Japanese current account during the first part of the twentieth century, see Obstfeld and Rogoff (1995), ch. 1.

${ }^{5}$ See Eichengreen (1990) for further discussion.

${ }^{6}$ The United States capital-account surplus, equal to $\$ 67.0$ billion $\Gamma \$ 62.2$ billion =
} 
Figure 2

\section{Saving, Investment, and the Current Account: Inter-War Era, 1921-1939}

\section{United States}

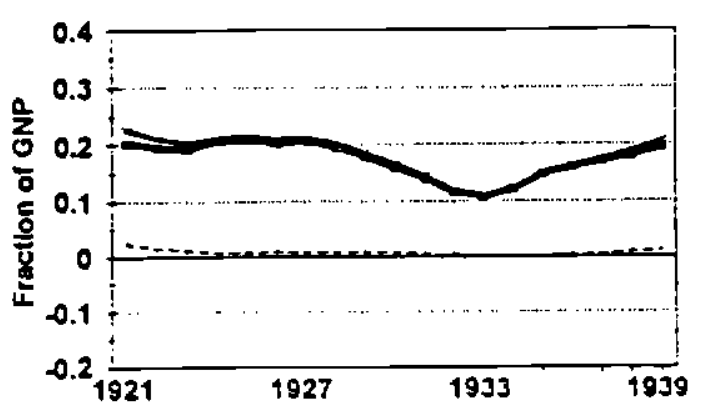

Canada

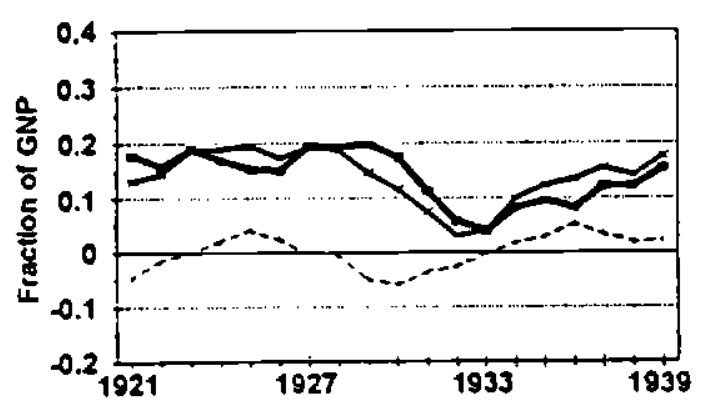

Japan

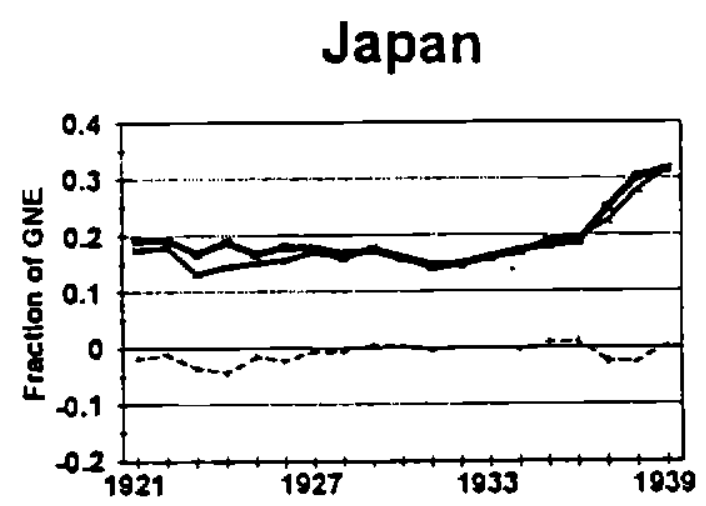

-investment

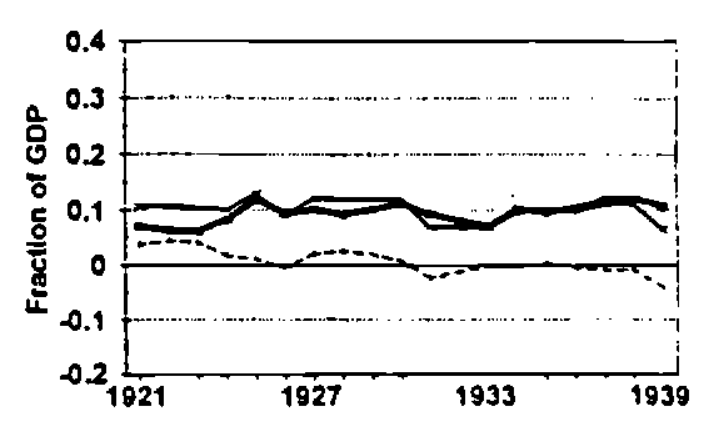

Germany

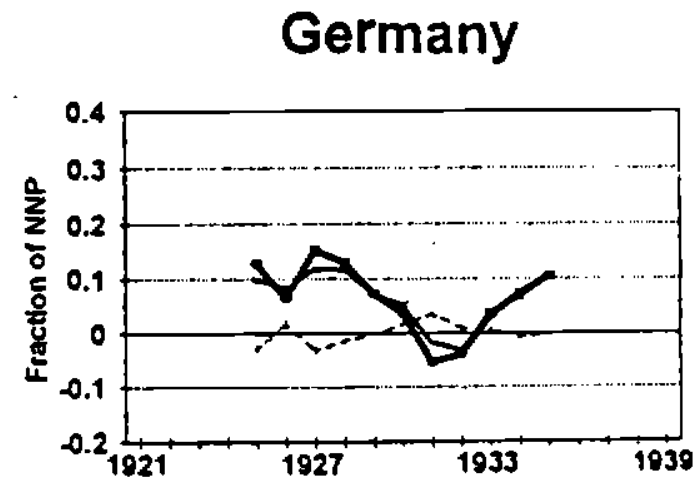

United Kingdom 
Figure 2

Saving, Investment, and the Current Account: Inter-War Era, 1921-1939

\section{Australia}

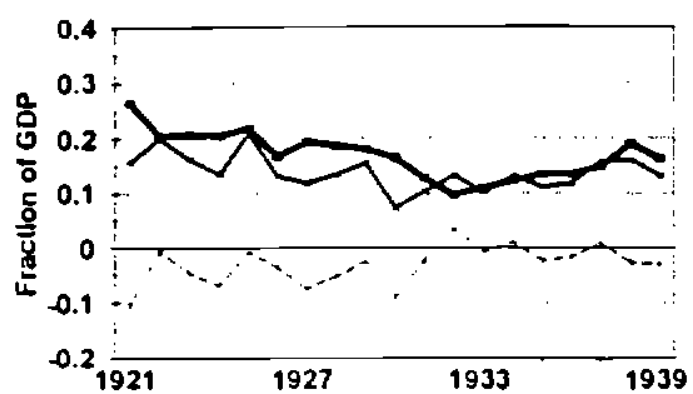

Sweden

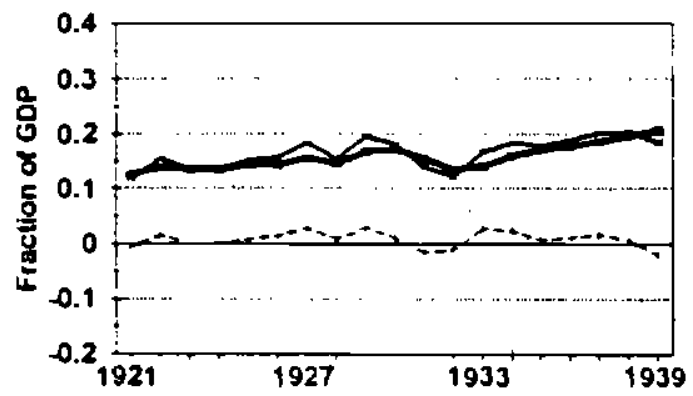

Denmark

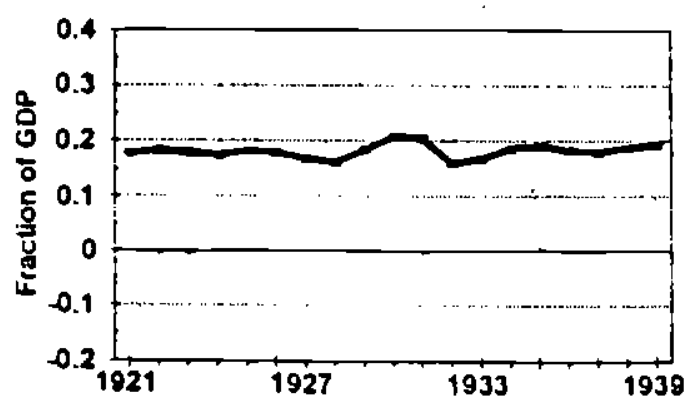

-Investment
Finland

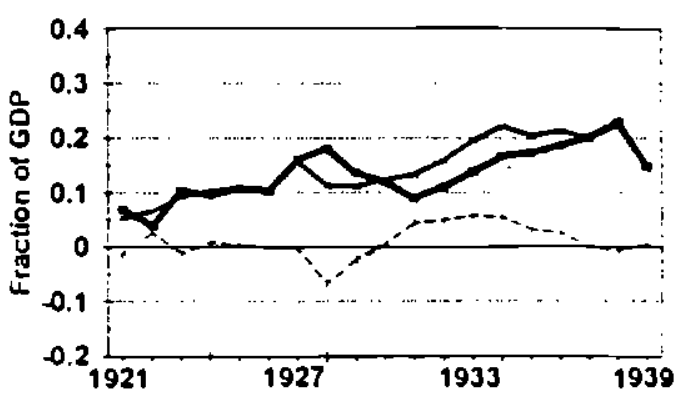

Norway

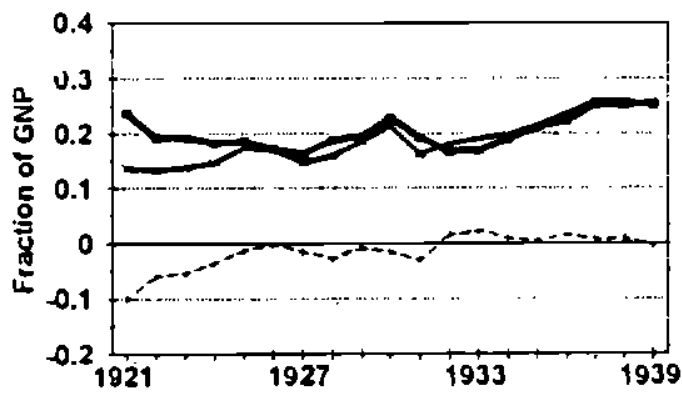

Italy

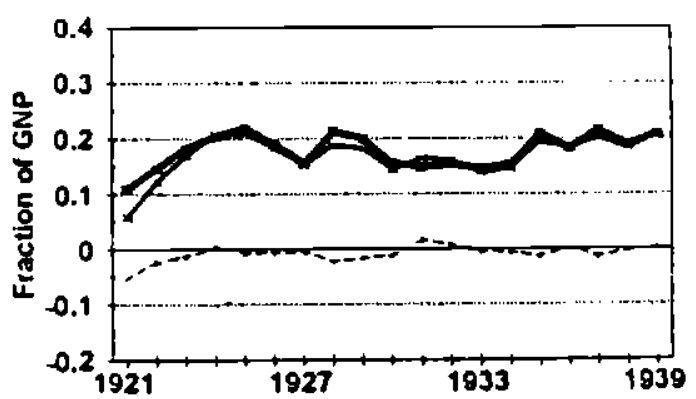

-Current Account 
Figure 3

\section{Saving, Investment, and the Current Account: Post-Bretton Woods Era, 1973-1991}

\section{United States}

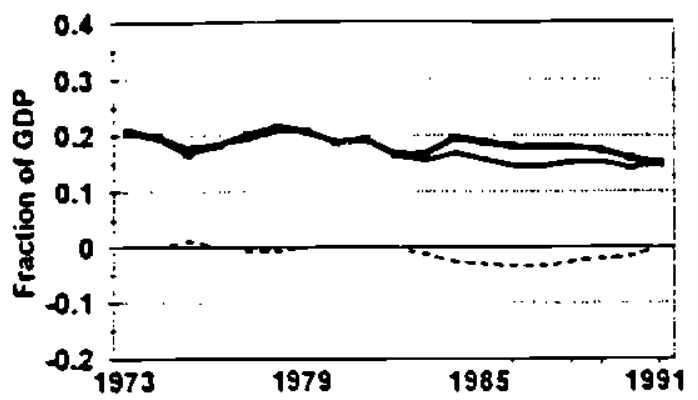

Canada

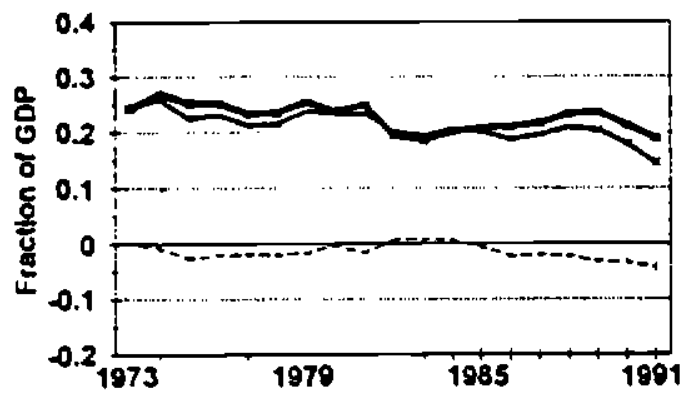

Germany

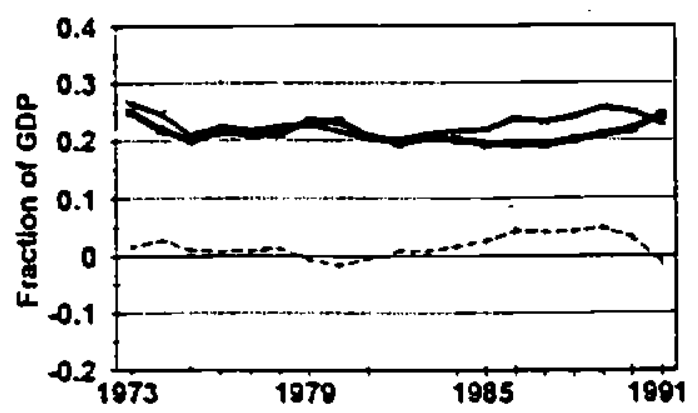

-Investment

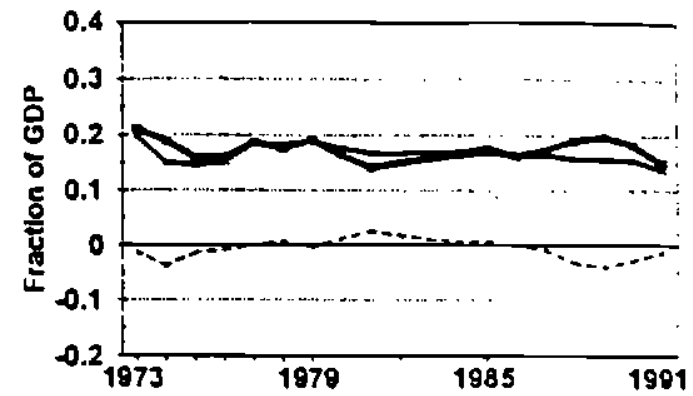

France

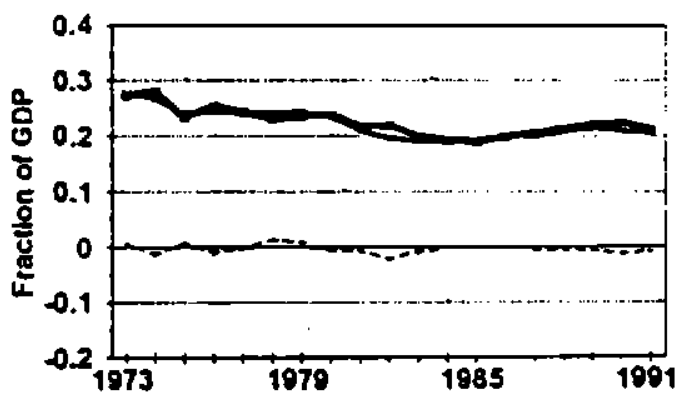

Japan

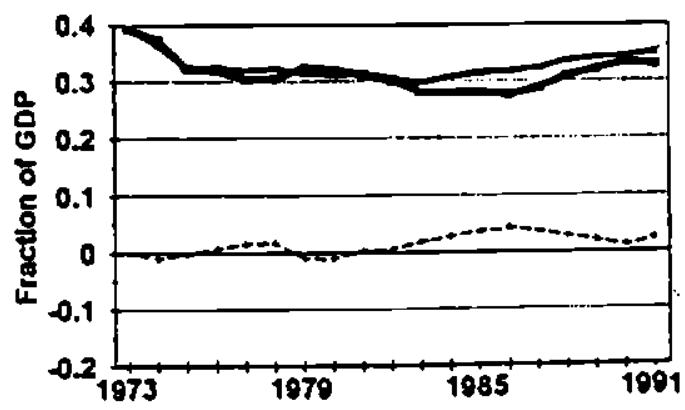

-Current Account 
Figure 3

\section{Saving, Investment, and the Current Account: Post-Bretton Woods Era, 1973-1991}

\section{Australia}

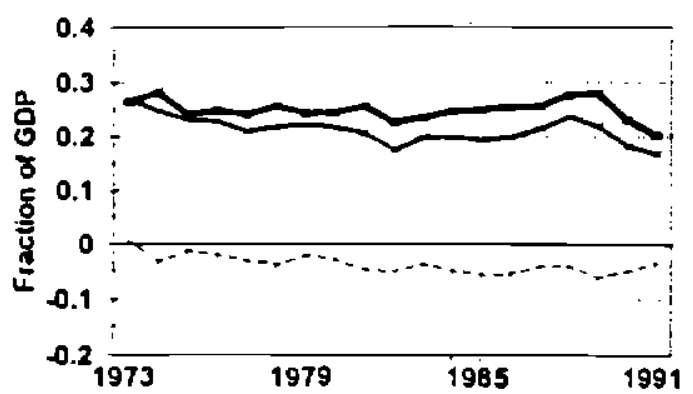

Sweden

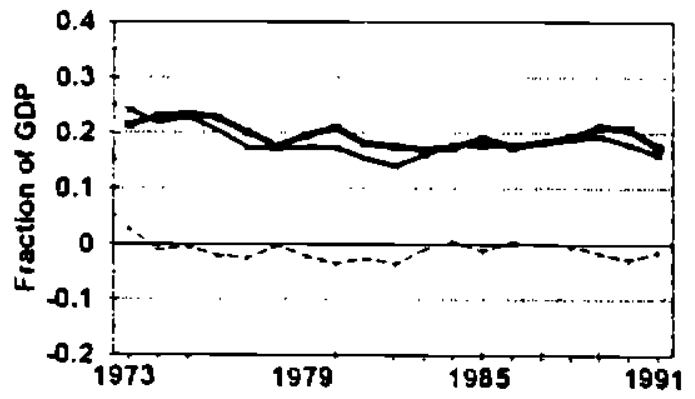

Denmark

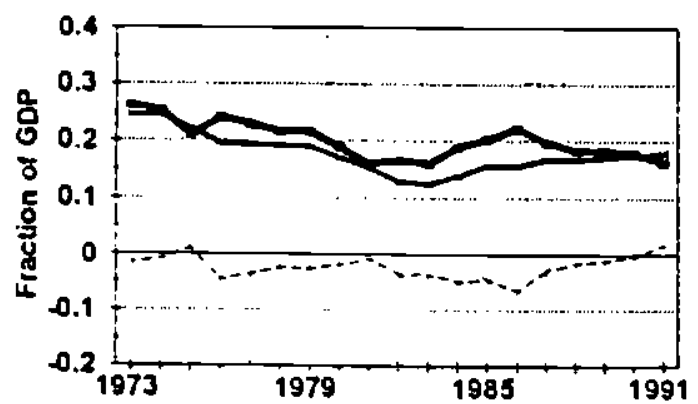

-Investment
Finland

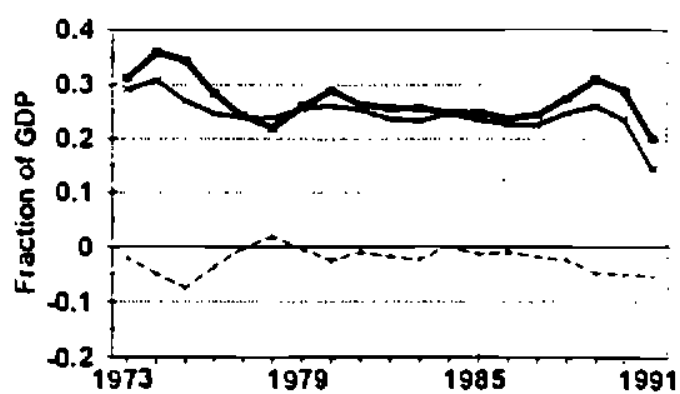

Norway

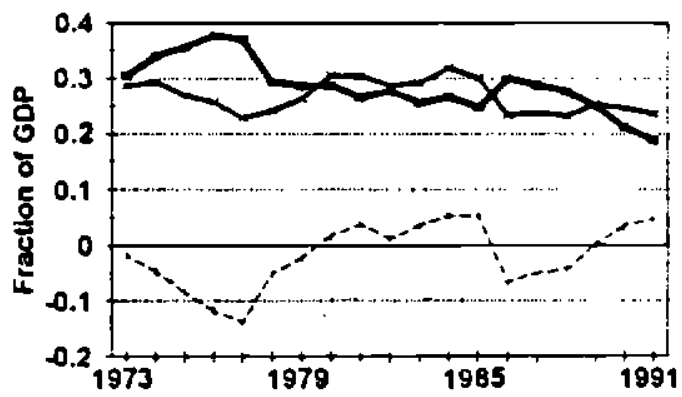

Italy

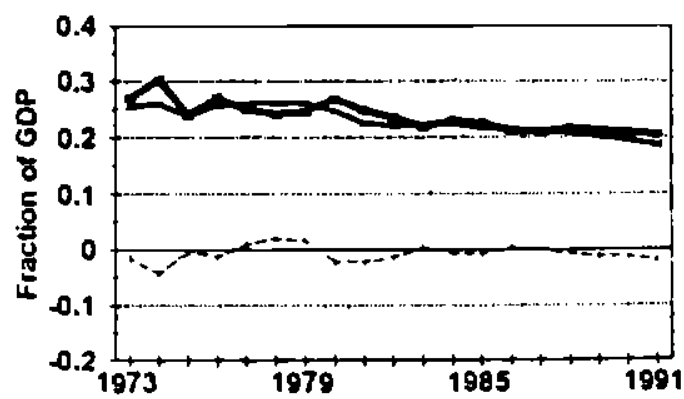

-Current Account 
In economic terms, the true dollar U.S. current-account deficit for 1991 is probably much closer to $-\$ 3.7$ billion $+\$ 67.8$ billion $-\$ 172.8=-\$ 108.7$ billion than to its simple NIPA measure. And even this figure reflects only partial coverage of international asset holdings.

The numbers in figures 1 through 3 are misleading for another reason. As section 3 shows, it is changes in real, not nominal, asset holdings that matter for a country's welfare. Thus, NIPA measures of the current account, even if corrected to include nominal capital gains and losses, must be adjusted as well to correct for the inflationary erosion of foreign assets' real values.

These problems plague all of the empirical literature discussed in section 4 , although it would be possible to remedy them somewhat for a few industrial countries. In empirically evaluating theories it is obviously crucial to achieve the best possible match between the conceptual framework and the data brought to bear in testing it.

\section{Intertemporal approaches to the current account}

A realistic economic model incorporating all elements relevant to the typical country's current account would be hopelessly complex. Instead of attempting to construct such a comprehensive model, we turn in this section to a succession of models that illustrate what we believe to be the key elements influencing saving-investment balances in the world economy. In following this strategy, we largely parallel the development of theoretical thinking on the current account over the past fifteen years An important set of insights can be derived even from deterministic models; this is our first order of business. We then introduce uncertainty about the economic environment and deduce a number of essential modifications of the preceding nonstochastic framework. The introduction of uncertainty is, of course, a prerequisite for the empirical analysis of the intertemporal approach that we discuss in section 4.

$\$ 4.8$ billion, differs from the recorded current-account deficit by a statistical discrepancy of $-\$ 1.1$ billion. 


\subsection{Deterministic models of the current account}

The first broad class of models to be described assumes that individual decision makers have perfect foresight and complete information about their economic environment. While these models lack realism along some dimensions, they serve at least two very useful purposes. First, they elucidate a number of questions for which uncertainty is of secondary importance, and second, they provide a benchmark against which to measure the predictions of richer stochastic models. As we shall see later, stochastic models in which real bonds are the only assets countries trade imply responses to shocks similar to the impulse responses of deterministic models.

\subsubsection{A one-good model with representative national residents}

Consider a small open economy that produces and consumes a single composite good and trades freely with the rest of the world. Free trade includes the international exchange of assets. We assume that the only traded asset is a consumption-indexed bond with fixed face value that pays net interest at the rate $r_{t}$ between periods $t-1$ and $t$. Importantly, labor is internationally immobile. In per capita terms, let $A_{t+1}$ denote the economy's stock of net foreign claims at the end of period $t, Y_{t}$ net domestic product or output in period $t, C_{t}$ private consumption, $G_{t}$ government consumption, and $I_{t}$ net investment. ${ }^{7}$ Then the identity linking net foreign asset accumulation - that is, the current account, $C A_{t}-$ to the saving-investment balance is:

$$
C A_{t}=A_{t+1}-A_{t}=r_{t} A_{t}+Y_{t}-C_{t}-G_{t}-I_{t}
$$

Define the market discount factor for date $s$ consumption by

$$
R_{t, s}=\frac{1}{\prod_{v=t+1}^{s}\left(1+r_{v}\right)}
$$

(where $R_{t, t}=1$ ). Forward iteration of eq. (1) leads to

$$
\left(1+r_{t}\right) A_{t}=\sum_{s=t}^{\infty} R_{t, s}\left(C_{s}+G_{s}+I_{s}-Y_{s}\right)+\lim _{s \rightarrow \infty} R_{t, s} A_{s}
$$

\footnotetext{
${ }^{7}$ We will assume for simplicity that capital does not depreciate in use.
} 
Because foreign lenders will not allow the economy to roll over a debt indefinitely through unlimited borrowing, the condition $\lim _{s \rightarrow \infty} R_{t, s} A_{s} \geq 0$ applies above. The resulting intertemporal budget constraint for the economy is thus:

$$
\sum_{s=t}^{\infty} R_{t, s}\left(C_{s}+G_{s}+I_{s}\right) \leq\left(1+r_{t}\right) A_{t}+\sum_{s=t}^{\infty} R_{t, s} Y_{s}
$$

In the models we survey no resources are willingly forgone, so (3) always holds with equality. In that case, (3) states that the present value of the economy's expenditures must equal its initial net foreign wealth plus the present value of domestic production.

The intertemporal budget constraint delimits the feasible choices of the economy. To describe the circumstances in which current-account imbalances will arise, however, one must specify how the components of expenditure and output are determined. We assume that the representative consumer maximizes the time-separable function

$$
U_{t}=\sum_{s=t}^{\infty} \beta^{s-t} u\left(C_{s}\right)
$$

where $\beta \in(0,1), u^{\prime}(C)>0, u^{\prime \prime}(C)<0$.

The intertemporal separability of preferences assumed in (4) will form the backbone of our formal analysis. Before going further, it is worthwhile to offer some justification for this decision.

1. One might wish to start with a very general intertemporally nonseparable utility function of the form $U_{t}=U\left(C_{t}, C_{t+1}, \ldots\right)$. But this would yield few concrete and testable behavioral predictions. Instead we prefer to begin with a tractable basic setup like eq. (4) with strong implications. Preferences then can be generalized if the basic setup seems to be leading us astray. ${ }^{8}$

2. Aggregation, across both goods and individuals, may cause intertemporal dependencies approximately to cancel out at the level of total per capita consumption.

${ }^{8}$ Plausible non-time-separable alternatives to (4) can be analyzed; see, for example, Devereux and Shi (1991), Obstfeld (1982), Shi and Epstein (1993), and Svensson and Razin (1983). 
3. At the levels of time aggregation common in macroeconomic models, the assumption of intertemporal separability is not implausible. In any event, while empirical research on data at these frequencies has raised interesting questions about the time-separable preference model, it does not clearly point to a superior nonseparable alternative.

Having defended our choice of time-separable preferences, we now begin to pursue their implications. Let $V_{t}$ be the real value of domestic firms at the end of period $t-1$ (after period $t-1$ dividends have been paid), $B_{t}$ the stock of interest-earning claims owned by the domestic private sector at the end of $t-1, w_{t}$ the real wage in period $t, L_{t}$ the per capita supply of labor, and $T_{t}$ lump-sum taxes levied by the home government. Then the intertemporal budget constraint of the representative consumer is ${ }^{9}$

$$
\sum_{s=t}^{\infty} R_{t, s} C_{s}=\left(1+r_{t}\right)\left(V_{t}+B_{t}\right)+\sum_{s=t}^{\infty} R_{t, s}\left(w_{s} L_{s}-T_{s}\right)
$$

When (4) is maximized subject to (5), consumption necessarily follows the intertemporal Euler equation

$$
u^{\prime}\left(C_{t}\right)=\beta\left(1+r_{t+1}\right) u^{\prime}\left(C_{t+1}\right)
$$

This optimality condition; stressed long ago by Irving Fisher (1930), equates the marginal rate of substitution of present for future consumption, which is just $\beta u^{\prime}\left(C_{t+1}\right) / u^{\prime}\left(C_{t}\right)$, to the price of future consumption in terms of present consumption, $1 /\left(1+r_{t+1}\right)$. An implication is that, leaving aside discrepancies between $\beta$ and $1 /\left(1+r_{t+1}\right)$, optimized consumption will follow a smooth, constant path (recall that $u(C)$ is strictly concave). A convenient closedform description of the current account is obtained by specializing further to the case in which $u(C)$ takes the isoelastic form

$$
u(C)=\frac{c^{1-\frac{1}{\sigma}}-1}{1-\frac{1}{\sigma}}
$$

\footnotetext{
${ }^{9}$ Strictly speaking, the way the next constraint is expressed assumes perfect foresight between dates $t-1$ and $t$, so that a rate of return of $r_{t}$ actually is earned on shares $e x$ post. This assumption is made only to avoid cluttering the notation, and is not imposed in what follows. A more general formulation simply would replace $\left(1+r_{t}\right) V_{t}$ by the ex post value (inclusive of dividends) of shares bought on date $t$.
} 
with $\sigma>0$ the elasticity of intertemporal substitution. In this case (6) implies that optimal consumption growth obeys

$$
C_{t+1}=\beta^{\sigma}\left(1+r_{t+1}\right)^{\sigma} C_{t}
$$

The consumption path described above must satisfy the intertemporal constraint; using (7) to eliminate $C_{*}(s>t)$ from (3) shows that the economy's date $t$ consumption will be:

$$
C_{t}=\frac{\left(1+r_{t}\right) A_{t}+\sum_{s=t}^{\infty} R_{t, s}\left(Y_{s}-G_{s}-I_{s}\right)}{\sum_{s=t}^{\infty} R_{t, s}\left(\beta^{s-t} / R_{t, s}\right)^{\sigma}}
$$

Eq. (8) leads to an illuminating general characterization of the current account. Define the 'permanent' level of variable $X$ on date $t, \tilde{X}_{t}$, by

$$
\tilde{X}_{t} \equiv \frac{\sum_{s=t}^{\infty} R_{t, s} X_{s}}{\sum_{s=t}^{\infty} R_{t, s}}
$$

and define $(\widetilde{\beta / R})^{\sigma}$ as the following weighted average ratio of the $(s-t)$-period subjective and market discount factors:

$$
(\widetilde{\beta / R})^{\sigma} \equiv \frac{\sum_{s=t}^{\infty} R_{t, s}\left(\beta^{s-t} / R_{t, s}\right)^{\sigma}}{\sum_{s=t}^{\infty} R_{t, s}}
$$

Then, after many steps, eqs. (1) and (8) show the current account surplus on date $t$ to be:

$C A_{t}=\left(r_{t}-\tilde{r}_{t}\right) A_{t}+\left(Y_{t}-\tilde{Y}_{t}\right)-\left(G_{t}-\tilde{G}_{t}\right)-\left(I_{t}-\tilde{I}_{t}\right)+\left[1-\frac{1}{(\widehat{\beta / R})^{\sigma}}\right]\left(\tilde{r}_{t} A_{t}+\tilde{Y}_{t}-\tilde{G}_{t}-\tilde{I}_{t}\right)$

(As we alluded in the introduction, there are several places where we advise the reader to consider holding off on reproducing a result until a later reading; this is the first.) Eq. (9) yields a number of important predictions (each of which requires a ceteris paribus clause): ${ }^{10}$

${ }^{10} \mathrm{~A}$ less general version of eq. (9) is presented by Sachs (1982), who credits the derivation to Michael Bruno. To derive the first entry on the right hand-side of (9), observe that

$$
\frac{1+r_{t}}{\sum_{s=1}^{\infty} R_{t, s}}=\frac{r_{t}+\sum_{t=i+1}^{\infty} R_{i, s} r_{s}}{\sum_{s=t}^{\infty} R_{t, s}}=\frac{\sum_{s=t}^{\infty} R_{t, s} r_{t}}{\sum_{s=t}^{\infty} R_{t, s}}=\tilde{r}_{t}
$$


1. If the economy is a net foreign claimant and the world interest rate is above its permanent average, then the current account will be in greater surplus as people smooth consumption in the face of temporarily high foreign interest income. If the economy is a net foreign debtor, temporarily high interest rates will have an opposite current-account effect.

2. Output above its permanent level will contribute to a higher currentaccount surplus, again due to consumption smoothing. Similarly, the private sector will use foreign borrowing to cushion its consumption from abnormally high government consumption and investment needs.

3. The last term in (9) reflects consumption tilting due to divergences in the current and future periods between world real interest rates and the domestic rate of time preference, $(1-\beta) / \beta$. When the home country is on average more impatient than the rest of the world, $\beta$ is lower than future world interest rates will tend to be, resulting in $(\beta / R)^{\sigma}<1$. There will then be a secular tendency toward currentaccount deficits, and thus toward secularly increasing foreign debt and declining consumption. When it is foreigners on the other hand who are (on average) more impatient, so that $(\beta / R)^{\sigma}>1$, consumption's time path will have an upward tilt. The tilting effect is proportional to the economy's 'permanent' resources. Also, the tilting effect is stronger the higher is the ease of intertemporal substitution in consumption, measured by $\sigma$.

Before exploring the short-run implications of eq. (9), it is useful to consider some of the model's predictions for steady-state current-account behavior in a growing economy. As we shall see, a growing economy can run a current-account deficit indefinitely.

Incorporating growth forces one to model explicitly the linkage between capital accumulation and production. Assume that the production function

where we have made use of the fact that

$$
\sum_{:=t+1}^{\infty} R_{t, 0} r_{0}=1
$$

The rest is straightforward; for details, see Obstfeld and Rogoff (1995), ch. 2. 
for a small economy is Cobb-Douglas:

$$
Y_{t}=\theta_{t} K_{t}^{\alpha} L^{1-\alpha}
$$

$(\alpha<1)$, where $K_{t}$ is the end of period $t-1$ capital stock (available for production in period $t$ ), $L$ is the constant labor force (which we will normalize to 1 for convenience), and the productivity coefficient $\theta$ grows so that .

$$
\theta_{t+1}=(1+g)^{1-\alpha} \theta_{t}
$$

with $g>0$. Assume also that the capital stock can adjust in a period, without installation costs. In the absence of unanticipated shocks, the marginal product of capital, $\alpha \theta_{t} K_{t}^{\alpha-1}$, thus must equal $r$, the constant world interest rate; $r>g$ by assumption. ${ }^{11}$ Then, in a steady-state equilibrium, investment is easily shown to be

$$
I_{t}=K_{t+1}-K_{t}=g\left(\frac{\alpha \theta_{t}}{r}\right)^{\frac{1}{1-\alpha}}=\left(\frac{\alpha g}{r}\right) Y_{t}
$$

Output and investment therefore both grow at rate $g$. If government spending is zero, then one can use (9) to show that the optimal current account is given by

$$
C A_{t}=A_{t+1}-A_{t}=-\left[1-(1+r)^{\sigma} \beta^{\sigma}\right] A_{t}-\frac{1+g-(1+r)^{\sigma} \beta^{\sigma}}{r-g}\left(1-\frac{\alpha g}{r}\right) Y_{t}
$$

Division by $Y_{t}$ yields a difference equation in $A / Y$,

$$
\frac{A_{t+1}}{Y_{t+1}}=\left(\frac{(1+r)^{\sigma} \beta^{\sigma}}{1+g}\right) \frac{A_{t}}{Y_{t}}-\frac{1+g-(1+r)^{\sigma} \beta^{\sigma}}{(1+g)(r-g)}\left(1-\frac{\alpha g}{r}\right)
$$

Provided $(1+r)^{\sigma} \beta^{\sigma}<1+g$, the steady state is stable; it is the negative number

$$
\overline{A / Y}=-\frac{1-(\alpha g / r)}{(r-g)} .
$$

${ }^{11}$ For the world economy as a whole, the assumption that the growth rate does not exceed the interest rate can be justified using any standard general equilibrium growth model. 
Notice that, because $\alpha g / r=I / Y$, the long-run ratio of foreign debt to output equals the ratio to current output of the entire present value of future output net of investment.

What size debt-output ratio does eq. (10) imply? Suppose the world real interest rate $r$ is 8 percent per year, $g$ is 4 percent per year, and $\alpha=0.4$. Then $\overline{A / Y}=-20$, and the economy's trade balance surplus each period must be $-(r-g) \overline{A / Y}=80$ percent of GDP!

Such large debt levels and debt burdens are never observed in practice: economies that must borrow at market interest rates rarely have debts as great as a single year's GDP. The anomalous prediction points to some shortcomings of the model. With finite lifetimes, individuals currently alive wouldn't be able to borrow against the entire present value of the economy's output. There is no allowance in the model for sovereign risk. Finally, we note that the world interest rate $r$ is determined by the rest of the world's growth rate. In this example, however, the world growth rate must equal $(1+r)^{\sigma} \beta^{\sigma}$ (see Obstfeld and Rogoff 1995 , ch. 2), which is less than $1+g$ by assumption. But if a small economy were to grow faster than the world for a sufficiently long period, it would cease being small and the fixed interest rate assumption would be violated. If, on the other hand, the country's growth rate eventually converges to the world growth rate, the country's ability and desire to borrow from world capital markets are reduced.

\subsubsection{The role of comparative advantage}

The theory of international trade offers a useful perspective on these results. The reason is that foreign borrowing and lending can be viewed as intertemporal trade, that is, as the exchange of consumption available on different dates. The principle of comparative advantage thus applies.

Imagine that the home country faces a constant world interest rate equal to $1+r=1 / \beta$ and that $Y_{t}>Y$, for $s>t$. Eq. (9) predicts that (absent other current-permanent differences) the country will have a current-account surplus. The principle of comparative advantage makes the same prediction. In the absence of trade, the country's autarky interest rates, equal to $u^{\prime}\left(Y_{t}\right) / \beta u^{\prime}\left(Y_{s}\right)$, lie below the corresponding world interest rates, $(1+r)^{s-t}$. It therefore pays for the representative resident to export present consumption by lending abroad, since present consumption is comparatively cheap at home, and to import future consumption by receiving repayment for the 
loans at a later date.

Similarly, temporarily high investment needs can raise a country's autarky interest rate above the world level, making it an importer of present consumption, that is, an external borrower.

This perspective makes clear that it is only the country-specific or idiosyncratic components of shocks that result in current-account imbalances. The global components of shocks, in contrast, affect all countries similarly and thus open up no new opportunities for gains through intertemporal trade. Countries cannot all smooth consumption perfectly in the face of a shock that temporarily depresses world output, for example. Instead, the world real interest rate is bid up and all countries tilt their consumption paths upward.

\subsubsection{Modeling output fluctuations and investment}

Our earlier investment example assumed that a nation's capital stock can be adjusted without cost to equate capital's marginal product to the world interest rate. Empirical observation makes this assumption difficult to swallow: even at the industry level, we simply do not observe large discrete changes in stocks of capital. If there are costs to installing capital, however, capital stocks will move more sluggishly and protracted deviations of capital's marginal product from $r$ are possible. A simple model illustrates how costly investment affects current-account dynamics. ${ }^{12}$

Assume that final output is produced according to the standard homogeneous and concave production function $\theta_{t} F\left(K_{t}, L_{t}\right)$, where, as before, $\theta_{t}$ captures shifts in total factor productivity, and where $K_{t}$ is given by past investment decisions. A firm making decisions on date $t$ maximizes the present discounted value of its profits (which equal the dividends shareholders receive):

$$
\sum_{s=t}^{\infty} R_{t, s}\left[\theta_{s} F\left(K_{s}, L_{s}\right)-w_{s} L_{s}-I_{s}-\frac{a I_{s}^{2}}{2 K_{s}}\right]
$$

Above, $\frac{a}{2}\left(I_{t}^{2} / K_{t}\right)$ is the deadweight output cost of installing

$$
K_{t+1}-K_{t}=I_{t}
$$

\footnotetext{
${ }^{12}$ Matsuyama (1987) develops an open-economy model with costly investment. The effects of residential investment are studied in Matsuyama (1990).
} 
units of capital, where $a>0$ is an adjustment-cost parameter. According to (11), the efficiency of investment in producing installed capital declines at an increasing rate as the ratio of investment to installed capital rises. Given (11), the economy's net output on date $t$ is $Y_{t}=\theta_{t} F\left(K_{t}, L_{t}\right)-\frac{a}{2}\left(I_{t}^{2} / K_{t}\right)$.

The conditions for maximizing profits subject to (12) include

$$
I_{t}=\frac{q_{t}-1}{a} K_{t}
$$

and the investment Euler equation

$$
q_{t}=\frac{\theta_{t+1} F_{K}\left(K_{t+1}, L_{t+1}\right)+\frac{a}{2}\left(I_{t+1} / K_{t+1}\right)^{2}+q_{t+1}}{1+r_{t+1}}
$$

where $q_{t}$ (Tobin's $q$ ) is the Lagrange multiplier on constraint (12) and has the usual interpretation as the shadow price of installed capital.

Forward iteration on (14) shows that

$$
q_{t}=\sum_{s=t+1}^{\infty} R_{t, s}\left[\theta_{s} F_{K}\left(K_{s}, L_{s}\right)+\frac{a}{2}\left(I_{s} / K_{s}\right)^{2}\right]
$$

(we have excluded bubbles in the price of capital). Eq. (15) states that $q_{t}$, the ex dividend shadow price of a unit of capital at the end of period $t$, equals the present value of its future marginal products plus the present value of its future contributions to lowering the costs of investment. ${ }^{13}$

Multiply eq. (14) by $K_{t+1}$ and use eq. (12) to express it as

$$
q_{t} K_{t+1}=\frac{\theta_{t+1} F_{K}\left(K_{t+1}, L_{t+1}\right) K_{t+1}+\frac{a}{2}\left(I_{t+1}^{2} / K_{t+1}\right)+q_{t+1}\left(K_{t+2}-I_{t+1}\right)}{1+r_{t+1}}
$$

Because the production function is homogeneous of degree one and $q_{t+1}=$ $1+a\left(I_{t+1} / K_{t+1}\right)$ (recall eq. (13)), the foregoing relationship, iterated forward successively to eliminate terms of form $q_{s} K_{s+1}$, implies that

$$
q_{t} K_{t+1}=\sum_{s=t+1}^{\infty} R_{t, s}\left[\theta_{s} F\left(K_{s}, L_{s}\right)-w, L_{s}-I_{s}-\frac{a I_{s}^{2}}{2 K_{s}}\right] \equiv V_{t+1}
$$

\footnotetext{
${ }^{13} \mathrm{Eq}$. (15) defines the ex dividend shadow price on date $t$ because it does not include the profit earned on that date and paid out to shareholders as dividends.
} 
Thus, the optimizing firm's ex dividend market value at the end of period $t$, $V_{t+1}$, is the same as the shadow value of its installed capital: in Hayashi's (1982) terminology, average $q$ equals marginal $q .^{14}$

To see some of the model's predictions for current account and investment dynamics, let us simplify by assuming that $r, \theta$, and $L$ are constant and consider a situation in which the capital stock $K$ is initially below its steady state level. Thus the marginal product of capital, $\theta F_{K}\left(K_{t}, L\right)$ exceeds $r$, $q>1$, and both $K$ and $Y$ are expected to rise over time. As the capital stock rises toward its steady-state level, $\bar{K}$, where $\theta F_{K}(\bar{K}, L)=r, q$ falls to one. ${ }^{15}$ According to (9) the current account (abstracting from governmentspending changes, and assuming the economy consists of a representative firm owned by a representative agent) is given by

$$
\begin{gathered}
C A_{t}=\left\{\left[\theta F\left(K_{t}, L\right)-\frac{a I_{t}^{2}}{2 K_{t}}\right]-\frac{r}{1+r} \sum_{o=t}^{\infty}\left(\frac{1}{1+r}\right)^{o-t}\left[\theta F\left(K_{s}, L\right)-\frac{a I_{s}^{2}}{2 K_{s}}\right]\right\} \\
-\left[\frac{q_{t}-1}{a} K_{t}-\frac{r}{1+r} \sum_{s=t}^{\infty}\left(\frac{1}{1+r}\right)^{s-t} \frac{q_{s}-1}{a} K_{s}\right]
\end{gathered}
$$

Since $K$ is rising over time, final output is rising over time as well. Since investment also is falling, ${ }^{16}$ date $t$ installation costs exceed their permanent level. Thus, $Y_{t}=\theta F\left(K_{t}, L\right)-\frac{a}{2}\left(I_{t}^{2} / K_{t}\right)$ falls short of its permanent level, contributing a negative component to the current account. The fact that investment also is above its permanent level contributes a second negative component to the current account.

\footnotetext{
${ }^{14}$ As Hayashi shows, this equality is due to the homogeneity of degree one of the production and installation-cost functions.

${ }^{15}$ For discussions of these dynamics, see Abel (1982) and Summers (1981).

${ }^{16}$ In vestment equals $(q-1) K / a$, but with $q$ falling while $K$ is rising, it may not be obvious that $I$ falls over time. The assertion in the text is always true in the neighborhood of the steady state. To see why, observe that
}

$$
\begin{aligned}
I_{t+1}-I_{t}=K_{t} & {\left[\frac{\left(q_{t+1}-q_{t}\right)}{a}+\frac{\left(q_{t+1}-1\right)\left(q_{t}-1\right)}{a^{2}}\right] } \\
& \doteq \bar{K}\left(\frac{q_{t+1}-q_{t}}{a}\right)
\end{aligned}
$$

to a first-order approximation. 
Suppose $K$ initially lies below its long-run steady-state value because the economy has just experienced an unanticipated permanent increase in factor productivity, $\theta$. We can see from the preceding analysis that the economy runs a current-account deficit. A classical example of this dynamic is Norway in the 1970s (figure 3), which borrowed extensively to build up its North Sea oil production following the first oil-price shock.

Note that an unanticipated permanent rise in $\theta$ not only leads to a current account deficit but causes an immediate rise in output as well. Therefore, with productivity shocks the model can in principle explain the welldocumented countercyclical behavior of the current account. ${ }^{17}$ Of course, this result rests on the assumption that the rise in $\theta$ is permanent. Imagine, in contrast, an unexpected rise in $\theta_{t}$ lasting only a single period. This change will not affect investment plans for future dates, and so the only effect is a level of output temporarily above the permanent level. Eq. (9) shows that a current account surplus will arise on date $t$. Productivity shocks with greater persistence cause some investment and hence smaller initial current-account surpluses, and, if persistent enough, they can produce an initial deficit, as in the permanent case.

The reader should note that in the present one-good small-economy model, changes in investment can affect consumption, but investment itself is determined by elements that are independent of consumption preferences. Investment decisions are made to maximize the present discounted value of the country's output, evaluated at the world interest rate. The country's saving behavior is irrelevant. This independence of investment from consumption preferences need not hold if the economy uses capital to produce nontraded goods and services as well as tradables; it can also break down if there is a nontraded input in production, such as labor. Introducing nontraded goods and services leads to a number of other modifications of our basic one-good model's results, as we shall see in the next section.

\subsubsection{Nontradables, consumption, and investment}

An economy that consumes and produces nontradables as well as tradables may behave quite differently from the one examined so far. We begin by seeing how nontradables can affect consumption decisions.

\footnotetext{
${ }^{17}$ See the article by Morris Goldstein and Mohsin S. Khan in volume 2 of this Handbook (Goldstein and Khan 1985).
} 
In this section, it will be convenient to reinterpret $C$ as a composite index of the representative individual's consumption of tradables and nontradables, $C_{T}$ and $C_{N}$, but retain the assumption that the period utility function $u(C)$ is isoelastic with intertemporal substitution elasticity $\sigma$. Assume, moreover, that composite consumption $C$ has the CES form:

$$
C=\left[\alpha^{\frac{1}{\rho}} C_{T}^{\frac{\rho-1}{\rho}}+(1-\alpha)^{\frac{1}{\rho}} C_{N}^{\frac{\rho-1}{\rho}}\right]^{\frac{\rho}{\rho-1}}
$$

Here, $\rho$ is the (intratemporal) substitution elasticity between tradables and nontradables. Take tradables as the numeraire commodity and let $p$ be the price of nontradables in terms of tradables. Then, as one can easily show, the exact consumer-price index (CPI) in tradables, defined as the minimal cost in tradables of a unit of subutility $C$, is given by

$$
P=\left[\alpha+(1-\alpha) p^{1-\rho}\right]^{\frac{1}{1-\rho}}
$$

For the special case $\rho=1$ (the case of Cobb-Douglas preferences), $P=$ $p^{1-\alpha} / \alpha^{\alpha}(1-\alpha)^{1-\alpha}$. These same calculations reveal that, given $C$, the optimal consumption levels for tradables and nontradables are:

$$
C_{T}=\alpha\left(\frac{1}{p}\right)^{-\rho} C, \quad C_{N}=(1-\alpha)\left(\frac{p}{P}\right)^{-\rho} C
$$

Given the intratemporal allocation rules in (19), the consumer's intertemporal decision problem can be analyzed entirely in terms of composite consumption $C$ and the price index $P$. The consumer maximizes (4) subject to the budget constraint corresponding to $(5)$ but written in terms of expenditure on $C$ :

$$
\sum_{s=t}^{\infty} R_{t, s} P_{s} C_{s}=\left(1+r_{t}\right)\left(\dot{V_{t}}+B_{t}\right)+\sum_{s=t}^{\infty} R_{t, s}\left(w_{s} L_{s}-T_{s}\right)
$$

(Above, asset stocks, wages, and taxes still are expressed in units of tradables). The intertemporal Euler equation for the consumption index $C$ is now

$$
C_{t+1}=\beta^{\sigma}\left(1+\tau_{t+1}\right)^{\sigma}\left(\frac{P_{t}}{P_{t+1}}\right)^{\sigma} C_{t}
$$


This relationship is analogous to Euler eq. (7), except that overall consumption growth depends on the utility-based real interest factor $\left(1+r_{t+1}\right)\left(\frac{P_{L}}{P_{t+1}}\right)$, and not simply on the relative intertemporal price of tradables $1+r_{t+1}$. (Dornbusch 1983 stresses this point.) Combining eqs. (19) and (20) shows that the Euler equation for tradables expenditure, $C_{T}$, is

$$
C_{T t+1}=\beta^{\sigma}\left(1+r_{t+1}\right)^{\sigma}\left(\frac{P_{t}}{P_{t+1}}\right)^{\sigma-\rho} C_{T t}
$$

Eqs. (20) and (21) show, in particular, that consumption need no longer be intertemporally smoothed when the time-preference rate and world tradable goods interest rate coincide. For example, if the CPI, $P$, is rising over time, the real interest rate will be below the own interest rate on tradables, $r$. So total consumption expenditure measured in tradables, $P C$, will fall over time if $\sigma>1$ and rise over time if $\sigma<1$. Similarly, while a rising path of $P$ tilts that of $C$ downward with an elasticity $\sigma$, the price changes cause $C_{T}$ to rise relative to $C$ with elasticity $\rho$ (see eq. (19)). If $\rho>\sigma$ and $\beta(1+r)=1$, for example, consumption of tradables will rise over time if $P$ is rising ${ }^{18}$

Some general-equilibrium implications of these points can be illustrated by a simple model in which the economy's output of nontradables, $Y_{N}$, is exogenous. If we assume (for simplicity) that neither the government nor the domestic investment process uses up nontradables, then the condition of equilibrium in the nontradable sector is simply $C_{N}=Y_{N}$, and by (19) the equilibrium relative price of nontradables is

$$
p=\left[\frac{(1-\alpha) C_{T}}{\alpha Y_{N}}\right]^{1 / \rho}
$$

In the Cobb-Douglas case $\rho=1$, and it is simple to write down the equilibrium growth process for tradables consumption by combining the preceding expression with eq. (21):

$$
C_{T t+1}=\beta^{\frac{\sigma}{\sigma-a(\sigma-1)}}\left(1+r_{t+1}\right)^{\frac{\sigma}{\sigma-\alpha(\sigma-1)}}\left(\frac{Y_{N t+1}}{Y_{N t}}\right)^{\frac{(1-\alpha)(\sigma-1)}{\sigma-\alpha(\sigma-1)}} C_{T t}
$$

\footnotetext{
${ }^{18}$ For a panel of 13 developing countries, Ostry and Reinhart (1992) present Eulerequation estimates of $\sigma=1.27$ or 1.22 and $\rho=0.38$ or 0.50 (depending on the instrumental variables used in estimation). These results indicate that the case $\sigma>\rho$ may be relevant.
} 
Notice that even when nontradables output is constant, the growth of tradables consumption usually reflects the presence of nontradables in the consumption basket. The reason: growth in $C_{T}$ affects $p$ and thus the domestic real interest rate.

A fundamental implication of these results is that empirical studies of the intertemporal approach should distinguish carefully between fluctuations in traded and nontraded outputs. As an example, suppose that the path of traded output is flat, that $\beta(1+r)=1$, and that $Y_{N t}>Y_{N t+1}$. According to eq. (22), consumption of tradables will be rising if $\sigma>1$ and falling if $\sigma<1$. Because the current account surplus is the difference between the economy's endowment of tradables and its absorption of tradables, even the sign of the current account balance may not be related in a simple way to the time path of the economy's total real output.

One can add a labor-leisure tradeoff to the intertemporal model by viewing leisure as a nontradable (assuming there is no international migration). In this context the real wage plays the role that the relative price of nontradables $p$ played above. ${ }^{19}$

Also, as we suggested at the end of the preceding section, the presence of a sector producing nontradables permits domestic consumption preferences to affect the economy's investment behavior. A shift in preferences toward nontradables, for instance, will reduce investment if the nontradables sector is the relatively labor-intensive one. ${ }^{20}$

Allowing for nontradables is an important step towards having a more realistic model of current account behavior. In the next section we consider another important modification.

\subsubsection{Consumer durables and the current account}

Eighteen percent of 1993 United States consumption spending was devoted to durables (including clothing and shoes). But the theory we have developed thus far does not capture the possibility that consumer purchases in one period may yield utility over several periods. We now illustrate how the presence of durables can alter current account responses.

\footnotetext{
${ }^{19}$ For an early analysis of the effects of introducing nontraded labor on current account dynamics, see Bean (1986).

${ }^{20} \mathrm{See}$, for example, Murphy (1986) and Engel and Kletzer (1989).
} 
In this subsection, let $C$ stand for the individual's consumption of nondurables and let $D$ be the stock of durables he or she owns; all goods can be traded. A stock $D$ of durables yields a proportional service flow each period, including the period in which it is acquired. The consumer in a small country maximizes

$$
U_{t}=\sum_{s=t}^{\infty} \beta^{s-t}\left[\alpha \log C_{s}+(1-\alpha) \log D_{s}\right]
$$

subject to the finance constraints

$$
A_{t+1}-A_{t}=r A_{t}+Y_{t}-C_{t}-G_{t}-\left(K_{t+1}-K_{t}\right)-p_{t}\left[D_{t}-(1-\delta) D_{t-1}\right]
$$

and a solvency condition. Here, $D_{t}$ is the stock of durables (including newly purchased durables) held over period $t, p_{t}$ is their price in terms of nondurables, $\delta$ is their depreciation rate, and $r$, the world interest rate, is constant. Note that $A, Y, C, G$, and $K$ are measured in nondurables.

In addition to the usual intertemporal Euler equation for nondurables consumption, the individual's first-order conditions include

$$
\frac{(1-\alpha) C_{t}}{\alpha D_{t}}=p_{t}-\frac{1-\delta}{1+r} p_{t+1} \equiv \iota_{t}
$$

which equates the marginal rate of substitution of nondurables for the services of durables to the user cost or rental price of durables.

Assuming $\beta=1 /(1+r)$, consumption of nondurables is

$$
C_{t}=\frac{\alpha r}{1+r}\left[(1+r) A_{t}+(1-\delta) p_{t} D_{t-1}+\sum_{s=t}^{\infty}\left(\frac{1}{1+r}\right)^{s-t}\left(Y_{s}-I_{s}-G_{s}\right)\right]
$$

while consumption of durables' services is

$$
D_{t}=\frac{(1-\alpha) r}{\iota_{t}(1+r)}\left[(1+r) A_{t}+(1-\delta) p_{t} D_{t-1}+\sum_{s=t}^{\infty}\left(\frac{1}{1+r}\right)^{s-t}\left(Y_{s}-I_{s}-G_{s}\right)\right]
$$

Let's suppose for simplicity that, $p_{t}$ and, hence, the user cost, $\iota_{t}$, are constant. The last equations then imply that the consumer smooths, not the path of expenditures $p\left[D_{t}-(1-\delta) D_{t-1}\right]$ on durables, but the service flow from durables, which is proportional to $D_{t}$. With durables, the current account is the same as implied by (9) (assuming, as we have here, that $r=(1-\beta) / \beta$ ), 
but with an additional term that depends on new durables purchases (we omit the derivation):

$$
C A_{t}=\left\{\left(Y_{t}-\tilde{Y}_{t}\right)-\left(G_{t}-\tilde{G}_{t}\right)-\left(I_{t}-\tilde{I}_{t}\right)\right\}+(\iota-p) \Delta D
$$

Noting that the price of purchasing a durable outright, $p$, must be greater than the one-period user cost $\iota$, we see that the introduction of durables necessarily increases the volatility of current-account responses to unexpected income changes.

\subsubsection{The terms of trade and the transfer problem}

One of the earliest problems motivating the intertemporal approach was the need to understand how changes in the terms of trade - the price of a country's exports in terms of its imports-affect saving and the current account. Early applications of Keynesian models by Harberger (1950) and Laursen and Metzler (1950) had modeled adverse terms-of-trade shocks as real income-reductions that reduce saving and the external surplus in proportion to Keynes's marginal propensity to save. Instead, the intertemporal approach emphasized the response of forward-looking individuals to the changes in lifetime consumption possibilities that terms-of-trade movements cause.

The simplest case is of a specialized economy with an exogenous endowment $Y$ of its export good, but which also consumes imports. As in the model with nontradables, we again assume an isoelastic period utility function defined over a CES index $C$; here it depends on the individual's consumptions $C_{M}$ of imports and $C_{X}$ of exports:

$$
C=\left[\alpha^{\frac{1}{\rho}} C_{M}^{\frac{\rho-1}{\rho}}+(1-\alpha)^{\frac{1}{\rho}} C_{X}^{\frac{\rho-1}{\rho}}\right]^{\frac{\rho}{\rho-1}}
$$

Let $p$ now denote the price of exports in terms of imports, which is determined exogenously in the world market. The consumption-based price level in terms of imports is again given by formula (18).

The natural benchmark case, assumed by Svensson and Razin (1983), supposes that intertemporal trade is done through bonds indexed to the consumption index, $C$. In this case $r$ is the own rate of interest on the 
consumption index, and the budget constraint corresponding to (3) in the present setup (abstracting from government) is

$$
\sum_{s=t}^{\infty} R_{t, s} C_{s}=\left(1+r_{t}\right) A_{t}+\sum_{s=t}^{\infty} R_{t, s}\left(\frac{p_{s} Y_{s}}{P_{s}}\right)
$$

The Euler equation for the consumption index is again (7), implying the consumption function corresponding to (8), which has $I=G=0$ and $p Y / P$ in place of $Y$. To focus on the terms of trade, it is helpful to assume that $r=(1-\beta) / \beta$ and $Y$ are constant, in which case the consumption function reduces to:

$$
C_{t}=r A_{t}+\frac{r}{1+r} \sum_{s=t}^{\infty}\left(\frac{1}{1+r}\right)^{s-t}\left(\frac{p_{s} Y}{P_{s}}\right)
$$

A fall in the terms of trade lowers $p$ (the relative price of exports in terms of imports) relative to $P$ (the overall CPI in terms of imports). Thus, fluctuations in the terms of trade affect the consumption index and the current account (which here is measured in consumption-index units) exactly like fluctuations in GDP at constant terms of trade. In particular, a temporary terms-of-trade setback causes a current-account deficit, a permanent setback an immediate shift to the new, lower consumption level consistent with external balance. Obstfeld (1982) and Svensson and Razin (1983) illustrate how this latter result depends on the intertemporal separability of utility. ${ }^{21}$

This subsection has, thus far, focused on the response of the current account to exogenous terms-of-trade changes. When countries have some monopoly power in trade, however, shifts in their current accounts may influence terms of trade by redistributing wealth internationally.

The impact of international wealth transfers on the terms of trade is a classic problem of international finance. In the 1920s, Keynes and Ohlin disagreed on the price effects of German reparations; in the 1990s, observers

${ }^{21}$ Ostry (1988) and Edwards (1989) study interactions between the terms of trade and the relative price of nontradables. Gavin (1990) considers the terms of trade in a richer dynamic setting. For developing countries, it may be natural to assume that bonds are indexed to imports (e.g., 'dollars'). In that case the intertemporal budget constraint differs from the one we have analyzed, so that the Euler equation for $C$ is formally the same as (20) Expected terms of trade movernents therefore have consurnption-tilting effects through the consumption-based real interest rate. 
of the protracted United States external deficits have debated the need for a fall in the relative price of American exports. ${ }^{22}$

For a cross-section of 15 OECD countries, figure 4 plots the percent change in the trade-weighted WPI real exchange rate (a terms-of-trade proxy) against the change in the ratio of net foreign assets to output. The net foreign asset series attempt to account not only for measured current account flows, but for capital gains and losses. ${ }^{23}$ The changes are calculated as the 1986-1990 average less the 1981-1985 average.

The figure shows a distinct positive relationship-an increase in a country's net foreign assets appears to be associated with an improvement in its terms of trade. The least-squares regression line is

$$
\Delta \log \left(p_{j}\right)=\underset{(0.027)}{0.039}+\underset{(0.433)}{1.042} \Delta(A / Y)_{j}+u_{j} ; R^{2}=0.31
$$

implying a statistically significant relationship. According to the regression, an increase of 1 percent in the ratio of net foreign assets to output is associated with a 1 percent improvement in the terms of trade.

Obviously, this regression provides only a nonstructural correlation. To assess accurately the consequences of an exogenous wealth transfer would require a full econometric structural model. Given the perennial importance of the transfer effect in policy discussions, the development of empirical intertemporal models that can explain its magnitude is a research priority.

Theoretically, the transfer effect can operate through several channels in a general-equilibrium setting. Two potential mechanisms are home preference for domestic exports and the presence of a nontradables sector that competes for resources with the exportable sector. A special case of the latter mechanism is due to the effect of a wealth change on labor supply and, hence, on the supply of exportables.

\footnotetext{
${ }^{22}$ See, for example, the papers in Bergsten (1991).

${ }^{23} \mathrm{Real}$ exchange rate data come from International Monetary Fund, International Financial Statistics. Net foreign asset positions come from OECD Economic Outlook 55 (June 1994), p. A54. The country sample is Australia (for which the CPI was used), BelgiumLuxembourg, Canada, Denmark, Finland, France, Germany, Italy, Japan, Netherlands, Norway, Spain, Sweden, the United States, and the United Kingdom. We are skeptical that the real appreciation of $\mathbf{3 3}$ percent that the IMF reports for Norway is accurate. (The IMF reports a similar number based on CPIs.) OECD data place Norway's real appreciation over 1981-1990 closer to 15 percent. However, the observation on Norway is not driving the regression results reported below.
} 
Figure 4

Real Currency Appreciation versus the Change in Foreign Assets, 1981-1990

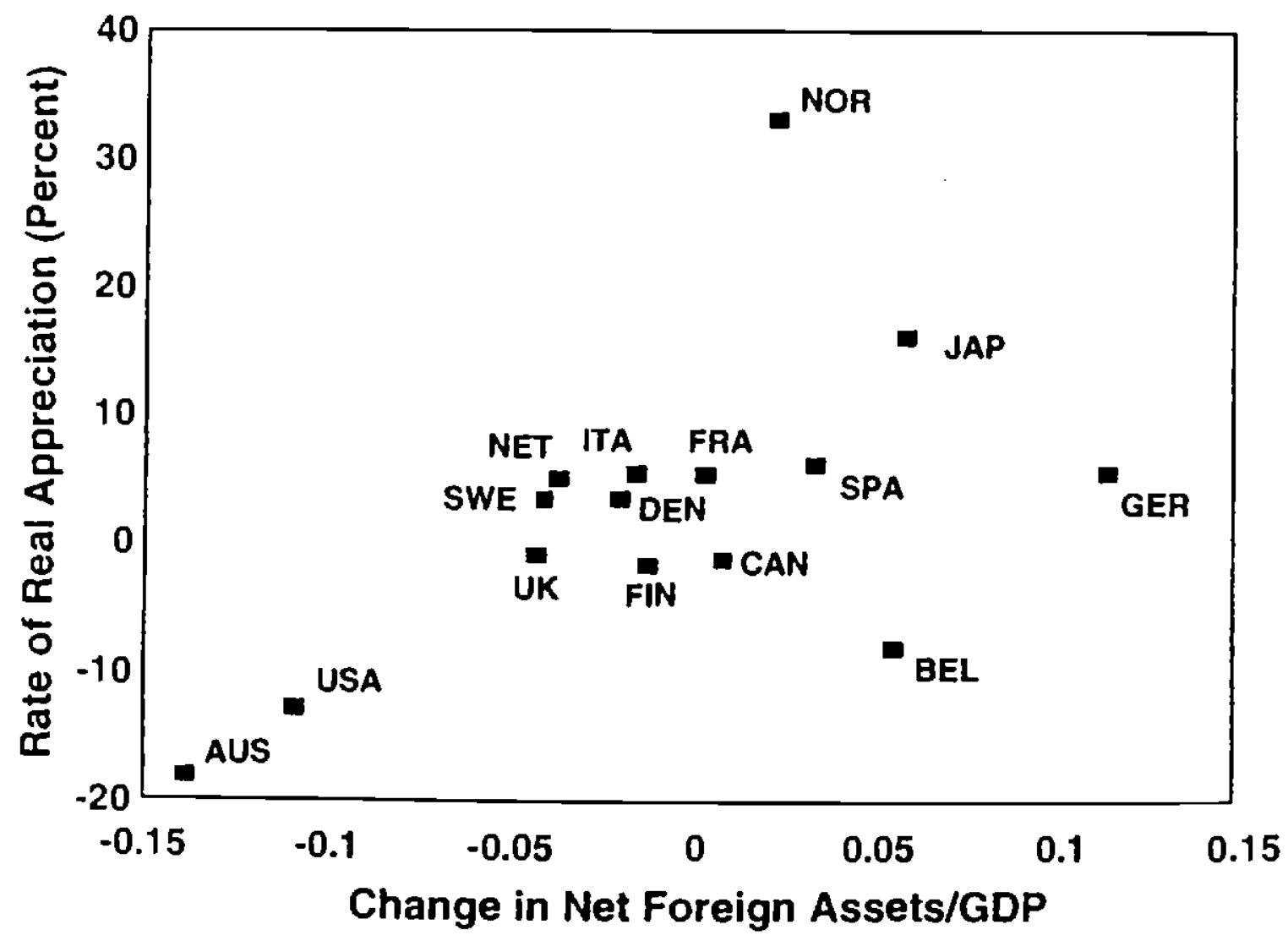


A simple two-country model exhibits the labor-supply channel for the transfer effect. Assume that the home country specializes in producing good $X$ and the foreign country good $M$. Moreover, assume that in both countries $\rho$, the elasticity of substitution in demand between the two produced goods, equals 1 . Let the period utility function, common to the home and foreign countries, be an isoelastic function of an index that depends on both consumption and leisure,

$$
C^{\xi}(H-L)^{1-\xi}=\left(C_{M}^{\alpha} C_{X}^{1-\alpha}\right)^{\xi}(H-L)^{1-\xi}
$$

where $0<\xi<1, H$ is an individual's endowment of time, and $L$ his or her labor supply. Let home output be produced according to the production function $Y=\omega L$ and foreign output according to $Y^{*}=\omega^{*} L^{*}$. Let $P$ once again denote the price of the index $C$ in terms of home imports, and assume bonds are indexed to $C$. The home country's net external assets are $A$, and the foreign country's, therefore, are $-A$. Using the steady-state consumption functions to solve for demand and supply in either of the goods markets, one can show (after many steps) that the equilibrium terms of trade satisfy the condition

$$
\frac{p \alpha \omega H}{P}-\frac{(1-\alpha) \omega^{*} H^{*}}{P}=\frac{(1-\xi)(1-\beta)}{\xi \beta} A
$$

From this implicit terms-of-trade equation one can easily see the effect of an exogenous shift in net external assets from the foreign to the home country (that is, of a rise in $A$ ). An absolute rise in $p$, the relative price of home exports, raises $p$ relative to $P$, and $P$ itself rises absolutely. If $A$ rises, a rise in $p$ therefore maintains equilibrium. The intuition why a wealth transfer to the home country improves its terms of trade is simple. If home residents receive a financial windfall, they spend some of it on leisure. Output of the home good thus falls and its relative price must rise.

\subsubsection{Demographic structure, fiscal policy, and the current ac- count}

The single representative agent paradigm followed so far in this chapter may furnish misleading predictions about the current account when the economy consists instead of heterogeneous families born on different dates and unconnected by altruistic links. A model based on the overlapping-generations 
structure in Weil (1989) illustrates some possible implications of allowing for demographic complexity. ${ }^{24}$

We will identify the economy's total population with its labor supply, $L_{t}$, which grows at rate $n: L_{t+1}=(1+n) L_{t}$, with $L_{0}$ normalized to 1 . This labor force, however, consists of immortal unconnected individuals (or dynasties) born on successive dates. A representative from the generation born on date $v$ (the generation's 'vintage') maximizes $U_{v, t}=\sum_{s=t}^{\infty} \beta^{s-t} u\left(C_{v, s}\right)$ subject to

$$
\sum_{s=t}^{\infty} R_{t, s} C_{v, s}=\left(1+r_{t}\right)\left(V_{v, t}+B_{v, t}\right)+\sum_{s=t}^{\infty} R_{t, s}\left(w_{s}-T_{s}\right)
$$

(each individual supplies one unit of labor per period.) Notice that consumption and wealth are vintage-specific, whereas all people face the same wage, interest rates, and (by assumption) lump-sum taxes. A key assumption is that $V_{v, v}=B_{v, v}=0$ : vintages are born with no financial wealth, only with a lifetime endowment equal to the present value of after-tax labor income. (One can think of the model as one in which primogeniture governs the bequest of family wealth.) Investment can be modeled exactly as before. The only difference is that a growing labor force requires positive steady-state investment.

To make the main points it suffices to work with the special case in which the interest rate is constant at $r$ and the period utility function is $u(C)=\log (C) \cdot{ }^{25}$ In this case,

$$
C_{v, t}=(1-\beta)\left[(1+r)\left(V_{v, t}+B_{v, t}\right)+\sum_{s=t}^{\infty}\left(\frac{1}{1+r}\right)^{s-t}\left(w_{s}-T_{s}\right)\right]
$$

is the consumption function.

In investigating the economy's aggregate behavior, it is helpful to work with per capita aggregate measures of macro-variables such as consumption and wealth. Let $X_{v, t}$ be the vintage-specific value of variable $X$ on date $t$. Observe that the size of generation $v=0$ is 1 , that of generation 1 is $(1+n)-1=n$, that of generation 2 is $(1+n)^{2}-(1+n)=n(1+n)$, and so on up through vintage $t$, which is of size $n(1+n)^{t-1}$. Thus the per capita

\footnotetext{
${ }^{24}$ For alternative open-economy models with overlapping generations, see Buiter (1981), Blanchard (1985), Persson (1985), Frenkel and Razin (1987), and Eaton (1988).

${ }^{25}$ This case corresponds to isoelastic preferences with $\sigma=1$.
} 
average value of $X$ on date $t$ is:

$$
X_{t}=\frac{X_{0, t}+n X_{1, t}+n(1+n) X_{2, t}+\ldots+n(1+n)^{t-1} X_{t, t}}{(1+n)^{t}}
$$

To compute aggregate per capita consumption, observe that $V_{t}$, defined as in the last equation, is the average per capita value of claims to domestic firms at the end of period $t-1$ and is still given by (11) if the quantities in that equation are interpreted as per capita aggregates. Eqs. (11), (24), and (25) thus imply ${ }^{26}$

$$
C_{t}=(1-\beta)\left[(1+r) B_{t}+\sum_{s=t}^{\infty}\left(\frac{1}{1+r}\right)^{s-t}\left(Y_{s}-T_{s}-I_{s}\right)\right]
$$

Consumption still depends on the time path of taxes. To understand this dependence, however, we must for the first time in this chapter explicitly consider exactly how the domestic government coordinates the time paths of expenditures and taxes.

Let $D_{t}$ denote the government's per capita debt at the end of date $t-1$. Then if $G_{t}$ denotes per capita government consumption, the intertemporal public-sector budget constraint on date $t$ is

$$
(1+r)(1+n)^{t} D_{t}+\sum_{s=t}^{\infty}\left(\frac{1}{1+r}\right)^{s-t}(1+n)^{s} G_{s}=\sum_{s=t}^{\infty}\left(\frac{1}{1+r}\right)^{s-t}(1+n)^{s} T_{s}
$$

This constraint equates the present value of tax revenues to the present value of spending plus initial debt. If $r \leq n$ neither the government's revenue nor its spending has a finite present value, so we assume $r>n$. Division of the preceding constraint by $(1+n)^{t}$ renders it in per capita terms as:

$$
(1+r) D_{t}+\sum_{s=t}^{\infty}\left(\frac{1+n}{1+r}\right)^{s-t} G_{s}=\sum_{s=t}^{\infty}\left(\frac{1+n}{1+r}\right)^{s-t} T_{s}
$$

\footnotetext{
${ }^{26}$ To derive this equation, we assume perfect foresight between dates $t-1$ and $t$, so that $(1+r) V_{t}=Y_{t}-w_{t}-I_{t}+V_{t+1}$. The next equation holds, however, even without the perfect foresight assumption, as can be seen by modifying consumers' intertemporal budget constraints as explained in the footnote preceding eq. (5) above. In deriving (26), we have made use of the fact that the production function is homogenous of degree one.
} 
To see what this constraint implies for private consumption, lead it one period and observe that

$$
D_{t+1}=\frac{(1+r) D_{t}+G_{t}-T_{t}}{1+n}
$$

Solving eq. (27) for $T_{t}$ and taking present values, we obtain

$$
\sum_{s=t}^{\infty}\left(\frac{1}{1+r}\right)^{s-t} T_{s}=(1+r) D_{t}-\sum_{s=t+1}^{\infty}\left(\frac{1}{1+r}\right)^{s-t-1} n D_{s}+\sum_{s=t}^{\infty}\left(\frac{1}{1+r}\right)^{s-t} G_{s}
$$

which, after rearranging, can be expressed in the form:

$$
\begin{gathered}
\sum_{s=t}^{\infty}\left(\frac{1}{1+r}\right)^{s-t} T_{s}=\sum_{s=t}^{\infty}\left(\frac{1}{1+r}\right)^{s-t} G_{s} \\
+(1+r)\left(1-\frac{n}{r}\right) D_{t}-\sum_{s=t}^{\infty}\left(\frac{1}{1+r}\right)^{s-t}\left(\frac{1+r}{r}\right) n\left(D_{s+1}-D_{s}\right)
\end{gathered}
$$

Expression (28) shows that in the overlapping-generations economy, higher future government deficits lower the present value of taxes for those currently alive, holding the path of government consumption constant. Why is this so? Eq. (27) shows that if $D_{t}$ were a unit higher the government would have to raise taxes in all future periods by only $r-n$ to keep the per capita public debt constant. Thus, an extra unit of government bonds in the hands of someone alive at the start of date $t$ raises his or her discounted stream of tax liabilities by only

$$
\sum_{s=t}^{\infty}\left(\frac{1}{1+r}\right)^{s-t}(r-n)=(1+r)\left(1-\frac{n}{r}\right)
$$

How do current and future government deficits alter the tax bill of current generations? Let the government cut per capita taxes by $1+n$ units in period $t$ and finance this tax cut by issuing enough additional debt to make $D_{t+1}$ one unit higher (see eq. (27)). If the government is to maintain this new higher per capita debt level, it must raise taxes by $r-n$ per capita from date $t+1$ on. Thus, for someone alive on date $t$, the net effect of a deficit-financed tax cut is to lower the present value of their taxes by

$$
1+n-\sum_{s=t+1}^{\infty}\left(\frac{1}{1+r}\right)^{s-t}(r-n)=\left(\frac{1+r}{r}\right) n
$$


Deficit-financed tax cuts in periods after $t$ have a corresponding discounted effect on the tax liabilities of those alive on date $t$.

The mechanism underlying these results is well known: the more debt the government issues, the more taxes can be shifted onto future generations yet unborn. Severing altruistic links between those alive today and some of those who will be alive tomorrow creates a situation in which current generations do not fully internalize the future tax liabilities arising from government debt issue. If, in contrast, $n=0$, there are no future entrants to the economy to be taxed and, as (28) shows, the time profile of government debt no longer matters to economic agents. In this case, government debt is not net wealth and the Ricardian equivalence of deficit- and tax-financed government expenditure holds. In the representative-agent economy considered earlier, government borrowing has no influence on the current account.

This is not the case here. Because the economy's overall net foreign assets are $A_{t}=B_{t}-D_{t}$, substitution of (28) into consumption function (26) shows that

$$
\begin{aligned}
C_{t}= & (1-\beta)\left\{\frac{n}{r} D_{t}+\sum_{s=t}^{\infty}\left(\frac{1}{1+r}\right)^{s-t}\left(\frac{1+r}{r}\right) n\left(D_{s+1}-D_{s}\right)\right. \\
& \left.+(1+r) A_{t}+\sum_{s=t}^{\infty}\left(\frac{1}{1+r}\right)^{s-t}\left(Y_{s}-I_{s}-G_{s}\right)\right\}
\end{aligned}
$$

In per capita terms, the date- $t$ current account is $(1+n) A_{t+1}-A_{t}=r A_{t}+$ $Y_{t}-C_{t}-I_{t}-G_{t}$, so, other things equal, a higher current level of government debt or a higher trajectory for future government deficits will raise current consumption and the economy's foreign borrowing.

Despite some notable episodes, it has proven difficult to verify a strong statistical correlation between budget and current-account deficits. Below we present cross-section regressions for industrialized countries over fiveyear subsamples of 1976-1990. ${ }^{27}$ Each subsample cross-section observation is formed by averaging a country's annual current-account surplus ratio to

${ }^{27}$ The sample consists of the OECD countries as of 1994, except for Belgium, Luxembourg and Turkey. The data for current-account deficits and central government budget deficits relative to GDP come from International Monetary Fund, International Financial Statistics. Due to lack of data, Switzerland is omitted from the 1981-1985 regression and Canada, New Zealand, and Switzerland are omitted form the 1986-90 regression. 
GDP and its central government deficit ratio to GDP.

$$
\begin{aligned}
& 1976 \text { - } 1980 \\
& (C A / Y)_{j}=-0.208-0.406(\Delta D / Y)_{j}+u_{j} ; R^{2}=0.23 \\
& \begin{array}{ll}
(0.907) & (0.171)
\end{array} \\
& (C A / Y)_{j}=\begin{array}{c}
1981-\mathbf{1 9 8 5} \\
0.995
\end{array}-\begin{array}{c}
0.506(\Delta D / Y)_{j}+u_{j} ; R^{2}=0.32 \\
(1.206)
\end{array}
\end{aligned}
$$

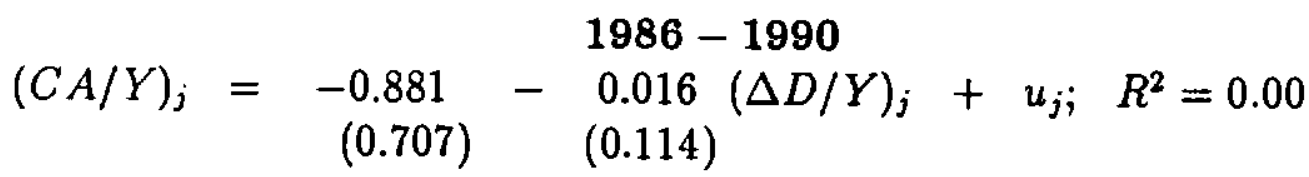

Over the first two subsamples there is a strong negative correlation between budget deficits and the current-account surplus, as the overlappinggenerations model would suggest. ${ }^{28}$ During the most recent subsample, however, the correlation evaporates. The last result suggests that factors other than government budgets dominated several countries' current accounts over 1986-1990. If one runs the same regression on a sample that includes nonindustrialized countries, the results are weaker. Beware: these simple correlations are merely suggestive and have no structural interpretation. In particular, they cannot tell us the effect of an exogenous increase in a government's budget deficit on the current account. Another serious issue is to choose the appropriate measure of the intergenerational incidence of budget policies. For example, even if the social security account of the budget is balanced, it represents a huge transfer from young to old. Clearly, a better understanding of the 'twin deficits' will require structural models and careful attention to intergenerational distribution.

Models incorporating more complex demographics have important implications aside from their predictions about government financial imbalances. Consider, for example, the implications of expected productivity growth. In a representative-agent framework, higher productivity growth will tend to weaken the current account as people borrow today against higher future income. (Investment effects would strengthen this result.) In a life-cycle

\footnotetext{
${ }^{28}$ In a sample including four industrialized countries and Mexico, Bernheim (1988) finds a similar correlation between budget deficits and current-account deficits over 1976-1985.
} 
setting the implications of higher productivity growth are less clear. If each individual benefits identically from the change regardless of his or her age, the results are much the same as in a representative-agent model. But suppose that productivity growth raises the labor incomes of young workers but does not affect the labor incomes of older workers. Because young savers will count more heavily in aggregate saving than old dissavers, saving will tend to rise and the current account to improve. Deaton (1992) discusses how life-cycle theories might explain the observed tendency for national saving and growth rates to be positively correlated in cross sections.

An important property of overlapping-generations models is that they permit a steady-state with positive consumption for a small open economy, even if individuals have fixed time-preference rates different from the world interest rate. In the Weil (1989) model just sketched, for example, the small economy can reach a steady state even if individual cohorts' consumption levels are rising or falling over time; what is needed is that the birth rate of new individuals be large enough to offset the discrepancy between $\beta(1+r)$ and 1. If $\beta(1+r)<1, n>0$ guarantees this outcome; if $\beta(1+r)>1$, the inequality $\beta(1+r)<1+n$ is necessary.

\subsection{Stochastic models of the current account}

A theory of current-account determination that makes no allowance for the uncertainty about the future underlying consumption and investment decisions cannot be fully satisfactory. Unfortunately, however, the introduction of stochastic elements can raise the technical difficulty of writing down solutions to individuals' maximization problems by an order of magnitude. Below we review the predictions of some leading stochastic models. A key theme emerging from the discussion is that the current-account response to various shocks depends on whether markets exist for insuring against the shocks' effects. This theme leads us, at the section's end, to consider a model in which the extent to which shocks are insurable is endogenous.

\subsubsection{Complete markets}

The most tractable case of uncertainty is that in which insurance markets exist for all future contingencies, with outcomes fully verifiable and contracts fully enforceable. In the classic Arrow-Debreu world of complete markets, 
equilibrium resource allocations are efficient and, from a formal point of view, the economy can be analyzed as if perfect certainty applied. There are simply many more commodities, commodities now being indexed by the state of nature in which they are demanded and supplied. ${ }^{29}$

Except for certain special cases, market completeness requires that people be able to trade as many independent assets as there are prospective states of nature. Equivalently, they must be able to trade a complete set of ArrowDebreu securities, each of which pays off only in one state. The result of this trade is that individuals everywhere in the world equalize their marginal rates of substitution of present for future state-contingent consumption to the same Arrow-Debreu prices, so that for all countries $i$ and $j$,

$$
\frac{u^{\prime}\left(C_{t+1}^{i}\right)}{u^{\prime}\left(C_{t}^{i}\right)}=\frac{u^{\prime}\left(C_{t+1}^{j}\right)}{u^{\prime}\left(C_{t}^{j}\right)}
$$

given shared rates of time preference (that is, the $\beta$ 's cancel). Condition (29) precludes further mutual gains, on any date or in any state, from intraconsumer borrowing and lending. Investment decisions are made to maximize the present value of profits evaluated at state-contingent output prices.

When all people throughout the world trade prospective risks in insurance markets, some local economic shocks effectively become global shocks and their current account effects are diminished or even eliminated. Consider, for instance, a pure exchange economy that experiences a temporary idiosyncratic positive output shock. Absent insurance markets, the country would run a current-account surplus, accumulating some foreign assets so as to smooth the benefits of the shock over all future periods. Under complete markets, however, the home economy has already traded much of its output risk to foreigners and purchased, in turn, claims on their risky output processes. Thus, the home economy's positive output shock will cause a small synchronized increase in every country's consumption under complete markets. But it will also cause a shift in every country's income as 'dividend' payments flow from the home country to its foreign shareholders.

\footnotetext{
${ }^{29}$ International models with complete markets are analyzed by Lucas (1982), Stockman (1988a), Stulz (1988), Cole and Obstfeld (1991), Stockman and Tesar (1991), Backus, Kehoe, and Kydland (1992), and Baxter and Crucini (1993a), among many others. Lucas's (1982) model does not actually assume complete markets, and in fact can contain far more states of nature than assets. However, other special assumptions made by Lucas result in an allocation the same as the one complete markets would produce.
} 
With isoelastic preferences, no current-account imbalances result. Indeed, in the isoelastic case, there are never unanticipated current account movements. (Regardless of the utility function, differences in time preference can generate nonzero current accounts under complete markets. The same is true when there are perfectly predictable trend differences in country output profiles.)

If period utility is not isoelastic, world output shocks can generate gains from intertemporal trade warranting current-account imbalances. Even in this case, shocks that affect the distribution of output across countries, but leave world output unchanged, have no current-account implications.

Returning to the case of isoelastic utility, a positive shock to the productivity of domestic investment causes a current-account deficit, as in our earlier perfect-foresight models. But that deficit will reflect only an influx of savings from abroad to share in ownership of the incremental investment. (Indeed, the existing capital of firms will already have a globally dispersed ownership.) The deficit does not reflect consumption-smoothing effects, because all countries' income profiles are rising in proportion. Despite the deficit-indeed, because of it-the international wealth distribution is constant.

Under literally complete markets, risks due to changes in government consumption also would be perfectly pooled among nations. An exogenous unexpected rise in United States spending on highway repairs due, say, to bad weather, would be financed mostly by contingent-contract payments from foreigners to the United States. The obvious adverse incentives introduced by such contracts illustrate why, in practice, asset markets are hardly complete. If a country's residents have sold most of domestic firms' future earnings on forward markets, its government has every incentive to raise corporate taxes sharply after the fact. More generally, under asymmetric information, moral hazards affecting private as well as government behavior impede complete risk sharing. Informal observation and statistical evidence both confirm that even in a domestic context, risks are far from being pooled as the completemarkets paradigm would predict. In the international context, sovereign risk and distance, together with cultural and legal differences, greatly magnify the difficulties. ${ }^{30}$

\footnotetext{
${ }^{30}$ See Obstfeld (1995) for a survey of evidence. The limited amount of international risk sharing has prompted Shiller (1993) to propose creating international markets in GDP futures.
} 


\subsubsection{Bonds as the only asset}

Let's look instead at the opposite extreme, that in which the only asset nations trade is a one-period bond indexed to tradable consumption goods and offering a certain one-period return. This restriction on the menu of assets is too severe to furnish a completely realistic model, but it does serve to produce a model quite comparable to the deterministic one studied earlier. Later on we discuss hybrid models in which there are markets for some, but not all, risks.

For simplicity, we again choose as our framework a representative-agent economy in which all goods are traded. Now the individual maximizes the conditional expectation

$$
U_{t}=\mathrm{E}_{t}\left\{\sum_{s=t}^{\infty} \beta^{s-t} u\left(C_{s}\right)\right\}
$$

subject to a budget constraint like (5) equating the present value of consumption to initial financial wealth plus the present value of after-tax labor income. The consumption levels in (30) are contingency plans for consumption that depend on the individual's history through the date the plan is implemented. The budget constraint depends on stochastic future earnings, taxes, and interest rates. The sequence of contingent consumption plans the consumer chooses on date $t$ must satisfy the budget constraint for every prospective history of the economy.

The intertemporal Euler equation derived in the certainty case now holds in expectation (cf. eq. (6)):

$$
u^{\prime}\left(C_{t}\right)=\beta\left(1+r_{t+1}\right) \mathrm{E}_{t}\left\{u^{\prime}\left(C_{t+1}\right)\right\}
$$

To obtain closed-form consumer decision rules, we approximate $u(C)$ by the quadratic function

$$
u(C)=C-\frac{h}{2} C^{2}
$$

With this approximation (31) becomes

$$
\mathrm{E}_{t} C_{t+1}=\frac{1}{\beta\left(1+r_{t+1}\right)} C_{t}+\frac{1}{h}\left(1-\frac{1}{\beta\left(1+r_{t+1}\right)}\right)
$$


Here we see that the relation between $\beta$ and the gross world interest rate induces a tilt in expected consumption growth as was also true in subsection $3.1^{31}$.

To simplify further, assume temporarily that the interest rate is constant at $r$, with $\beta(1+r)=1$; the result is the 'random walk' prediction for consumption derived by Hall (1978):

$$
\mathrm{E}_{t} C_{t+1}=C_{t}
$$

In equilibrium, the economy's intertemporal budget constraint, eq. (3), must hold for every possible sequence of outcomes when its elements are random. Applying the date- $t$ expectations operator to both sides of (3) and using (32), we have the certainty-equivalence consumption function:

$$
C_{t}=\frac{r}{1+r} \mathrm{E}_{t}\left\{(1+r) A_{t}+\sum_{s=t}^{\infty}\left(\frac{1}{1+r}\right)^{s-t}\left(Y_{s}-G_{s}-I_{s}\right)\right\}
$$

Eq. (33) yields predictions for current accounts qualitatively similar to those of the deterministic consumption function (8) developed earlier. As a result, this equation and its relatives provide the leading vehicles for empirical studies of current-account determination. The linear-quadratic formulation has, however, at least three conceptual drawbacks:

1. Under quadratic utility $u^{\prime \prime \prime}(C)=0$, so there is no precautionary saving. When, instead, $u^{\prime \prime \prime}(C)>0$, marginal utility $u^{\prime}(C)$ is a convex function. This convexity implies that an increase in uncertainty over future consumption raises its expected marginal utility and, thus, saving. We return to current-account models incorporating a precautionary savings motive in our discussion of empirical work in section $4 .^{32}$

2. In both estimating and simulating intertemporal models, it is frequently convenient to be able to linearize or log-linearize first-order Euler conditions. Assuming quadratic period utility is really just another way of

\footnotetext{
${ }^{31}$ In the preceding equation the ratio of the gross interest rate to $1 / \beta$ enters both in the slope and in the intercept, with opposite effects on expected date- $(t+1)$ consumption. The quadratic utility specification makes sense, however, only so long as $C<1 / h$, ensuring that the marginal utility of consumption is positive. Under this assumption, it is clear that the intercept effect dominates: lowering $\beta$, for example, lowers expected date- $(t+1)$ consumption in the last equation.

${ }^{32}$ On precautionary saving behavior, see Leland (1968).
} 
linearizing. The basic problem with this approach is that a linearized model will be very inaccurate far away from the point of approximation. Yet if the linearization implies, as in (32), that consumption follows a random walk, consumption will eventually drift arbitrarily far from any initial level. As Obstfeld (1982) and Svensson and Razin (1983) showed, one way to avoid a unit root in consumption is to assume an endogenous, rather than fixed, rate of time preference. If the rate of impatience rises with the level of consumption, a stationary consumption distribution is possible. Another solution is to assume overlapping cohorts of finite-lived agents who leave no bequests. Unfortunately, neither alternative can match the linear-quadratic infinite-lifetime framework for easy empirical implementation. Ultimately the justification for using the latter setup must rest on the presumption that it yields a reasonable approximation to behavior away from boundaries. More research proving or disproving this presumption would be useful. ${ }^{33}$

3. The consumption function (33) does not necessarily constrain consumption to be non-negative in all states of the world. If negative levels of consumption are ruled out, consumption cannot literally follow a random walk as in (32)..$^{34}$

We turn next to investigating how, when bonds are the only internationally traded asset, the separation between domestic investment and consumption implied by complete markets can break down.

It is natural to assume again that the domestic firm makes its investment decision on date $t$ to maximize the present discounted value of profits. But with uncertainty, it is no longer obvious what discount rate should be used to value the risky stream of dividends the firm issues to shareholders. With population normalized to 1 , the firm's ex dividend value, $V_{t+1}$, is the price of a share in the firm in date $t$ asset trading. Using dynamic programming (the

\footnotetext{
${ }^{33}$ Clarida (1990) develops an exact general-equilibrium model of international borrowing and lending under endowment uncertainty, heterogenous fixed discount rates, and lower limits on individual assets. He finds that when there is no aggregate output uncertainty, there is a stationary distribution of wealth and consumption levels in which sone households are borrowing-constrained.

${ }^{34}$ The problem of nonnegativity constraints afficts the commonly used consumption functions derived in continuous-time models by stochastic dynamic programming. See Cox and Huang (1989).
} 
details are omitted here), one can show that $V_{t+1}$ follows a stochastic process such that the following Euler equation holds

$$
\begin{gathered}
V_{t+1} u^{\prime}\left(C_{t}\right)=\beta E_{t}\left\{\left[\theta_{t+1} F\left(K_{t+1}, L_{t+1}\right)-w_{t+1} L_{t+1}\right.\right. \\
\left.\left.-I_{t+1}-a I_{t+1}^{2} / 2 K_{t+1}+V_{t+2}\right] u^{\prime}\left(C_{t+1}\right)\right\}
\end{gathered}
$$

Iterated forward substitutions for $V$ yield a stochastic version of (16),

$$
V_{t+1}=\mathrm{E}_{t}\left\{\sum_{s=t+1}^{\infty} \beta^{s-t} \frac{u^{\prime}\left(C_{s}\right)}{u^{\prime}\left(C_{t}\right)}\left[\theta_{s} F\left(K_{s}, L_{s}\right)-w_{s} L_{s}-I_{s}-\frac{a I_{s}^{2}}{2 K_{s}}\right]\right\}
$$

Given that the firm is owned entirely by domestic residents, the present value of a claim to its future dividends in any particular state of nature depends on domestic consumer's marginal utility in that state of nature relative to current marginal utility.

We can decompose (34) further as ${ }^{35}$

$$
\begin{aligned}
V_{t+1} & =\sum_{s=t+1}^{\infty} \mathrm{E}_{t}\left\{\beta^{s-t} \frac{u^{\prime}\left(C_{s}\right)}{u^{\prime}\left(C_{t}\right)}\right\} \mathrm{E}_{t}\left\{\theta_{s} F\left(K_{s}, L_{s}\right)-w_{s} L_{s}-I_{s}-\frac{a I_{s}^{2}}{2 K_{s}}\right\} \\
+ & \sum_{s=t+1}^{\infty} \beta^{s-t} \operatorname{Cov}_{t}\left\{\frac{u^{\prime}\left(C_{s}\right)}{u^{\prime}\left(C_{t}\right)}, \theta_{s} F\left(K_{s}, L_{s}\right)-w_{s} L_{s}-I_{s}-\frac{a I_{s}^{2}}{2 K_{s}}\right\}
\end{aligned}
$$

Define $R_{t, s}^{L}$ to be the market discount factor between periods $t$ and $s$, that is, the price of sure (that is, noncontingent) date $s$ consumption in terms of date $t$ consumption. Of course, $R_{t, t+1}^{L}$ is simply the inverse of the gross short rate, $1+r_{t+1} \cdot{ }^{36}$ The $(s-t)$-period analog of eq. (31) is

$$
u^{\prime}\left(C_{t}\right)=\left(\beta^{s-t} / R_{t, s}^{L}\right) \mathrm{E}_{t}\left\{u^{\prime}\left(C_{s}\right)\right\}
$$

so the previous equation can be written as

$$
V_{t+1}=\sum_{s=t+1}^{\infty} R_{t, s}^{L} \mathrm{E}_{t}\left\{\theta_{s} F\left(K_{s}, L_{s}\right)-w_{s} L_{s}-I_{s}-\frac{a I_{s}^{2}}{2 K_{s}}\right\}
$$

\footnotetext{
${ }^{35}$ The result below uses the fact that if $X$ and $X^{\prime}$ are two random variables, $\mathrm{E}\left(X X^{\prime}\right)=$ $\mathrm{E}(X) \mathrm{E}\left(X^{\prime}\right)+\operatorname{Cov}\left(X, X^{\prime}\right)$.

${ }^{36}$ In a deterministic model, $R_{t, s}^{L}=R_{t, s}$ as defined in eq. (2). The equality breaks down here because future short rates are stochastic, whereas $R_{t, s}^{L}$ is known on date $t$.
} 


$$
+\sum_{s=t+1}^{\infty} \beta^{s-t} \operatorname{Cov}_{t}\left\{\frac{u^{\prime}\left(C_{s}\right)}{u^{\prime}\left(C_{t}\right)}, \theta_{s} F\left(K_{s}, L_{s}\right)-w_{s} L_{s}-I_{s}-\frac{a I_{s}^{2}}{2 K_{s}}\right\}
$$

Eq. (35) shows that the firm's value is the conventional present value of dividends plus a risk premium: the firm is valued more highly if it pays out unexpectedly high dividends when the marginal utility of owners' consumption is unexpectedly high. The presence of a risk premium introduces an additional channel through which shifts in consumption preferences can influence investment behavior. We discuss later the interpretation of (35) when shares in domestic firms are traded internationally.

The firm's investment behavior can be characterized by maximizing the sum of current profits and (34) subject to (12). As in the deterministic case current investment is governed by (13), where $q_{t}=V_{t+1} / K_{t+1}$ and $V_{t+1}$ is given by (34). The result is a richer $q$ model of investment with currentaccount predictions similar to those of subsection $3.1 .^{37}$

\subsubsection{Partially complete markets}

In reality countries trade not only bonds but a rich menu of assets, including equity shares, currency-denominated instruments, and other securities with state-contingent payoffs. This trade ensures that some, if not all, consumption risks can be pooled and that the current-account effects arising in the last set of models will be muted.

Eq. (31) implies that whenever there is free trade in noncontingent bonds between two countries $i$ and $j$, the expected growth rates of their residents' marginal utilities from consumption are equal, assuming a common rate of time preference. Thus,

$$
\mathrm{E}_{t}\left\{\frac{u^{\prime}\left(C_{t+1}^{i}\right)}{u^{\prime}\left(C_{t}^{i}\right)}\right\}=\mathrm{E}_{t}\left\{\frac{u^{\prime}\left(C_{t+1}^{j}\right)}{u^{\prime}\left(C_{t}^{j}\right)}\right\}
$$

Under complete markets (see eq. (29)), this equation holds ex post, not just in expectation. When only (36) holds, however, differences in marginal rates of intertemporal substitution can occur after the fact.

When some, but not all, risks can be traded between countries, consumption behavior will be intermediate between the predictions of (29) and (36).

${ }^{37}$ See, for example, Baxter and Crucini (1993b) and Glick and Rogoff (1993). 
Specifically, (29) predicts that marginal rate of intertemporal substitution differences do not arise, while (36) predicts these differences can arise unexpectedly. In the intermediate case, the ex post difference

$$
\frac{u^{\prime}\left(C_{t+1}^{i}\right)}{u^{\prime}\left(C_{t}^{i}\right)}-\frac{u^{\prime}\left(C_{t+1}^{j}\right)}{u^{\prime}\left(C_{t}^{j}\right)}
$$

will be conditionally uncorrelated with any date- $(t+1)$ random variable on which contingent contractual payments can be conditioned. Thus, if $X_{t+1}$ is a random variable on which contracts can be written prior to date $t+1$,

$$
\operatorname{Cov}_{t}\left\{\frac{u^{\prime}\left(C_{t+1}^{i}\right)}{u^{\prime}\left(C_{t}^{i}\right)}-\frac{u^{\prime}\left(C_{t+1}^{j}\right)}{u^{\prime}\left(C_{t}^{j}\right)}, X_{t+1}\right\}=0
$$

For example, if people in different countries can effectively pool the idiosyncratic consumption risks due to nominal exchange-rate fluctuations through foreign exchange market deals, then realized exchange rate fluctuations will be statistically unrelated to international differences in the growth of $u^{\prime}(C) .^{38}$ Because it is only partial, however, such insurance clearly leaves scope for unexpected differences in autarky interest rates and, thus, for current-account movements.

Svensson (1988) develops a two-period model in which period 1 asset trading serves to pool consumption risks for period 2. Period 1 consumption risks have not been pooled, however, so unbalanced current accounts will, as a general rule, arise then. Svensson shows that the usual logic of trade theory can be extended to analyze not only the current account under uncertainty, but also the asset composition of gross capital flows between countries. He develops a two-period pure exchange model of international trade in a possibly incomplete set of risky assets. In that model, a multicommodity comparative advantage principle applies (see Dixit and Norman 1980, p. 95): the inner product of a country's net asset import vector with the vector of home minus foreign autarky asset prices is positive.

When countries trade equity shares as well as noncontingent bonds, the separation between domestic investment and consumption may still obtain even though asset markets are incomplete. As (37) shows, domestic and foreign residents must attach the same values to the state-contingent profits

\footnotetext{
${ }^{38}$ For a formal derivation, see Obstfeld (1994).
} 
of a firm that they trade. A sufficient condition for the separation property to hold is that investment decisions themselves do not change these common valuations (see Ekern and Wilson 1974).

\subsubsection{Endogenous market incompleteness}

We have seen that some of the model's predictions concerning current account behavior depend critically on the structure of asset markets and in particular the degree to which complete markets prevail. We have argued that the complete markets model is inadequate empirically, but if so it would be helpful to have a deeper understanding of the frictions that impinge on market completeness, rather than just assuming market limitations exogenously.

In this section we present an example, drawn from Gertler and Rogoff (1990), of how international capital flows behave in the presence of moral hazard deriving from asymmetric information at the microeconomic level. A key insight from the model, which carries over to other settings, is that international asset markets can bring the global allocation of resources part of the way, but only part of the way, toward the full-information optimum. Thus, the intertemporal approach, as sketched above, may well get the directions of net international capital flows right while overstating magnitudes.

We now adopt a two-period, single good setup in which each of the numerous atomistic residents of a small country maximizes

$$
u\left(C_{1}, C_{2}\right)=C_{2}
$$

given exogenous endowments $E_{1}$ of the consumption good in period 1 and $E_{2}$ in period 2. The utility function (38) is obviously very special (clearly $C_{1}=0$ is optimal) but it allows to greatly simplify the analysis while still making our main points. The focus, instead, is on investment. Each resident has two ways to transform $E_{1}$ into future consumption. He or she may lend in the world capital market and earn a riskless net rate of return $r$. Alternatively, current resources can be invested in a risky domestic project. If a resident invests $K$ in period 1, then the project's stochastic payoff in period 2 is $Y$, where

$$
Y=\left\{\begin{array}{cl}
\phi>0 & \text { with probability } \pi(K) \\
0 & \text { with probability } 1-\pi(K)
\end{array}\right.
$$

Above, $\pi(K)$ is increasing, strictly concave, and twice continuously differentiable, with $\pi(0)=0, \pi(\infty)=1$, and $1+r<\phi \pi^{\prime}(0)<\infty$. These assumptions 
ensure that higher investment increases the likelihood of a successful outcome (but at a diminishing rate) and that the prospect of success would justify nonzero investment under symmetric information. Every individual has one potential investment project and different individuals' investment outcomes are statistically independent.

In this model, the optimal full-information investment level is $K^{*}$, defined by

$$
\pi^{\prime}\left(K^{*}\right) \phi=1+r
$$

At this point, the marginal return to investing equals the return that can be earned through lending abroad. Let us assume that

$$
E_{1}+\frac{E_{2}}{1+r}<K^{*}
$$

This inequality implies that each resident needs to borrow a positive amount from foreigners to be able to invest optimally. Furthermore, the condition is equivalent to the inequality $E_{2}<(1+r)\left(K^{*}-E_{1}\right)$, which states that it is infeasible for lenders to finance the investment level $K^{*}$ through a riskfree loan. If an investment project fails, even the borrower's entire period 2 endowment is insufficient to repay lenders $(1+r)\left(K^{*}-E_{1}\right)$. Thus, loan contracts take the following, state-contingent, form: in return for a loan of size $L$ in period 1, the borrower promises to repay $Z^{g}$ in period 2 in the event his or her investment is successful and $Z^{b}<Z^{g}$ in the event it fails. Lenders are competitive and do not offer a loan contract unless its expected gross return equals $1+r$ :

$$
\pi(K) Z^{g}+[1-\pi(K)] Z^{b}=(1+r) L
$$

The provisions of loan contracts are assumed to be fully enforceable.

The moral hazard problem underlying the model arises from its information structure. Lenders observe a borrower's endowments and the output of the investment project (that is, whether the project is successful or not); of course, they also know the size of the loan. They cannot, however, verify the level of investment, $K$. Thus, borrowers cannot commit themselves to any specific level of investment by writing promises about $K$ into the loan contract. For example, there is no way lenders can prevent borrowers from investing nothing at all and instead secretly placing all of their resources, borrowed as well as nonborrowed, in foreign assets (an action reminiscent of 
'capital flight'). But if borrowers do so, there is no chance their projects will succeed. The informational asymmetry allowing this kind of behavior leads to inefficient investment and borrowing levels, as we now show. ${ }^{39}$

Given the available loan contract, a typical borrower maximizes expected second period consumption

$$
\mathrm{E}\left\{C_{2}\right\}=\pi(K)\left(\phi-Z^{g}\right)-[1-\pi(K)] Z^{b}+(1+r)\left(E_{1}+L-K\right)+E_{2} .
$$

subject to the constraint

$$
E_{1}+L \geq K
$$

Constraint (42) does not bind when the borrower is secretly investing resources abroad rather than at home. The necessary Kuhn-Tucker conditions for a maximum are:

$$
\begin{gathered}
\pi^{\prime}(K)\left[\phi-\left(Z^{g}-Z^{b}\right)\right]=1+r+\lambda \\
\lambda \geq 0, \quad \lambda\left(E_{1}+L-K\right)=0
\end{gathered}
$$

Conditions (43) and (44) imply that even a borrower with access to a loan $L$ large enough to permit the desired investment level (so that $\lambda=0$ ) picks a $K$ that satisfies

$$
\pi^{\prime}(K)\left[\phi-\left(Z^{g}-Z^{b}\right)\right]=1+r
$$

and, thus, is strictly below the full-information optimum level described by eq. (39). The reason is that the change in payoff to the borrower when a project succeeds is

$$
\phi-Z^{g}-\left(-Z^{b}\right)=\phi-\left(Z^{g}-Z^{b}\right)<\phi
$$

Although lenders can't observe $K$ directly, they have rational expectations and thus can figure out the level of $K$ borrowers will choose for a given

\footnotetext{
${ }^{39}$ If borrowers could commit to invest $K^{*}$, lenders would break even by lending them $L=$ $K^{*}-E_{1}$ and setting $Z^{b}=E_{2}, Z^{g}=(1+r)\left[K^{*}-E_{1}-\left(1-\pi\left(K^{*}\right)\right) E_{2}\right] / \pi\left(K^{\bullet}\right)$. (Because $\pi(K)$ is strictly concave and $\pi(0)=0, Z^{g}<\phi+E_{2}$.) In this model, there is an implicit assumption that foreign direct investment cannot substitute perfectly for lending; that is, foreigners cannot circumvent the agency problem by purchasing investment opportunities in the borrowing country and exploiting them optimally themselves. This assumption could be justified by a threat of nationalization, or simply by a comparative informational advantage of local residents in finding suppliers, monitoring workers, greasing the collective palm of local officialdom, etc.
} 
loan contract. They therefore offer a loan contract such that the $K$ the borrower chooses, given $L, Z^{g}$, and $Z^{b}$, satisfies the required rate of return condition (40). Competition among lenders ensures that this contract is optimal for the borrower, subject to the constraints mentioned. Formally, the optimal incentive-compatible contract $\left(L, Z^{g}, Z^{b}\right)$ maximizes $\mathrm{E}\left\{C_{2}\right\}$ subject to (40), (42), (45), and the inequality $Z^{b} \leq E_{2}$.

The optimal contract satisfies $Z^{b}=E_{2}$ (so as to minimize the gap $\check{Z} \equiv$ $Z^{g}-Z^{b}$ and, thus, the gap between $K$ and $\left.K^{*}\right) \cdot{ }^{10}$ Furthermore, the contract satisfies (42) with equality: increasing $L$ above $K-E_{1}$ would force a rise in $Z^{g}$ and, with it, a worsening in investment incentives. Combining these facts with the incentive-compatibility constraint (45) and the lenders' zeroprofit condition (40), we see that the optimal contract is the solution to the three-equation system

$$
\begin{gathered}
\pi^{\prime}(K)(\phi-\check{Z})=1+r \\
\check{Z}=(1+r)\left(K-E_{1}-\frac{E_{2}}{1+r}\right) / \pi(K) \\
L=K-E_{1} .
\end{gathered}
$$

This solution has a number of important implications:

1. The incentive-compatible investment level is below the full-information optimum of (39). Accordingly, period 1 capital inflows are below the level a full-information model would predict.

2. An increase in the productivity parameter $\phi$ increases the period 1 capital inflow and investment level, but it also widens the spread $\check{Z}$ between the good- and bad-outcome loan payments. Thus, (under mild restrictions on $\pi(K)$ ) the resulting capital inflow is less than in the fullinformation case.

3. The expected marginal product of capital, $\pi^{\prime}(K) \phi$, exceeds the world (and domestic) riskless interest rate, $1+r$.

4. An increase in either endowment, $E_{1}$ or $E_{2}$, raises investment by lowering $\check{Z}$. In the first case this effect is due to a lesser reliance on external funds, in the second to the possibility of a larger loan payment in

\footnotetext{
${ }^{40}$ See Gertler and Rogoff (1990) for details.
} 
the bad-outcome state. The invariance of investment with respect to intertemporal preferences that characterized the single-sector models described earlier need not hold when investment is subject to moral hazard. ${ }^{41}$

In a two-country general equilibrium version of the model, one can show that endogenous differences in capital market imperfections can dramatically reduce the flow of capital from rich to poor countries, and even reverse it (see Gertler and Rogoff 1990).

The preceding model has abstracted both from the consumption smoothing motive behind the current account and from the borrowers' desire to engage in asset trades that reduce the uncertainty of second-period consumption. It is straightforward to add second-period risk aversion to the model by assuming that (38) is replaced by

$$
u\left(C_{1}, C_{2}\right)=C_{2}-\frac{h}{2} C_{2}^{2}
$$

In order to focus on the new issues that arise, it is convenient to suppose that $E_{1} \geq K^{*}$. In this case, domestic residents' endowment is large enough so that they have not need to borrow to finance investment, and their only motive for tapping the international capital market is to insure period 2 consumption. Here again we have a moral hazard problem because nonverifiable investment decisions affect the probability distribution of second-period output. It can be shown that under the optimal incentive-compatible contract, consumption insurance will be partial and $K$ will be below $K^{*}{ }^{* 2}$

The general conclusion is that asymmetric information need not cause financial markets to break down entirely. Instead, financial markets may do only partially the job they could do in a world of full information. Note also that in thinking about the incompleteness of markets, it may be misleading to think of risks as being either insurable or noninsurable. In many cases, through what is basically a coinsurance mechanism, some gains from trade across states of nature will be realized even under moral hazard. ${ }^{43}$ The same point applies to trade across time.

\footnotetext{
${ }^{41}$ It is again easy to see that $Z^{g}<\phi+E_{2}$.

${ }^{42}$ See Obstfeld and Rogoff (1995), ch. 6.

${ }^{43}$ The implications of adverse selection problems can be quite different, although we do not consider them here. Atkeson and Lucas (1992) study a different moral hazard problem, one in which people (or countries) wish to insure against preference shocks. They find that
} 
We have focused on capital-market imperfections arising from asymmetric information at the micro level. Another very important cause of international capital-market imperfection is sovereign default risk at the macro level. Sovereign risk need not be related to asymmetric information, but can have qualitatively similar implications. ${ }^{44}$ Jonathan Eaton and Raquel Fernandez present a detailed analysis of the effects of sovereign risk in their chapter in this Handbook. A common theme in sovereign-risk models is that the consumption-smoothing and risk-sharing roles of international capital markets still operate, but are tempered by default risk.

\section{Empirical evidence on the intertemporal approach}

The intertemporal approach to the current account has been subjected to extensive formal testing; much of the methodology used grows out of Hall's (1978) seminal work on the implications of the rational-expectations assumption for forward looking consumption theories. A less formal empirical methodology, pioneered by Feldstein and Horioka (1980), has been used to argue that the close relationship between national saving and investment rates in post-World War II data furnishes a prima facie case against the practical relevance of the intertemporal approach. These two research avenues are closely intertwined, as any attempt to reconcile the Feldstein-Horioka findings with the intertemporal approach rests on the validity of models such as those surveyed in section $3 .^{45}$

under optimal incentive-compatible arrangements, the degree of consumption inequality in the world increases continually.

${ }^{44}$ Atkeson (1991) presents an interesting analysis incorporating both asymmetric information and sovereign risk.

${ }^{45}$ We do not survey the methodology of calibrating open-economy models with incomplete markets so as to match moments of actual aggregate data. Interesting recent work along this line, exemplified by Baxter and Crucini (1993b) and Kollmann (1992), is discussed in Marianne Baxter's chapter in this Handbook. We also refrain from more than a brief and highly selective account of the copious literature on measuring international capital mobility. See Frankel (1993) and Obstfeld (1995) for recent surveys. 


\subsection{The relationship between national saving and do- mestic investment rates}

In a closed economy, national saving equals domestic investment and the current account is always zero. Furthermore, any observed increase in national saving will automatically be accompanied by an equal rise in domestic investment. A basic premise of the intertemporal approach is that capital is to some degree internationally mobile, so that current account imbalances are a possibility. Given this premise, the intertemporal approach predicts a number of situations in which divergences between saving and investment will arise. An empirical finding that national saving rates affect domestic investment rates with unit coefficients would therefore appear to be strong evidence against the applicability of the intertemporal approach.

Feldstein and Horioka (1980), in the first of a series of related papers by Feldstein and coauthors, argued that capital mobility is sufficiently limited, at least over long horizons, that changes in national saving rates ultimately feed through fully to domestic investment rates. As evidence, they reported cross-sectional regressions of gross domestic investment rate averages $(I / Y)$ on gross national saving rate averages $(S / Y)$. These ratios of nominal flows, of course, suffer from all the conceptual deficiencies discussed at the end of section 2. For a sample of 16 OECD countries over 1960-74, Feldstein and Horioka found that:

$$
(I / Y)_{j}=\underset{(0.018)}{0.035}+\underset{(0.074)}{0.887}(S / Y)_{j}+u_{j} ; R^{2}=0.91
$$

Feldstein and Bacchetta (1991) report similar results for a 1974-86 sample of 23 OECD members. Figure 5 shows the cross-sectional saving-investment association in the OECD sample over the decade 1982-91, with Luxembourg, which is an outlier, omitted. The estimation result for this sample, leaving out developing Turkey, is:

$$
(I / Y)_{j}=\underset{(0.020)}{0.088}+\underset{(0.094)}{0.622}(S / Y)_{j}+u_{j} ; R^{2}=0.69
$$

This equation shows a weakening, but still very significant, positive association.

Feldstein and his collaborators argue that if capital indeed were highly mobile among countries, coefficients like the one above should be much 
Figure 5

Saving and Investment Averages, 1982-1991 (as a Fraction of GDP)

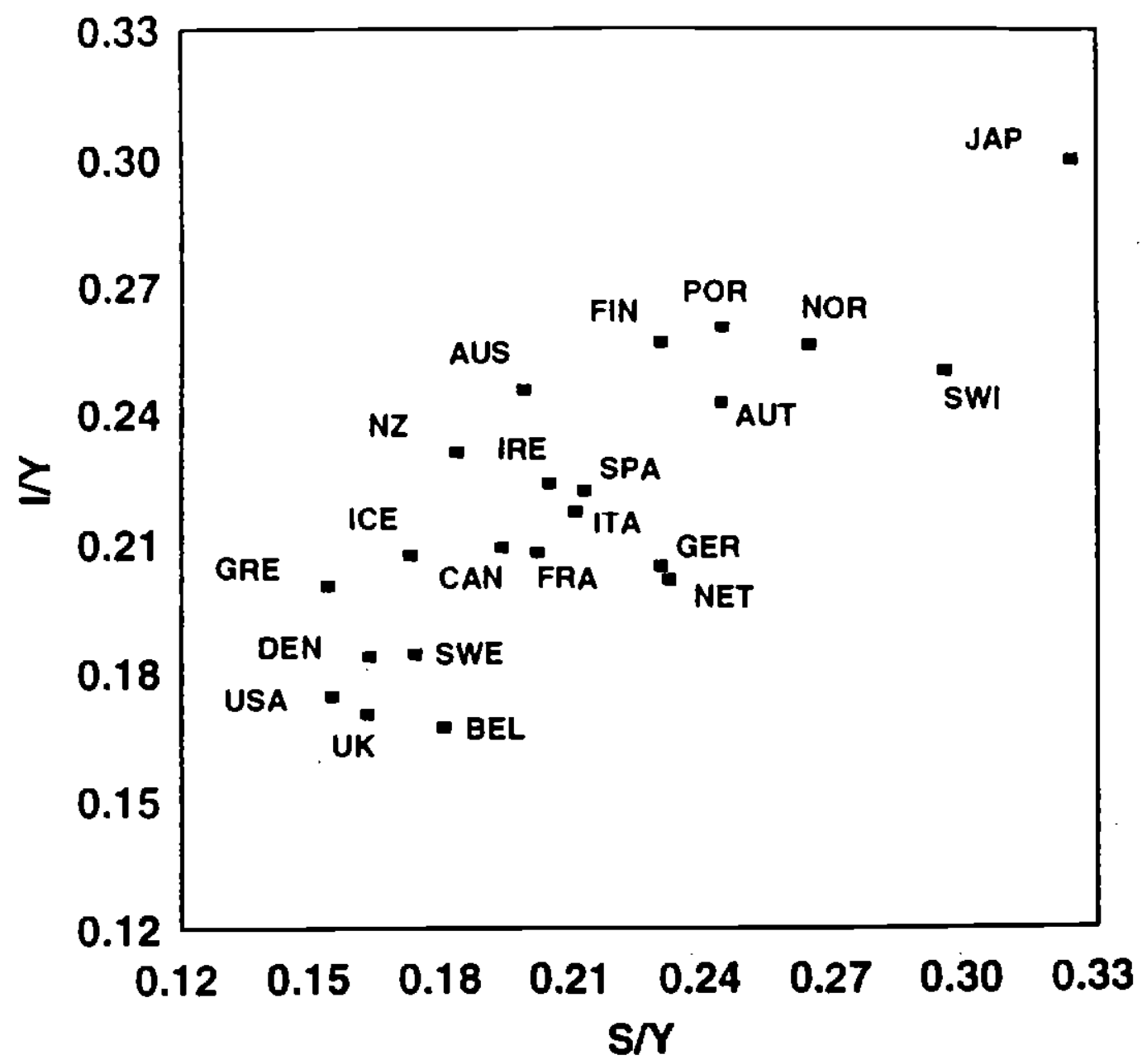


smaller than 1, as a country's savings would then be free to seek out the most productive investment opportunities worldwide. Although the intertemporal approach is consistent with a world in which changes in saving behavior impinge on domestic investment, it certainly does not support the policy conclusion, preferred by Feldstein, that government measures to raise a country's saving rate will automatically cause a long-run pari passu increase in its investment rate.

If capital is truly immobile and the intertemporal approach irrelevant, however, then the time-series relationship between individual countries' saving and investment rates, like the cross-sectional relationship among long saving and investment averages, also should be close. We can think of the timeseries relationship among contemporaneous detrended saving and investment rates as capturing the coherence of high-frequency changes, while the Feldstein-Horioka regression captures the association between low-frequency or 'sustained' changes. Indeed, it is hard to see how capital could be truly immobile in the long run but not in the short run, since the long run is just a succession of short runs. And even if international trade in long-term instruments or long-lived assets were highly limited-a hypothesis that the data do not support-short-term instruments can be rolled over.

The time-series and cross-section aspects of the saving-investment relationship are quite distinct: the time-series relationship could be close and the cross-section relationship not, or vice versa. An example is provided by the United Kingdom during the pre-World War I gold standard (figure 1). It is apparent that the short-run saving-investment correlation is very close. ${ }^{46}$ Nonetheless, the U.K. ran current-account surpluses approaching 10 percent of GDP in this same period.

It is a 'stylized fact,' somewhat sensitive to the detrending method adopted, that the time-series saving-investment correlation is fairly strong in recent data. (See figure 3 for some industrial-country data, but note the exceptions, the most glaring of which is Norway with its highly negatively correlated saving and investment rates.) For the OECD countries including Luxembourg but excluding Turkey, the average correlation between saving and investment rates is 0.495 over $1974-90$ after linear time detrending. The correlation is 0.512 when the data are first-differenced to remove trend.

Even in a world of complete capital mobility though, such correlations

${ }^{46}$ See Obstfeld (1986) for a more detailed statistical analysis of the U.K. data. 
are not necessarily surprising and can easily explained on the basis of the intertemporal approach. For example, the discussion of gradual capital-stock adjustment in section 3 implies that a shock to total factor productivity, if short-lived but not completely transitory, raises saving as well as investment. Baxter and Crucini (1993a,b) and Mendoza (1991) (the latter in a smallcountry setting, the former in a global-economy setting) have shown that intertemporal mobile-capital models based on investment-adjustment costs can easily produce time-series saving-investment correlations at least as large as those in the data. Part of the mechanism underlying the Baxter-Crucini findings is allowance for global economic shocks, which obviously will induce positive saving-investment correlations.

We have been focusing on time-series evidence, but Feldstein and Horioka's cross-sectional findings can also be rationalized by the presence of common factors that might simultaneously influence countries' saving and investment rates.

It seems likely that of the many potential explanations of the FeldsteinHorioka results, no single one fully explains the behavior of all countries. Taken together, however, and combined with other evidence indicating substantial international mobility of capital, the arguments suggest that the Feldstein-Horioka finding provides no basis at all for dismissing the basic premises of the intertemporal approach:

1. Even post-1973, governments have sometimes adjusted fiscal or monetary policies to avoid large and protracted current-account imbalances. The evidence on this current-account targeting hypothesis is mostly anecdotal, however, and their are of course prominent instances (like the United States in the 1980s) in which macroeconomic policies have instigated major external imbalances. ${ }^{47}$

2. OECD countries may be sufficiently well endowed with capital to have reached stochastic steady states for their external debt or asset levels. In this situation the intertemporal budget constraint of the economy would imply that long averages of saving-investment differences are small. Developing countries, which presumably could realize greater

\footnotetext{
${ }^{47}$ The fragility of the econometric evidence is illustrated by Feldstein and Bacchetta's (1991) reinterpretation of the regressions Summers (1988) offers as evidence of currentaccount targeting.
} 
gains from intertemporal trade through borrowing for investment purposes, are likely to be more distant from a stationary distribution of foreign debt. This interpretation seems borne out by the cross-sectional results for developing countries prior to the onset of their debt crisis in 1982. For this sample, the cross-sectional saving-investment association is much looser than for the OECD sample. ${ }^{48}$

3. The Gertler-Rogoff investment model discussed in section $\mathbf{3}$ shows why investment may respond positively to higher retained earnings, that is, to higher corporate saving. Thus, it seems plausible that in countries with higher saving rates, the cost of capital will be lower and investment higher. A main prediction of the moral-hazard model is that risk-free interest rates are equalized among countries-as indeed they mostly are in the industrialized world (Obstfeld 1995)-whereas the marginal product of capital is high in countries with low corporate wealth. Although there is some evidence in favor of this hypothesis, an account of how corporate saving and investment are related need not have strong implications for the relationship between total saving and investment. For example, private domestic owners of firms may pierce the corporate veil and offset corporate saving decisions through their own consumption. To the extent that the investing firms are owned by foreigners, their decision to retain earnings increases foreign rather than domestic saving, other things equal.

4. In the life-cycle theory of consumption, sustained demographic changes that increase a country's long-term investment rate also may increase its saving rate. Section 3.1.7's discussion of overlapping-generations models provides a leading example: higher productivity growth that affects most strongly the incomes of young workers will cause saving as well as investment to rise. Feldstein and Bacchetta (1991) and Summers (1988) have dismissed this line of explanation, notwithstanding some supportive evidence offered by Tesar (1991). In a more recent contribution, however, Taylor (1993) revisits the Feldstein-Horioka equation, controlling for (a) measures of domestic relative prices, (b) the agestructure of the population, and (c) the interaction of the age structure with the growth rate of domestic output. He finds that for a number of

${ }^{48}$ See Fieleke (1982), Dooley, Frankel, and Mathieson (1987), and Summers (1988). 
country samples the cross-sectional saving-investment association disappears.

Far from showing the irrelevance of the intertemporal approach, the large literature spawned by Feldstein and Horioka's (1980) nonstructural exploration suggests to us that models like those reviewed in section 3 capture key elements behind the cross-sectional and time-series regularities governing saving and investment rates. The further empirical challenge for the intertemporal approach is to show that structural forward-looking models of the current account are not grossly incompatible with actual experience. We turn next to tests of such models.

\subsection{Tests of intertemporal current-account models}

Most structural time-series studies of the intertemporal approach to the current account essentially test versions of eq. (9), according to which the current account depends on deviations of interest rates, output, government spending, and investment from 'permanent' levels. Indeed, most (but not, as we shall see, all) of these studies focus on the special case of (9) where constant real interest rate $r=(1-\beta) / \beta$

$$
C A_{t}=\left(Y_{t}-\tilde{Y}_{t}\right)-\left(G_{t}-\tilde{G}_{t}\right)-\left(I_{t}-\tilde{I}_{t}\right)
$$

Though less general than eq. (9), eq. (46) embodies many central elements of the intertemporal approach. It therefore is reasonable to ask whether there is any evidence in favor of (46) before turning to more complex models. For example, do temporary rises in government spending cause current-account deficits? Questions like this one seem simple enough, but a number of empirical subtleties arise in answering them.

\subsubsection{Measuring permanent values: A digression}

Even before turning to the econometric studies, it is useful to address what is perhaps the most problematic issue of all, the construction of the expected permanent values $\tilde{Y}, \tilde{G}$, and $\tilde{I}$.

A first difficulty is that it is not obvious what real interest rate to use to discount expected future output flows. ${ }^{19}$ Most of the studies surveyed below

\footnotetext{
${ }^{49}$ Sometimes this issue can be finessed; see the discussion of Glick and Rogoff (1993) below.
} 
use fairly low discount rates, in the range of 2 to 4 percent per year. These numbers correspond roughly to average ex post real returns on U.S. Treasury bills post-World War II. But is a (nominally) riskless rate the appropriate one for discounting very risky future output flows? For the United States, the mean rate of return on risky assets has historically been much higher than that on bonds (Mehra and Prescott 1985), at least since the late nineteenth century. To the extent data are available, a similar result seems to hold for a number of other countries. Bernanke (1985) argues that an annual real interest rate as high as 14 percent is needed to rationalize U.S. consumptionincome relationships in a related closed-economy setting.

A second difficulty concerns the sensitivity of empirical measures of $\bar{Y}$, $\tilde{G}$, and $\tilde{I}$ to apparently benign differences in the time series process generating the underlying values of $Y, I$, and $G$. This problem interacts with the previous one, because the sensitivity to the data-generating process is especially acute under a low interest rate. ${ }^{50}$ Consider the following example, in which output (expressed as a deviation from mean output) is generated by the process

$$
Y_{t}=\rho Y_{t-1}+v_{t}
$$

with $0 \leq \rho \leq 1, v_{t}$ a white-noise error, and time measured in years. If a low real interest rate is used to construct permanent output

$$
\tilde{Y}_{t}=\frac{r}{1+r}\left[Y_{t}+\frac{\mathrm{E}_{t} Y_{t+1}}{1+r}+\frac{\mathrm{E}_{t} Y_{t+2}}{(1+r)^{2}}+\ldots\right]
$$

distant future incomes will have relatively large weights. When $r=0.03$, $E_{t} Y_{t+20}$, for example, though discounted, still has a weight more than half that of current output, $Y_{t}$. This means that when $r$ is low, estimates of $\tilde{Y}_{t}$ may be very sensitive to the serial-correlation parameter $\rho$, especially in the neighborhood of $\rho=1$. Noting that under eq. (47) $E_{t} Y_{t+k}=\rho^{k} Y_{t}$, one sees that eq. (48) implies:

$$
\tilde{Y}_{t}=\frac{r}{1+r-\rho} Y_{t} \equiv \mu Y_{t}
$$

When $\rho=1, \mu=1$ and so $\tilde{Y}_{t}=Y_{t}$, regardless of the value of $r$. But when $r=0.03$ and $\rho=0.97$ (a value differing from 1 by an amount generally too small to detect empirically), $\mu$ drops to only 0.5 : permanent output is

${ }^{50}$ This discussion draws on Glick and Rogoff (1993). 
half of current output. As $\rho$ becomes small this hypersensitivity abates. In practice, unfortunately, $\rho$ tends to be quite close to 1 , so that the presence of a unit root is difficult to reject. It should be clear that estimates of $\tilde{Y}_{t}$ can be similarly sensitive to estimates of time trends. ${ }^{51}$

The present-value calculations are less sensitive to $\rho$ when the real interest rate is higher. How high must real interest rates be? With $r=0.14$ (the value mentioned by Bernanke) and $\rho=0.97$ in eq. (49), $\mu=0.824$. With $r=0.5, \mu=0.943$. Real interest rates high enough to make $\mu$ insensitive to $\rho$ in the vicinity of a unit root appear implausible.

With these cautions in mind we proceed to look at the literature.

\subsubsection{Early tests}

Early econometric tests of the intertemporal approach as represented by eq. (46) include Ahmed (1986, 1987), Hercowitz (1986), and Johnson (1986). Hercowitz, who looks at Israeli data over 1950-1981, presents some support for an intertemporal model but also finds that the model exaggerates the current account's response to output fluctuations. Johnson focuses on Canada over 1952-1976. He rejects Ricardian equivalence, but concludes that Canada's private sector can plausibly be modeled in line with a version of the intertemporal approach that allows for some liquidity-constrained consumers. ${ }^{52}$

Ahmed's papers are distinctive in their use of long historical data series on government expenditures from the United Kingdom. In the 1986 paper, Ahmed looks at annual 1908-80 data to gauge the impact of U.K. government spending on the current account (actually, the trade balance, $T B$ ). The 1987 paper analyzes a pre-World War I sample on public military spending and trade balances running from 1732 to 1913 . Ahmed argues that the expenditures accompanying Britain's wars were largely exogenous and were almost certainly viewed as temporary by the public. Thus, on the basis of

${ }^{51}$ The same problems arise in the macroeconomic literature on estimating consumption functions. Deaton (1987), for example, argues that if income is stationary in growth rates (a hypothesis that is difficult statistically to reject given the limited post-WWII time series), then consumption should move more than one-for-one with income innovations. There is, on the other hand, no 'Deaton's paradox' if income is highly serially correlated but still stationary.

${ }^{52}$ Roubini (1988) combines the intertemporal approach with the tax-smoothing theory of government deficits, finding mixed results for a sample of OECD countries. 
the intertemporal approach, one might expect Britain to have been running external deficits during wars. ${ }^{53}$ In the twentieth century, swings in British government spending have been dominated by the two world wars, both of which were accompanied by large current-account deficits. Figure 6 uses data from Ahmed's papers to graph military spending against the current account over 1701-1938. ${ }^{54}$ This 238 -year sample provides a more demanding testing ground than the twentieth century alone, as the period is punctiated by many wars. ${ }^{55}$

A negative correlation between surges in government spending and the current account is fully consistent with theories other than the intertemporal approach, for example, a Keynesian multiplier model. To reduce the set of alternative theories consistent with the data, Ahmed explores formal econometric tests. A representative result from Ahmed (1986) is

$$
T B_{t}=-0.21\left(G_{t}-\tilde{G}_{t}\right)-0.44 \tilde{G}_{t}+\varepsilon_{t} ; R^{2}=0.28, \quad D . W .=2.32
$$

which is estimated over $1908-80 .{ }^{56}$ This regression shows that the temporary component of government spending has a significant negative influence on the current account, whereas the permanent component itself does not, consistent with (46). Unfortunately, the regression's specification leaves open the possibility that $G_{t}$ is the only significant determinant of the current account and that $\tilde{G}_{t}$ plays no role at all-as an atemporal Keynesian model would predict.

\footnotetext{
${ }^{53}$ The result that temporary war-time increases in public spending should lead to an external deficit does not necessarily hold if the whole world is at war. In an all-encompassing global war, higher government spending everywhere would push up world interest rates with current account implications that would depend mostly on countries' net external asset holdings. This point illustrates the distinction between global and country-specific shocks emphasized in section 3 above.

${ }^{54}$ Both series have had a 2 percent annual growth trend removed, as in Ahmed (1987). The current account has been constructed from Ahmed's trade balance data using a 3 percent per annum sterling rate of return on foreign assets starting from an assumed zero net foreign asset position in 1701. We thank Shaghil Ahmed for providing us with the data from his papers.

${ }^{55}$ The possible gain or loss of colonial territories and privileges, which was the motive for much warfare before World War I, naturally could be expected to exert an additional wealth effect on the current account. Ideally, this effect should be controlled for in estimation.

${ }^{56}$ See table 1, regression I (with $\rho=0.02$ ) on p. 211.
} 
Figure 6

United Kingdom: Military Spending and Current Account, 1701-1938 (Detrended Annual Data)

1854 Pounds (Millions)

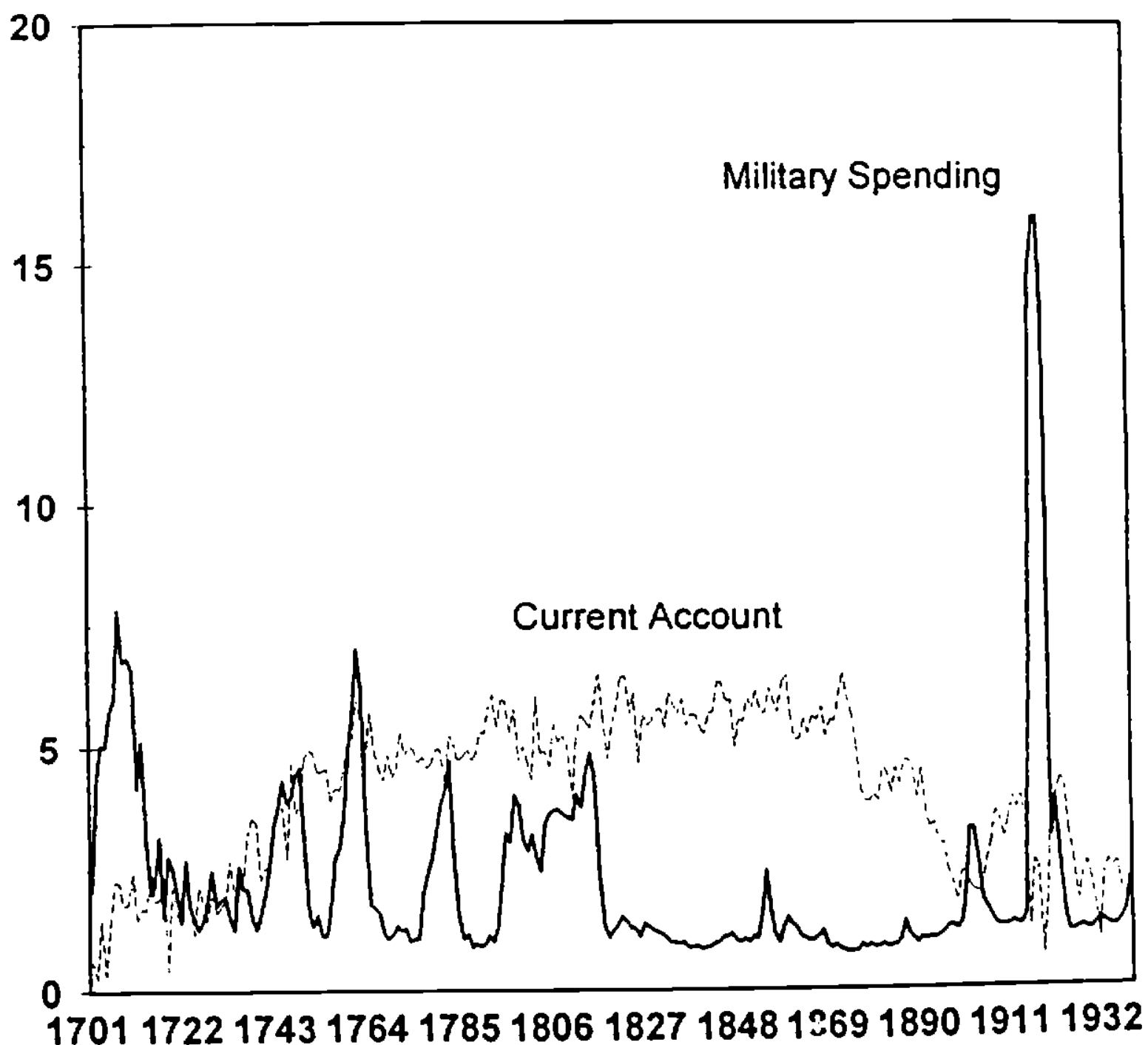


Using our estimated current account in place of the trade balance, we have run a similar regression on the 1701-1938 data, but while keeping $G_{t}-$ $\tilde{G}_{t}$ in the regression we replace $\tilde{G}_{t}$ by $G_{t}$ so as to encompass transparently the intertemporal and Keynesian alternatives within a single test. ${ }^{57}$ The resulting regression, run using a Cochrane-Orcutt correction for first-order serial correlation is ${ }^{58}$

$$
C A_{t}=\underset{(0.013)}{-0.016\left(G_{t}-\tilde{G}_{t}\right)-\underset{(0.093)}{0.028 G_{t}}+\varepsilon_{t} ; \rho=0.907}
$$

In this specification, neither current or permanent government spending coefficient is individually significant. As usual, it is unclear whether the intertemporal approach is simply false, or whether the many extraneous simplifications and maintained hypotheses imposed by the econometrician are to blame. It is therefore useful to turn to a newer empirical approach based on a less restrictive framework.

\subsubsection{Present-value models of the current account}

Ghosh (1995), Otto (1992), and Sheffrin and Woo (1990) apply an alternative methodology that makes use of the information embodied in past current accounts to make more accurate predictions of $\tilde{Y}, \tilde{G}$, and $\tilde{I}$. These studies build on the methodology developed by Campbell (1987) and by Campbell and Shiller (1987). ${ }^{59}$

Define

$$
Q \equiv Y-G-I
$$

The starting point for the present-value methodology is again eq. (46), expressed in the form

$$
C A_{t}=Q_{t}-\tilde{Q}_{t}
$$

\footnotetext{
${ }^{57}$ To form $\bar{G}$ we used an autoregressive forecasting model of detrended government spending.

${ }^{58}$ Similar results are obtained when we use the trade balance in place of the current account, as Ahmed (1987) does.

${ }^{59}$ Campbell's (1987) study of private U.S. saving is especially relevant to the currentaccount studies we are about to discuss. Comparison with Campbell's results is difficult, however, because he examines a different question, the accumulation of private wealth of all kinds in response to fluctuations in after-tax labor income.
} 
The new variable $Q$ can be thought of as the net private noninterest cash flow. Although the main innovation of the Campbell-Shiller approach does not really require it, Ghosh, Sheffrin-Woo, and Otto all follow Campbell and Shiller in rewriting eq. (50) as

$$
C A_{t}=-\mathrm{E}_{t}\left\{\sum_{\mathrm{s}=t+1}^{\infty}\left(\frac{1}{1+r}\right)^{\mathrm{s}-t} \Delta Q_{\mathrm{s}}\right\}
$$

where $\Delta Q_{t}=Q_{t}-Q_{t-1}$ is the difference of the cash flow variable. Eq. (51) says that the current account balance tends to be negative when net cash flow is expected to rise, and positive when net cash flow is expected to fall.

What advantage is there to estimating eq. (51), where $Q_{t}$ enters in differenced form, rather than eq. (50), where its level enters? The differenced version is appropriate if one is concerned that there is a unit root in $Q_{t}$, so that removal of a time trend is not sufficient for stationarity. ${ }^{60}$ If $Q_{t}$ is indeed I(1) (has a unit root), then, as Campbell and Shiller have emphasized, eq. (51) allows one to use the stationary variable $\Delta Q_{t}$ as a regressor without having to difference both $C A$ and $Q$, which is inefficient in the likely event that $C A$ is stationary. ${ }^{61}$

The fundamental difference between the Ghosh-Sheffrin-Woo-Otto approach and earlier studies concerns how one proxies for private agents' expectations of future values of $Q$. The basic insight of the Campbell-Shiller methodology is that as long the information set used by the econometrician does not contain all the information available to private agents, then past values of $C A$ contain information useful in constructing estimates of agents' expectations of future values of $Q$. Obviously, incorporating this insight doesn't actually require using first differences, as in eq. (51), rather than levels, as in eq. (50).

Suppose, for example, that one forms expectations of future values of $\Delta Q_{t}$ by first estimating a first-order VAR (the generalization to higher-order VARs is straightforward):

$$
\left[\begin{array}{l}
\Delta Q_{t} \\
C A_{t}
\end{array}\right]=\left[\begin{array}{ll}
\psi_{1} & \psi_{2} \\
\psi_{3} & \psi_{4}
\end{array}\right]\left[\begin{array}{l}
\Delta Q_{t-1} \\
C A_{t-1}
\end{array}\right]+\left[\begin{array}{l}
\varepsilon_{1 t} \\
\varepsilon_{2 t}
\end{array}\right]
$$

\footnotetext{
${ }^{60}$ Ghosh (1995) cannot reject the hypothesis of a unit root in $Q_{t}$ for his sample. Sheffrin and Woo (1990) and Ot to (1992) report similar results.

${ }^{61}$ Trehan and Walsh (1991) discuss conditions under which stationarity of $C A$ is necessary for intertemporal budget balance.
} 
and then make use of its implication that

$$
\mathrm{E}_{t}\left[\begin{array}{c}
\Delta Q_{t+k} \\
C A_{t+k}
\end{array}\right]=\left[\begin{array}{ll}
\psi_{1} & \psi_{2} \\
\psi_{3} & \psi_{4}
\end{array}\right]^{k}\left[\begin{array}{l}
\Delta Q_{t} \\
C A_{t}
\end{array}\right]
$$

to form an estimated current account, $\widehat{C A}_{t} \cdot{ }^{62}$ If $\mathrm{I}$ is the identity matrix and $\Psi$ the matrix of the $\psi \mathrm{s}$, then eqs. (51) and (53) imply that

$$
\begin{gathered}
\widehat{C A}_{t}=-\left[\begin{array}{ll}
1 & 0
\end{array}\right]\left[(1+r)^{-1} \mathbf{\Psi}\right]\left[\mathbf{I}-(1+r)^{-1} \mathbf{\Psi}\right]^{-1}\left[\begin{array}{l}
\Delta Q_{t} \\
C A_{t}
\end{array}\right] \\
\equiv\left[\begin{array}{ll}
\Phi_{\Delta Q} & \Phi_{C A}
\end{array}\right]\left[\begin{array}{l}
\Delta Q_{t} \\
C A_{t}
\end{array}\right]
\end{gathered}
$$

If the version of the intertemporal approach embodied in (51) is true, then the theoretically predicted value of $\left[\begin{array}{cc}\Phi_{\Delta Q} & \Phi_{C A}\end{array}\right]$ in (54) is simply $\left[\begin{array}{ll}0 & 1\end{array}\right] !$ The reason this restriction emerges is obvious when the VAR captures all information people use to forecast future cash flow. The same restriction also holds true, however, when the VAR captures only a subset of that information. The reason is that $-C A_{t}$ captures the representative consumer's best estimate of the present value of future cash-flow changes, regardless of what other information he or she has.

Applying the above approach, Sheffrin and Woo find that the restriction $\widehat{C A}_{t}=C A_{t}$ is rejected for Canada, Denmark, and the U.K. in their 1955-85 sample, although it is not rejected for Belgium. Ghosh, whose sample period is $1960-88$, finds that the restriction is not rejected for the U.S., but that it fails for Canada, Germany, Japan, and the United Kingdom.

Eq. (54) leads to a stringent test of the model, but a number of more general tests less sensitive to maintained hypothesis could be applied. One basic implication of the model is that $C A_{t}$ should Granger-cause $\Delta Q_{t}$. Ghosh finds that in his full sample, even this weaker test still is passed only by the United States data. Sheffrin and Woo arrive at more positive results. Another approach is adopted by Otto (1992), who tests the restriction that

$$
\mathrm{E}_{t-1}\left\{C A_{t}-\Delta Q_{t}-(1+r) C A_{t-1}\right\}=0
$$

\footnotetext{
${ }^{62}$ Once again, this requires a choice of the constant real risk-free interest rate $r$.
} 
which follows straightforwardly from eq. (51). Otto rejects the present-value model for Canada and the U.S. after finding that lagged variables help in predicting $C A_{t}-\Delta Q_{t}-(1+r) C A_{t-1}$.

While the formal evidence therefore is very mixed, ${ }^{63}$ Ghosh, Sheffrin and Woo, and Otto all stress that the informal evidence obtained by simply lining up actual current accounts with the model's predictions can be quite impressive. This perspective is useful, because no empirical model is likely to be literally true. (Of course, one should not make too much of such pictures, either, since the lagged current account, used in constructing the VAR estimates, is likely to be a good predictor of today's current account regardless of the validity of the present-value model). In figure 7, we graph two illustrative cases, Sweden and the United Kingdom, using data for 1955-1992; both figures are based on a first-order VAR with $\triangle Q$ and $C A$ as discussed above. The model performs very well for Sweden, but poorly for the United Kingdom. One problem might be that the model does not explicitly incorporate the effects of oil prices changes, which have been important for Britain in recent years.

Indeed, if one extends the data on Great Britain over a longer historical period, the model's performance looks much better. For annual British data over the period $1870-1991$, a first-order VAR for $\Delta Q$ and $C A$ yields ${ }^{64}$

$$
\left[\begin{array}{l}
\Delta Q_{t} \\
C A_{t}
\end{array}\right]=\left[\begin{array}{cc}
0.24 & -0.14 \\
-0.11 & 0.84
\end{array}\right]\left[\begin{array}{l}
\Delta Q_{t-1} \\
C A_{t-1}
\end{array}\right]
$$

Figure 8 is constructed using the above estimates and assuming a real interest rate of 4 percent per annum. Extending the data set yields a dramatically better fit than when one estimates the model over post-World War II data alone. Though the visual evidence is fairly striking, the model still fails a

\footnotetext{
${ }^{63}$ Ghosh and Ostry (1993) apply the present-value approach to developing countries and argue that, if anything, it performs better than for industrialized countries. They find that across a large sample of developing countries, the level and volatility of net capital movements predicted by their consumption-smoothing model closely parallels those in the data. This finding is puzzling-developing countries' capital markets tend to be less open than those of the industrialized countries-but one possible explanation relies on the distinction between global and country-specific shocks that we make below. Plausibly, de veloping countries are relatively more susceptible to country-specific as opposed to global shocks, so that the present-value model, which assumes a given and constant real interest rate, does somewhat better.

${ }^{64}$ Historical data are from Feinstein (1972) and Maddison (1991).
} 
Figure 7

\section{Sweden: Actual and Predicted Current Account Balance (Annual Data)}

1985 Kronor per Capita

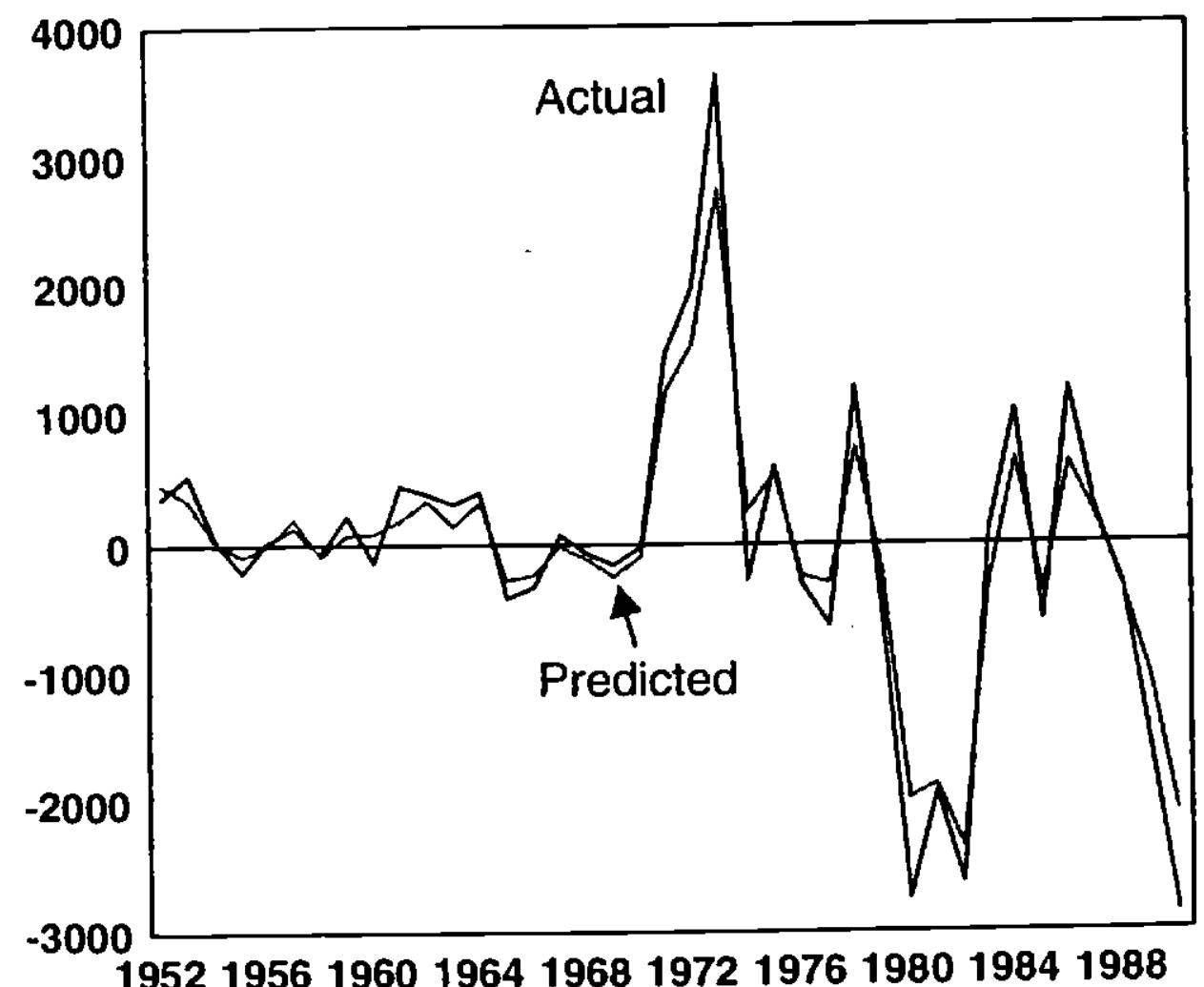


Figure 7

\section{United Kingdom: Actual and Predicted Current Account Balance (Annual Data)}

1985 Pounds per Capita

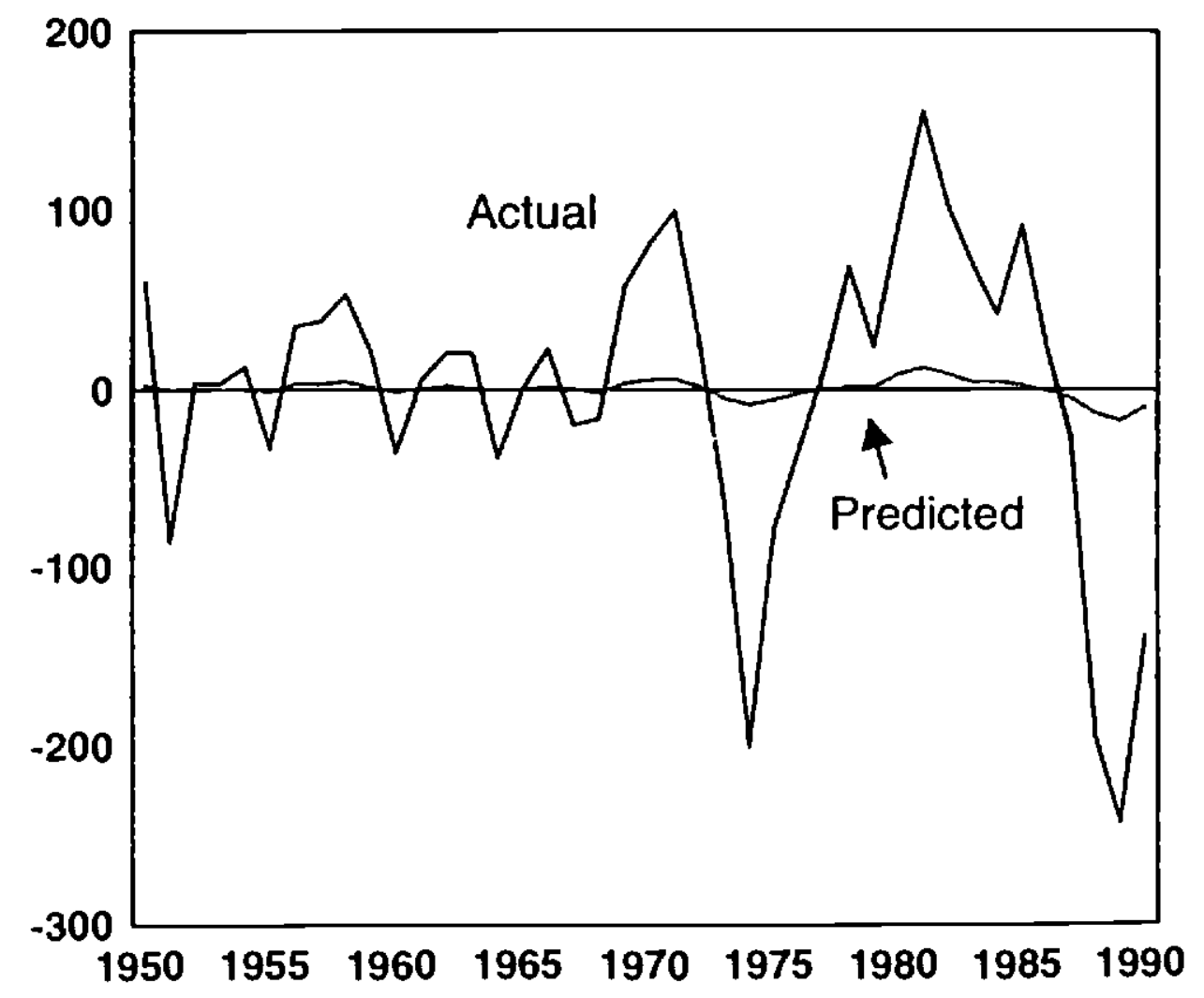


Figure 8

\section{United Kingdom: Actual and Predicted Current Account Balance (Annual Data)}

1914 Pounds per Capita

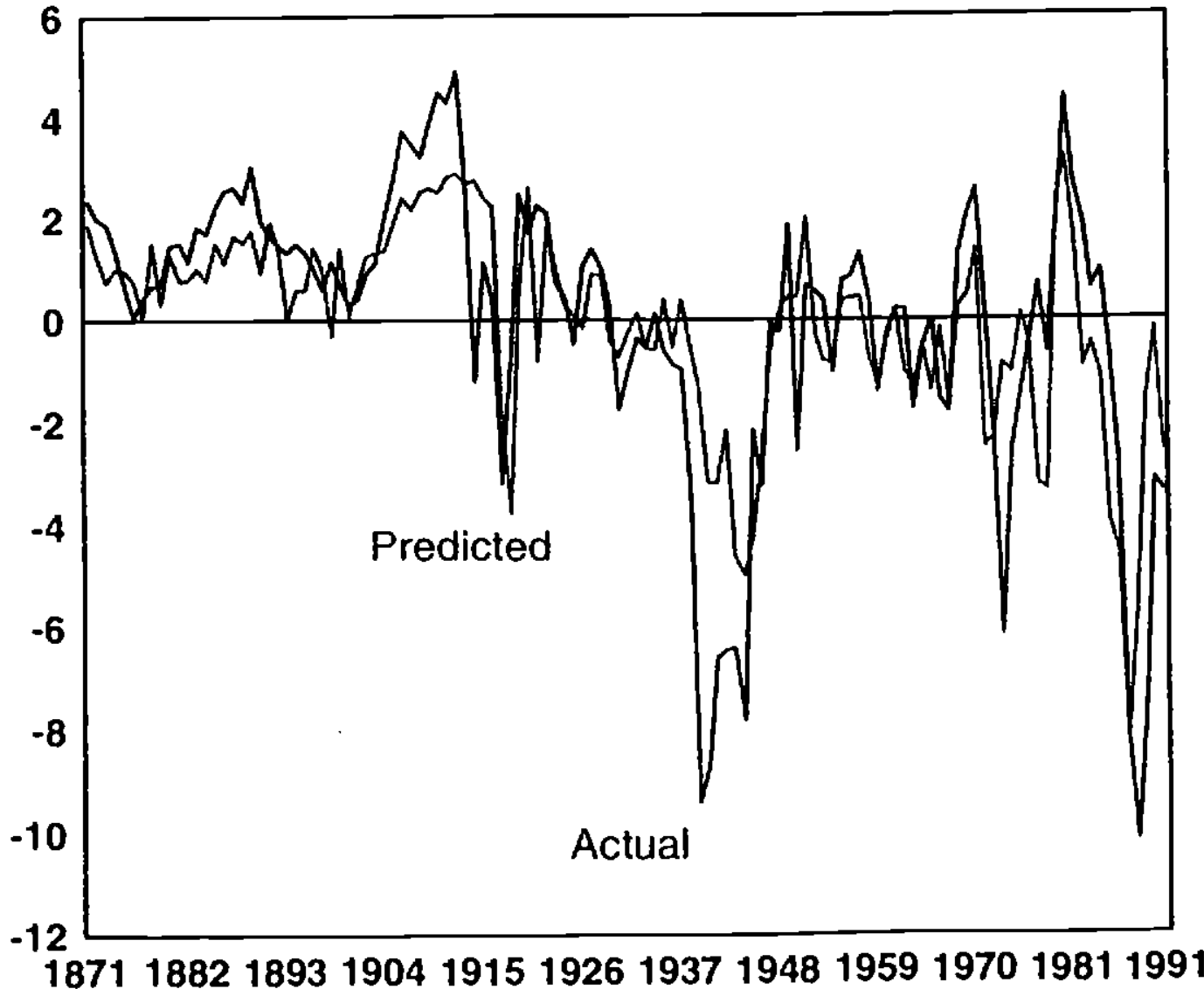


formal test of the restriction embodied in eq. (54). From the above VAR estimates, one obtains $\left[\begin{array}{ll}\hat{\Phi}_{\Delta Q} & \hat{\Phi}_{C A}\end{array}\right]=\left[\begin{array}{ll}-0.26 & 0.54\end{array}\right]$, which differs significantly from the null hypothesis value of $\left[\begin{array}{ll}0 & 1\end{array}\right]$.

A common theme in the graphical evidence presented by Ghosh, SheffrinWoo, and Otto is that the actual current account is often far more volatile than the predicted current account. This seems to contradict the FeldsteinHorioka conclusion that current account movements are relatively small compared to what one would expect in theory. Ghosh (1994) formally compares the variances of the predicted and actual current account series and finds that, except in the U.S. case (where he cannot reject equality of the variances), the variance of the actual series is higher. Otto similarly finds that Canada's current account is six times as volatile the that of the predicted series. ${ }^{65}$ Ghosh interprets his finding as evidence of 'too much' capital mobility, in contrast to the Feldstein-Horioka claim of too little. One possible explanation of the Ghosh-Otto findings is to view them as related to Deaton's paradox of excessive consumption smoothness. The Deaton paradox can be resolved by stipulating that income, though highly serially correlated, does not literally contain a unit root. (When income is stationary in growth rates rather than in levels, a small change in current income can imply a very large change in permanent income and, hence, in predicted consumption.) Just as the assumption of a unit root in income can lead to the conclusion that consumption is too smooth, it can also produce the result that saving or the current account is too volatile. This may help explain the Ghosh-Otto volatility results, though further investigation is required.

\subsubsection{Global versus country-specific shocks and the current ac- count}

One shortcoming of the studies considered so far is their implicit assumption that all shocks to cash flow are purely idiosyncratic. ${ }^{66}$ In reality, even a small country's output growth or investment may be highly correlated with that in the rest of the world. Output shocks which identically impact all countries should, however, express themselves primarily through the global interest

\footnotetext{
${ }^{65}$ Sheffrin and Woo's data (which they generously supplied to us) yields similar results.

${ }^{66}$ This criticism, of course, applies with equal force to much of the macroeconometric literature on consumption.
} 
rate, and not in individual countries' current accounts. Glick and Rogoff (1995) argue that this issue is empirically important and try to confront it. Their model also attempts to trace shocks to output and investment back to changes in factor productivity, allowing for more structure than the empirical studies just discussed. ${ }^{67}$ A simpler version of the Glick-Rogoff framework suffices to illustrate their main points.

Let's label the country-specific component of cash flow $Q^{c}$ and the global component $Q^{w}$, so that

$$
\Delta Q=\Delta Q^{c}+\Delta Q^{w}
$$

The global component is the part of $Q$ that is perfectly correlated with average world $Q$. Then, assuming that $Q^{c}$ is $I(1)$, and that initial net foreign asset positions are zero, one can (after many steps) show that eq. (51) is replaced by the approximate current-account equation ${ }^{68}$

$$
C A_{t}=-\mathrm{E}_{t}\left\{\sum_{s=t+1}^{\infty}\left(\frac{1}{1+r}\right)^{s-t} \Delta Q_{s}^{c}\right\}
$$

where the interest rate used is that prevailing along an initial steady-state path. According to (55), only country-specific shocks affect current accounts. ${ }^{69}$

To separate $Q^{c}$ from $Q^{w}$, Glick and Rogoff consider annual data for the G-7 countries over 1960-90, treating these countries as the world (which, in terms of economic size, isn't a bad approximation for most of their sample period). They consider two alternative methods of separating shocks into local and global components. The simplest is to form $Q^{c}$ as $Q-Q^{w}$, where $Q^{w}$ is taken to be a mean-GNP weighted average for the entire group. The more sophisticated approach is to regress each country's $\Delta Q$ on an index of the remaining countries' cash flows, defining $Q^{c}$ as the regression residual. Glick and Rogoff find that the two approaches yield similar results for their

\footnotetext{
${ }^{67}$ Leiderman and Razin (1991) develop a model similar to Glick and Rogoft's, although they do not distinguish between global and country-specific shocks.

${ }^{68}$ The derivation of equation (55) requires that the variances of the underlying productivity shocks be constant. The global component of the shock, $Q^{w}$, affects world interest rates but not the current account.

${ }^{69}$ If initial net foreign asset positions are not zero, the interest-rate effects of global shocks can redistribute income from debtors to creditors in a way that alters current accounts. (Recall eq. (9) above.) Glick and Rogoft show that this effect is empirically small. Note that it would be more natural to specify the approximate model in logarithms; working in levels is only an expository simplification.
} 
ultimate current-account and investment equations. Overall, global shocks appear to account for a very significant portion of total productivity shocks in the G-7 countries, roughly 50 percent. ${ }^{70}$ Glick and Rogoff find that the global versus country-specific distinction greatly improves the ability of the intertemporal approach to explain actual current accounts: the coefficients on the global shocks are invariably much smaller than those on the countryspecific shocks, and are usually insignificant.

\subsubsection{Extensions}

The empirical consumption-smoothing models discussed so far all ignore the precautionary motive for saving, as was remarked earlier. Caballero (1990) has shown, however, that under specified assumptions one can obtain closedform consumption functions based on the period utility function $u(C)=$ $-\exp (-\nu C)$, where $\nu$ is the coefficient of absolute risk aversion. Thus, there is no need to rely exclusively on a linear-quadratic formulation for closedform solutions. Ghosh and Ostry $(1992,1994)$ apply Caballero's results to add a precautionary saving effect to the present-value model of the current account. ${ }^{71}$ The key new parameter appearing in their extended framework is $\sigma_{\xi}^{2}=\operatorname{Var}(\xi)$, where

$$
\xi_{t}=\tilde{Q}_{t}-\mathrm{E}_{t-1} \tilde{Q}_{t}
$$

is the date- $t$ innovation to expected permanent private cash flow. Ghosh and Ostry (1992) look at quarterly 1955-90 time-series data for Canada, Japan, the United Kingdom, and the United States. Because they are looking at time-series rather than cross-section data, they must negotiate the difficult issue of time variation in $\sigma_{\xi}^{2}$, which is a conditional variance in a dynamic setting. Long enough intervals must be allowed for accurate measures of $\sigma_{\xi}^{2}$, but intervals should not be so long as to preclude enough data points for meaningful time-series regressions. ${ }^{72}$ Using two- to five-year intervals to

\footnotetext{
${ }^{70}$ Costello (1993) and Stockman (1988) have found, for slightly different country samples and industry-level data, that global productivity or output shocks seem to be less correlated between similar manufacturing industries in different countries than between differ ent industries in the same country. That evidence apparently points to a greater role for country-specific shocks, and it remains to reconcile it with the results discussed in the text.

${ }^{71}$ An alternative theoretical treatment is Rodriguez (1993).

${ }^{72} \mathrm{An}$ alternative approach would be to adopt an explicit parameterization of $\operatorname{Var}_{t-1}\left(\xi_{t}\right)$.
} 
measure $\sigma_{\xi}^{2}$, Ghosh and Ostry find that their precautionary variable usually enters significantly and with the correct sign in present-value current account regressions. Ghosh and Ostry (1994) find similarly positive results for developing countries. Their point estimates suggest that precautionary savings are of the order of magnitude of 5 percent of imports for the African region, 4 percent for commodity exporters, and 14 percent for fuel exporters.

None of the empirical studies discussed thus far distinguishes between durables and nondurables or between tradables and nontradables. As we emphasized in our theoretical discussion, both distinctions can be important for the current account. Burda and Gerlach (1993) argue that, in theory, durable-goods imports are much more sensitive to expected movements in the real exchange rate than are nondurables (due to capital gains and losses). Estimating their model poses a number of difficulties: in particular, the theory calls for a measure of the stock of consumer durables, but this is difficult to obtain in practice. Using a vector error-correction time-series specification including quarterly data on the current account, expected permanent net income, the relative price of durables in terms of nondurables, and a variable capturing expected changes in that price, Burda and Gerlach find that the expected price changes have a significant correlation with the U.S. current account over 1970-88. This finding, they argue, provides support for the empirical role of the durables versus nondurables distinction. It is difficult to compare these results with those of the empirical models discussed earlier because the Burda-Gerlach setup, with its very general lag structure, imposes much less theoretical structure. It would be interesting to pursue an alternative approach based on eq. (23). ${ }^{73}$

Rogoff (1992) incorporates nontraded goods into an empirical intertemporal model, although his primary focus is on explaining the well-documented near random-walk behavior of real exchange rates. His main result is that intertemporal consumption smoothing in traded goods might account for the persistence of innovations in real exchange rates. In the simplest case, assume exogenous output of tradables and nontradables, a Cobb-Douglas period utility function ( $\rho=1$ in eq. (17)), and an intertemporal substitution elasticity, $\sigma$, of 1 . In this case, as we saw earlier, people smooth their consumption of tradables independently of the evolution of their nontradables consumption. As above, the real exchange rate, the relative price of nontradables on date

\footnotetext{
${ }^{73}$ For some preliminary empirical results, see Obstfeld and Rogoft (1995), ch. 2.
} 
$t$, depends on $C_{T t}, Y_{N t}$, and consumers' expenditure shares. A permanent shock to tradables output raises $C_{T}$ permanently and thereby permanently raises the relative price of nontradables. But even a temporary rise in tradedgoods output raises $C_{T}$ permanently because of consumption smoothing. The model thus can explain why the persistence in real exchange rate movements might be much greater than that of the underlying exogenous shocks. A country's ability to borrow and lend in international markets is the key to this result: it would not obtain absent international capital mobility. Rogoff (1992) applies his model to data for Japan and the United States, finding some support, though further testing is required.

\section{How useful is the theory?}

Even in the its most rudimentary forms, the intertemporal approach to the current account has proved valuable for analyzing a host of important problems. As noted in the introduction, it provides an extremely useful framework for thinking about the current-account and world interest rate effects of oil price shocks. Without an intertemporal approach, it would be hard to analyze or evaluate the current-account patterns that followed the two oil shocks of the 1970s. The dynamic budget constraints emphasized throughout this chapter are also essential in analyzing episodes of capital-market disruption, such as the developing-country debt crisis of the 1980s. True, the standard intertemporal models must be extended to take account of default risk but, as we have seen, the main qualitative insights do not change. More generally, models that fail to integrate investment, saving, and growth make it virtually impossible to understand why some countries have persistent current account imbalances. Why, for example, are Canada's and Australia's current accounts perennially in deficit, and Japan's in surplus, despite wide swings in their currencies' real exchange rates? Overlapping-generations variants of the intertemporal model are indispensable for thinking about how, say, the aging of Japan's population could eventually lead to a fall in Japan's persistent trade surpluses.

As positive descriptions of the current account, the simple intertemporal theories are not without their limitations. As we saw above, time-series models based on consumption smoothing seem to work fairly well for some countries (for example, Sweden) but, in other cases, clearly miss much of 
the action. Further research allowing for time-varying interest rates, multiple goods, durables, nominal price rigidities, and some liquidity-constrained consumers might lead to better descriptive power. If the simplest infinitelylived representative agent models are to be believed, then it is a puzzle that ratios of foreign debt to output seldom exceed 1:1 when plausible parameter estimates suggest that ratios of $5: 1$ or $10: 1$ could easily be sustainable and even optimal.

Observed debt-GDP ratios are easier to rationalize in economies with finite-lived dynasties, but such models, while capable of embracing a wider set of empirical phenomena, also pose empirical puzzles. A fairly robust implication is that government deficits lead to current-account deficits, but the empirical evidence supporting this prediction, while suggestive, is hardly a basis for strong conclusions. The striking industrial-country correlation observed over 1976-1985 is not clearly evident later on. Promising directions for future investigation include models with richer intergenerational structures and a more comprehensive accounting of the intergenerational transfers implied by fiscal and social insurance policies.

The models we have discussed in this chapter provide only a starting point. Obviously, the task of building and empirically applying richer and more realistic intertemporal models will not be an easy one. But there is no avoiding this challenge, since the two leading alternatives to the intertemporal model are seriously flawed.

One alternative that has been explored extensively in recent research is the complete markets model, in which country-specific shocks of all types-to human as well as financial wealth, to personal as well as corporate taxes-can be insured internationally. If this approach is correct, of course, then the current account is little more than an accounting convention without major significance even for a country's relative wealth position. (See the discussion in section 3.2.1.) We have argued that real-world international capital markets are very far from the frictionless, full-information, complete-markets ideal. Factors inhibiting complete domestic capital markets include moral hazard problems in lending at the microeconomic level, finite lifetimes, and diffculties in insuring labor income. In international markets, these problems are compounded by sovereign default risk, difficulties in insuring national government spending shocks, and cultural and institutional differences. Of course, it would be vastly preferable to model explicitly these capital-market imperfections rather than simply to assume limited asset trade, especially 
for understanding the impact of government policy. We have discussed some work along these lines and presented a simple example. Until these models have been more fully developed, however, the intertemporal model seems to provide a much closer description of reality than does the complete markets model.

Complete-market models represent an extreme alternative to the intertemporal approach. At the opposite pole are variants of the open-economy ISLM model due to Mundell (1968) and Fleming (1962). This approach, which ignores intertemporal choice and even intertemporal budget constraints, remains overwhelmingly dominant in policy circles. But as a framework for addressing fundamentally dynamic phenomena such as the current account and government debt, the Mundell-Fleming paradigm, even when jerry-rigged with dynamic add-ons, is fatally handicapped.

The Mundell-Fleming approach offers no valid benchmark for evaluating external balance. In practice, policymakers often strive to avoid a negative current account. Just as efficient international trade generally requires unbalanced trade within commodity groups, however, efficient trade across time often calls for an unbalanced current account. The intertemporal approach identifies circumstances, for example, a transitory fall in output or a rise in domestic investment productivity, that justify a current account deficit. On these issues, the Mundell-Fleming approach has nothing to say.

Evaluating the real exchange rate consistent with full employment and external balance is another prime concern of policy: intervention or realignment decisions may hinge on the determination that a currency's value is 'misaligned.' Since the Mundell-Fleming approach has nothing to say about external balance, it is, a fortiori, unable to address the possibility of misalignment.

Because it lacks microfoundations or even the most basic intertemporal budget constraints, the Mundell-Fleming approach provides no grounds for normative judgments on current accounts or international macroeconomic policies. No economist would take seriously an assessment of tax, trade, or regulatory policy based on a model with these shortcomings. The intertemporal approach to the current account offers a viable framework for assessing macroeconomic policy, one that must supplant the Mundell-Fleming framework for normative questions.

It is hard to portray Mundell-Fleming as a successful positive currentaccount theory, either. Without denying the theory's empirical appeal in 
capturing short-run macroeconomic developments over some episodes, the core model has no clear, much less testable, predictions about current-account dynamics. Again, as intertemporal models become more tractable and enjoy wider empirical testing, it seems to us that they must ultimately come to supplant modified Mundell-Fleming models for positive as well as normative questions.

\section{References}

[1] Abel, A. B. (1982), 'Dynamic effects of permanent and temporary tax policies in a $q$ model of investment,' Journal of Monetary Economics 9: 353-373.

[2] Ahmed, S. (1986), 'Temporary and permanent government spending in an open economy: Some evidence for the United Kingdom,' Journal of Monetary Economics 17: 197-224.

[3] Ahmed, S. (1987), 'Government spending, the balance of trade and the terms of trade in British history,' Journal of Monetary Economics 20: 195-220.

[4] Alexander, S. S. (1952), 'Effects of a devaluation on a trade balance,' International Monetary Fund Staff Papers 2: 263-278.

[5] Atkeson, A. (1991), 'International lending with moral hazard and risk of repudiation,' Econometrica 59: 1069-1089.

[6] Atkeson, A. and R. E. Lucas, Jr. (1992), 'On efficient distribution with private information,' Review of Economic Studies 59: 427-453.

[7] Backus, D. K., P. J. Kehoe and F. E. Kydland (1992), 'International real business cycles,' Journal of Political Economy 100: 745-775.

[8] Bardhan, P. K. (1967), 'Optimum foreign borrowing,' in: K. Shell, ed., Essays in the theory of optimal economic growth. Cambridge, MA: MIT Press.

[9] Baxter, M. and M. J. Crucini (1993a), 'Explaining saving-investment correlations,' American Economic Review 83: 416-436. 
[10] Baxter, M. and M. J. Crucini (1993b), 'Business cycles and the asset structure of foreign trade,' Working Paper, University of Rochester.

[11] Bean, C. R. (1986), 'The terms of trade, labour supply and the current account,' Economic Journal 96: 38-46.

[12] Bergsten, C. F., ed. (1991), International adjustment and financing: The lessons of 1985-1991. Washington, D. C.: Institute for International Economics.

[13] Bernanke, B. (1985), 'Adjustment costs, durables, and aggregate consumption,' Journal of Monetary Economics 15: 41-68.

[14] Bernheim, B. D. (1988), 'Budget deficits and the balance of trade,' in L. Summers, ed., Tax policy and the economy, vol. 2, Cambridge: MIT Press.

[15] Blanchard, O. J. (1985), 'Debt, deficits, and finite horizons,' Journal of Political Economy 93: 223-247.

[16] Bruno, M. (1970), 'Trade, growth and capital,' Working Paper, MIT.

[17] Buiter, W. H. (1981), 'Time preference and international lending and borrowing in an overlapping-generations model,' Journal of Political Economy 89: 769-797.

[18] Burda, M. and S. Gerlach (1992), 'Intertemporal prices and the U.S. trade balance,' American Economic Review 82: 1235-1253.

[19] Caballero, R. (1990), 'Consumption puzzles and precautionary savings,' Journal of Monetary Economics 25: 113-136.

[20] Campbell, J. Y. (1987), 'Does saving anticipate declining labor income? An alternative test of the permanent income hypothesis,' Econometrica $55: 1249-1274$.

[21] Campbell, J. Y. and R. J. Shiller (1987), 'Cointegration and tests of present value models,' Journal of Political Economy 95: 1062-1088. 
[22] Clarida, R. H. (1990), 'International lending and borrowing in a stochastic stationary equilibrium,' International Economic Review 31: 543-558.

[23] Cole, H. L. and M. Obstfeld (1991), 'Commodity trade and international risk sharing: How much do financial markets matter?' Journal of Monetary Economics 28: 3-24.

[24] Costello, D. M. (1993), 'A cross-country, cross-industry comparison of productivity growth,' Journal of Political Economy 101: 207-222.

[25] Cox, J. C. and C. Huang (1989), 'Optimal consumption and portfolio policies when asset prices follow a diffusion process,' Journal of Economic Theory 49: 33-83.

[26] Deaton, A. (1987), 'Life cycle models of consumption: Is the evidence consistent with the theory? in: T. F. Bewley, ed., Advances in econometrics: Fifth world congress, vol. 2. Cambridge, U.K.: Cambridge University Press.

[27] Deaton, A. (1992), Understanding consumption. Oxford, U.K.: Clarendon Press.

[28] de Roover, R. (1966), The rise and decline of the Medici bank, 13971494. New York: W. W. Norton.

[29] Devereux, M. B. and S. Shi (1991), 'Capital accumulation and the current account in a two-country model,' Journal of International Economics 30: 1-25.

[30] Dixit, A. K. and V. Norman (1980), Theory of international trade: A dual, general equilibrium approach. Welwyn and Cambridge, U.K.: James Nisbet \& Co. Ltd. and Cambridge University Press.

[31] Dooley, M., J. Frankel and D. J. Mathieson (1987), 'International capital mobility: What do saving-investment correlations tell us?' International Monetary Fund Staff Papers 34: 503-530.

[32] Dornbusch, R. (1983), 'Real interest rates, home goods, and optimal external borrowing,' Journal of Political Economy 91 (February): 141153. 
[33] Eaton, J. (1988), 'Foreign-owned land,' American Economic Review 78: $76-88$.

[34] Edwards, S. (1989), Real exchange rates, devaluation, and adjustment. Cambridge, MA: MIT Press

[35] Eichengreen, B. (1990), 'Trends and cycles in foreign lending,' in: $H$. Siebert, ed., Capital flows in the world economy. Tubingen: J. C. B. Mohr.

[36] Ekern, S. and R. Wilson (1974), 'On the theory of the firm in an economy with incomplete markets,' Bell Journal of Economics and Management Science 5: 171-180.

[37] Engel, C. and K. Kletzer (1989), 'Saving and investment in an open economy with non-traded goods,' International Economic Review 30: 735-752.

[38] Feinstein, C.H.(1972), National income, expenditure, and output of the United Kingdom, 1855-1965. Cambridge, U.K.: Cambridge University Press.

[39] Feldstein, M. and P. Bacchetta (1991), 'National saving and international investment,' in: B. D. Bernheim and J. B. Shoven, eds., National saving and economic performance. Chicago, IL: University of Chicago Press.

[40] Feldstein, M. and C. Horioka (1980), 'Domestic saving and international capital flows,' Economic Journal 90: 314-329.

[41] Fieleke, N. S. (1982), 'National saving and international investment,' in: Saving and government policy. Boston, MA: Federal Reserve Bank of Boston.

[42] Fisher, I. (1930), The theory of interest. New York: Macmillan.

[43] Fleming, J. M. (1962), 'Domestic financial policies under fixed and under floating exchange rates,' International Monetary Fund Staff Papers 9: $369-379$. 
[44] Frankel, J. A. (1993), 'Quantifying international capital mobility in the 1980s,' in: On exchange rates. Cambridge, MA: MIT Press.

[45] Frenkel, J. A. and A. Razin (1987), Fiscal policies and the world economy: An intertemporal approach. Cambridge, MA: MIT Press.

[46] Gavin, M. (1990), 'Strucural adjustment to a terms of trade disturbance: The role of relative prices,' Journal of International Economics 28: $217-243$.

[47] Gertler, M. and K. Rogoff (1990), 'North-South lending and endogenous domestic capital market inefficiencies,' Journal of Monetary Economics 26: 245-266.

[48] Ghosh, A. (1995), 'Capital mobility amongst the major industrialized countries: Too little or too much?' Economic Journal 105: in press.

[49] Ghosh, A. and J. Ostry (1992), 'Macroeconomic uncertainty, precautionary savings, and the current account,' Working Paper, International Monetary Fund.

[50] Ghosh, A. and J. Ostry (1993), 'Do capital flows reflect fundamentals in developing countries?' Working Paper, International Monetary Fund.

[51] Ghosh, A. and J. Ostry (1994), 'Export instability and the external balance in developing countries,' Working Paper, International Monetary Fund.

[52] Glick, R. and K. Rogoff (1995), 'Global versus country-specific productivity shocks and the current account,' Journal of Monetary Economics: in press.

[53] Goldstein, M. and M. S. Khan (1985), 'Income and price effects in foreign trade,' in R. W. Jones and P. B. Kenen, eds., Handbook of international economics, vol. 2. Amsterdam: North-Holland.

[54] Hall, R. E. (1978), 'Stochastic implications of the life cycle-permanent income hypothesis: Theory and evidence,' Journal of Political Economy 86: $971-987$. 
[55] Hamada, K. (1969), 'Optimal capital accumulation by an economy facing an international capital market,' Journal of Political Economy 77: 684-697.

[56] Harberger, A. C. (1950), 'Currency depreciation, income and the balance of trade,' Journal of Political Economy 58: 47-60.

[57] Hayashi, F. (1982), 'Tobin's marginal $q$ and average $q$ : A neoclassical interpretation,' Econometrica 50: 213-224..

[58] Hercowitz, Z. (1986), 'On the determination of the external debt: The case of Israel,' Journal of International Money and Finance 5: 315-334.

[59] Johnson, D. (1986), 'Consumption, permanent income, and financial wealth in Canada: Empirical evidence on the intertemporal approach to the current account,' Canadian Journal of Economics 19: 189-206.

[60] Jones, M. T. and M. Obstfeld (1995), 'Saving and investment under the gold standard,' Working Paper, University of California at Berkeley.

[61] Kollmann, R. (1992), 'Incomplete asset markets and international real business cycles,' Working Paper, University of Montreal.

[62] Laursen, S. and L. A. Metzler (1950), 'Flexible exchange rates and the theory of employment,' Review of Economics and Statistics 32: 281299.

[63] Leiderman, L. and A. Razin (1991), 'Determinants of external imbalances: The role of taxes, government spending, and productivity,' Journal of the Japanese and International Economies 5: 421-450.

[64] Leland, H. E. (1968), 'Savings and uncertainty: The precautionary demand for savings,' Quarterly Journal of Economics 82: 465-473.

[65] Lucas, R. E., Jr. (1976), 'Econometric policy evaluation: A critique,' Carnegie-Rochester Conference Series on Public Policy 1: 19-46.

[66] Lucas, R. E., Jr. (1982), 'Interest rates and currency prices in a twocountry world,' Journal of Monetary Economics 10: 335-359. 
[67] Maddison, A. (1991), Dynamic forces in capitalist development. Oxford, U.K.: Oxford University Press.

[68] Matsuyama, K. (1987), 'Current account dynamics in a finite horizon model,' Journal of International Economics 23: 299-313.

[69] Matsuyama, K. (1990), 'Residential investment and the current account,' Journal of International Economics 28: 137-153.

[70] Mehra, R. and E. C. Prescott (1985), 'The equity premium: A puzzle,' Journal of Monetary Economics 15: 145-161.

[71] Mendoza, E. G. (1991), 'Real business cycles in a small open economy,' American Economic Review 81: 797-818.

[72] Mundell, R. A. (1968), International economics. New York: Macmillan.

[73] Murphy, R. G. (1986), 'Productivity shocks, non-traded goods and optimal capital accumulation,' European Economic Review 30: 10811095.

[74] Neal, L. (1990), The rise of financial capitalism: International capital markets in the age of reason. Cambridge, U. K.: Cambridge University Press.

[75] Obstfeld, M. (1982), 'Aggregate spending and the terms of trade: Is there a Laursen-Metzler effect?' Quarterly Journal of Economics 97: 251-270.

[76] Obstfeld, M. (1986), 'Capital mobility in the world economy: Theory and measurement,' Carnegie-Rochester Conference Series on Public Policy 24: 55-103.

[77] Obstfeld, M. (1994), 'Are industrial-country consumption risks globally diversified?' in: L. Leiderman and A. Razin, eds., Capital mobility. Cambridge, U. K.: Cambridge University Press.

[78] Obstfeld, M. (1995), 'International capital mobility in the 1990s,' in P. B. Kenen, ed., Understanding interdependence: The macroeconomics of the open economy. Princeton, NJ: Princeton University Press. 
[79] Obstfeld, M. and K. Rogoff (1995), Foundations of international macroeconomics. Manuscript.

[80] Obstfeld, M. and A. C. Stockman (1985), 'Exchange-rate dynamics,' in R. W. Jones and P. B. Kenen, eds., Handbook of international economics, vol. 2. Amsterdam: North-Holland.

[81] Ostry, J. D. (1988), 'The balance of trade, terms of trade, and real exchange rate,' International Monetary Fund Staff Papers 35: 541-573.

[82] Ostry, J. D. and C. M. Reinhart (1992), 'Private saving and terms of trade shocks,' International Monetary Fund Staff Papers 39: 495-517.

[83] Otto, G. (1992), 'Testing a present-value model of the current account: Evidence from US and Canadian time series,' Journal of International Money and Finance 11: 414-430.

[84] Persson, T. (1985), 'Deficits and intergenerational welfare in open economies,' Journal of International Economics 19: 1-19.

[85] Razin, A. (1995), 'The dynamic optimizing approach to the current account: Theory and evidence,' in P. B. Kenen, ed., Understanding interdependence: The macroeconomics of the open economy. Princeton, NJ: Princeton University Press.

[86] Rodriguez, A. (1993), 'Precautionary saving and the Laursen-Metzler effect,' Journal of International Money and Finance 12: 332-343.

[87] Rogoff, K. (1992), 'Traded goods consumption smoothing and the random walk behavior of the real exchange rate,' Bank of Japan Monetary and Economic Studies 10: 1-29.

[88] Roubini, N. (1988), 'Current accounts and budget deficits in an intertemporal model of consumption and taxation smoothing.' Working Paper 2773, National Bureau of Economic Research.

[89] Sachs, J. D. (1981), 'The current account and macroeconomic adjustment in the 1970s,' Brookings Papers on Economic Activity: 201-268.

[90] Sachs, J. D. (1982), 'The current account in the macroeconomic adjustment process,' Scandinavian Journal of Economics 84: 147-159. 
[91] Sheffrin, S. M. and W. T. Woo (1990), 'Present value tests of an intertemporal model of the current account,' Journal of International Economics 29: 237-253.

[92] Shi, S. and L. G. Epstein (1993), 'Habits and time preference,' International Economic Review 34: 61-84

[93] Shiller, R. J. (1993), Macro markets: Creating institutions for managing society's largest economic risks. Oxford, U.K.: Clarendon Press.

[94] Stockman, A. C. (1988a), 'Fiscal policies and international financial markets,' in: J. A. Frenkel, ed., International aspects of fiscal policies. Chicago, IL: University of Chicago Press.

[95] Stockman, A. C. (19Eלb), 'Sectoral and national aggregate disturbances to industrial output in seven European countries,' Journal of Monetary Economics 21: 387-409.

[96] Stockman, A. C. and L. L. Tesar (1990), 'Tastes and technology in a two-country model of the business cycle: Explaining international comovements,' Working Paper 3566, National Bureau of Economic Research.

[97] Stulz, R. (1988), 'Capital mobility and the current account,' Journal of International Money and Finance 7: 167-180.

[98] Summers, L. H. (1981), 'Taxation and corporate investment: A $q$ theory approach,' Brookings Papers on Economic Activity: 67-127.

[99] Summers, L. H. (1988), 'Tax policy and international competitiveness,' in: J. A. Frenkel, ed., International aspects of fiscal policies. Chicago, IL: University of Chicago Press.

[100] Svensson, L. E. O. (1988), 'Trade in risky assets,' American Economic Review 78: $375-394$.

[101] Svensson, L. E. O. and A. Razin (1983), 'The terms of trade and the current account: The Harberger-Laursen-Metzler effect,' Journal of Political Economy 91: 97-125. 
[102] Taylor, A. M. (1993), 'Domestic saving and international capital flows reconsidered,' Working Paper, Northwestern University.

[103] Tesar, L. L. (1991), 'Savings, investment, and international capital flows,' Journal of International Economics 31: 55-78.

[104] Trehan, B. and C. E. Walsh (1991), 'Testing intertemporal budget constraints: Theory and applications to U.S. federal budget and current account deficits,' Journal of Money, Credit and Banking 23: 206-223.

[105] Weil, P. (1989), 'Overlapping families of infinitely-lived agents,' Journal of Public Economics 38: 183-198. 